\title{
POWER MANAGEMENT OF A GRID-CONNECTED DISTRIBUTED ENERGY RESOURCE SYSTEM
}

\author{
by \\ Danilo $\mathrm{Yu}$ \\ Bachelor of Science in Electrical Engineering, Cebu Institute of Technology, 1981 \\ Master of Engineering in Computer Applications, Asian Institute of Technology, 1984
}

\author{
A project \\ presented to Ryerson University \\ in partial fulfillment of the \\ requirements for the degree of \\ Master of Engineering \\ in the Program of \\ Electrical and Computer Engineering
}

Toronto, Ontario, Canada, 2014

(C) Danilo Yu, 2014 


\section{AUTHOR'S DECLARATION FOR ELECTRONIC SUBMISSION OF A PROJECT}

I hereby declare that I am the sole author of this project. This is a true copy of the project report, including any required final revisions, as accepted by my examiners.

I authorize Ryerson University to lend this project to other institutions or individuals for the purpose of scholarly research.

I further authorize Ryerson University to reproduce this project by photocopying or by other means, in total or in part, at the request of other institutions or individuals for the purpose of scholarly research.

I understand that my project may be made electronically available to the public. 


\title{
POWER MANAGEMENT OF A GRID-CONNECTED \\ DISTRIBUTED ENERGY RESOURCE SYSTEM
}

Master of Engineering, 2014

Danilo Yu

Electrical and Computer Engineering, Ryerson University

\begin{abstract}
This project introduces a modeling software that manages the power flow of a grid-connected distributed energy system on a daily basis. The system uses a control strategy that prioritizes the use of renewable energy sources over storage devices and conventional sources. Wind turbines and PV arrays are the primary sources of energy. Battery bank is used as the permanent storage device and small natural gas generators and the grid are the conventional sources. The software can manage the power flow of electric vehicles as mobile storage units. The power optimization algorithm monitors the power available from each energy source, analyzes and combines their outputs to meet the load demand. Output of the energy sources are analyzed using 15-minute time series simulations. The computer model was developed using MATLAB with a graphical user interface for easy setup, operation and analysis of the results.
\end{abstract}




\section{ACKNOWLEDGEMENTS}

I would like to express my extreme gratitude to my supervisor Dr. Kaamran Raahemifar for his guidance and confidence in me. Dr. Raahemifar has been a mentor and friend, providing assistance, resources and wisdom throughout the development of this project.

I would like to thank Traian Miciu and Kong Ting Wong for the load profiles used in this project. Both have gone out of their way to provide me the data that I needed. Special thank you to Steven Craig for the generator and grid models and Morgan Cunningham for the electric vehicle model used in this project.

Thank you to my colleagues in the Electrical and Computer Engineering department of Ryerson University who supported me in the pursuit of my Master's degree, specially to Mohammad Syed Irtaza, Muhammad Zubair Nasir and Nima Alibabael who offered me their talent and insights. 


\section{TABLE OF CONTENTS}

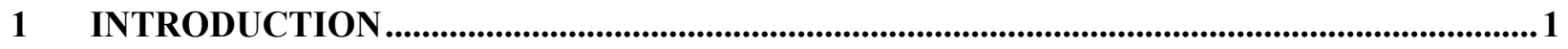

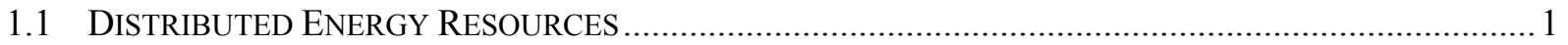

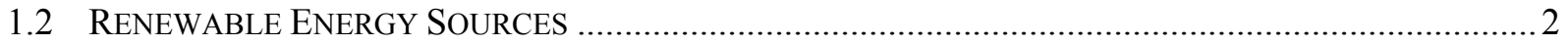

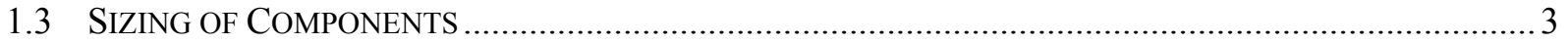

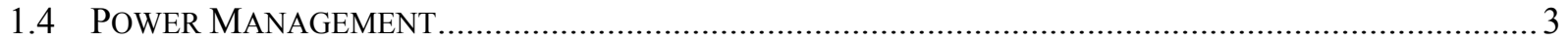

1.5 Motivation, OBJECTIVE AND REPORT ORGANIZATION …....................................................... 4

2 SYSTEM CONFIGURATION

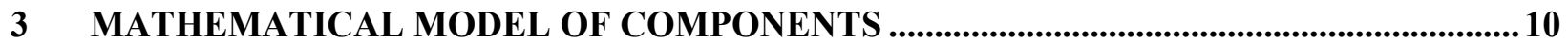

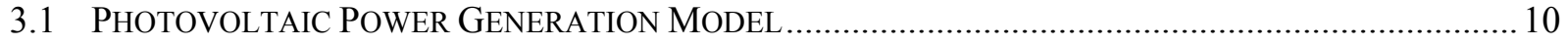

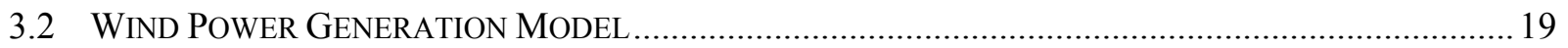

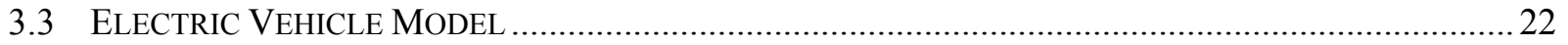

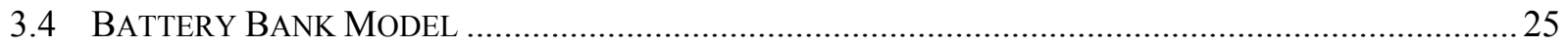

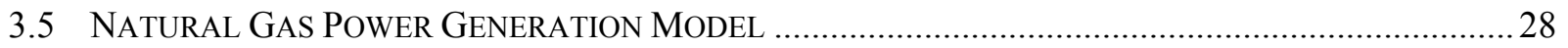

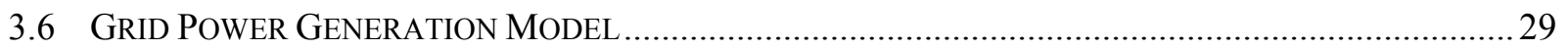

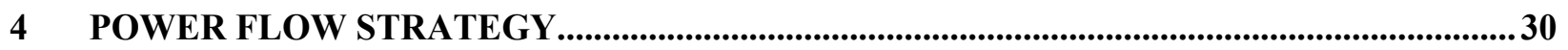

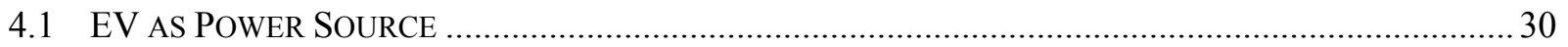

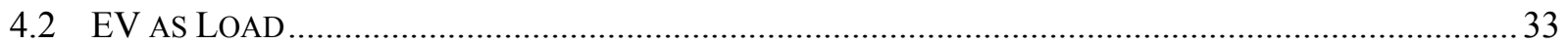

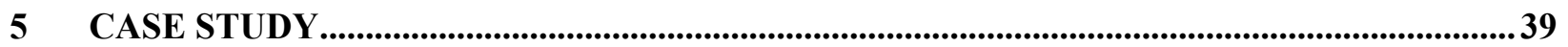

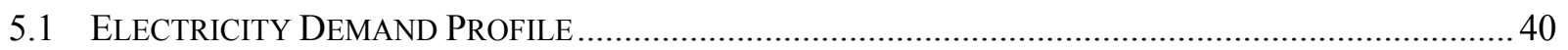

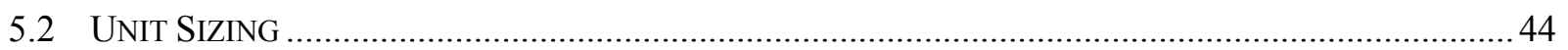

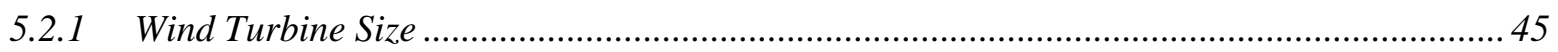

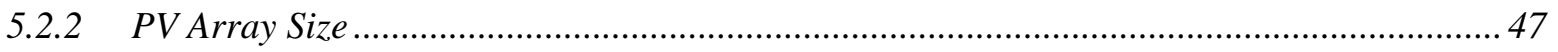

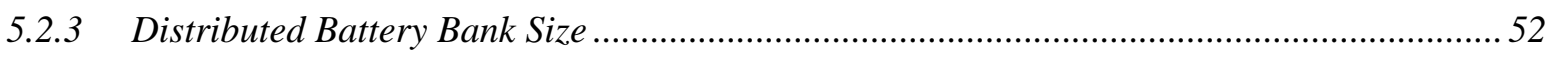

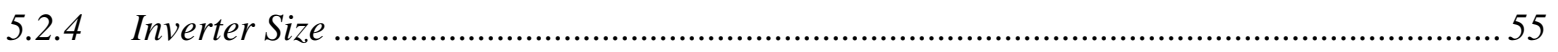

5.2.5 Natural Gas Power Generator Size .............................................................................5

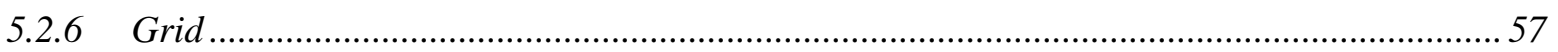

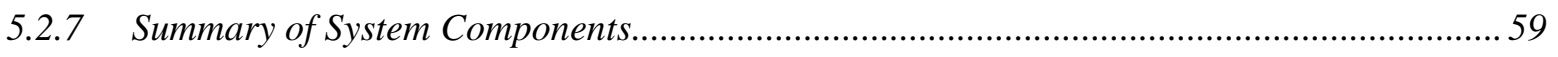

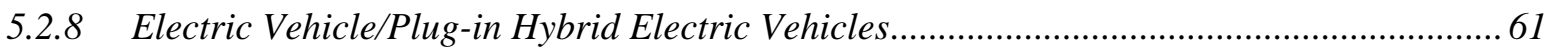




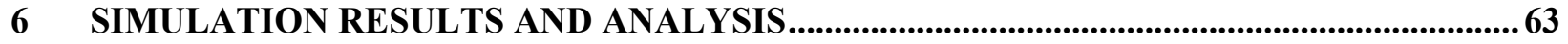

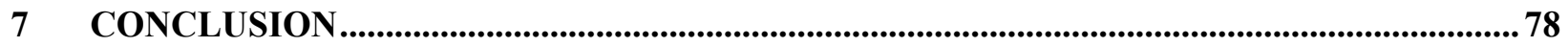

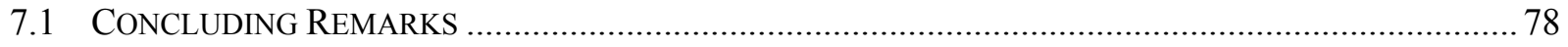

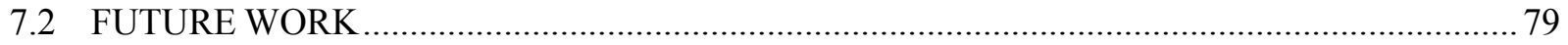

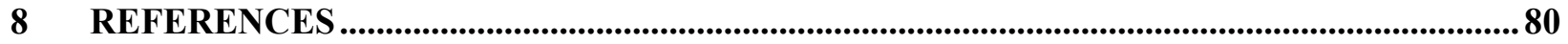




\section{LIST OF TABLES}

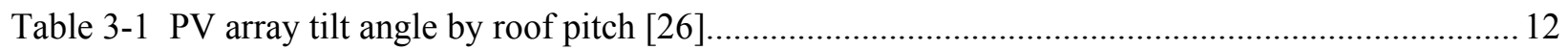

Table 3-2 Sample EV Charge/Discharge Schedule ...............................................................................2 25

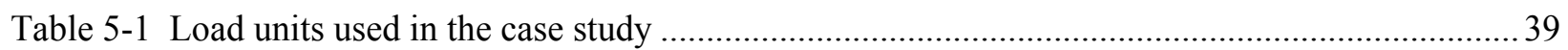

Table 5-2 Demand of each load unit during summer and winter..........................................................4 44

Table 5-3 Wind turbines available to each load unit................................................................................... 46

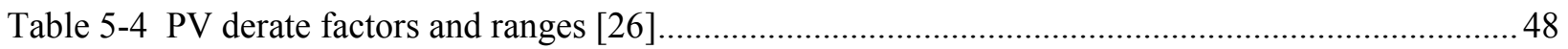

Table 5-5 PV panels available to the load units and the derate factors applied ........................................50

Table 5-6 FIT/microFIT Price Schedule as at Aug 26, 2013 .............................................................. 51

Table 5-7 Wind and PV Component Sizes, Power Outputs and Deficits/Surplus ..................................52

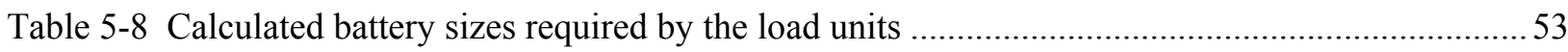

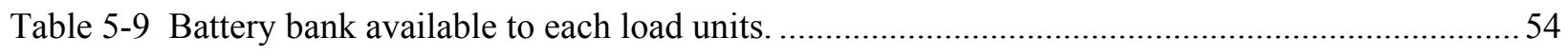

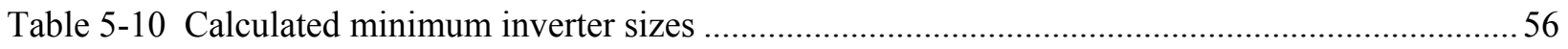

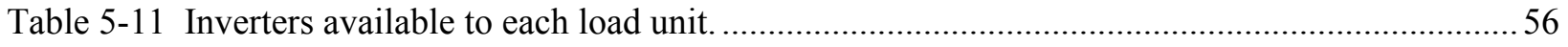

Table 5-12 Natural gas generators available to each load unit ............................................................57

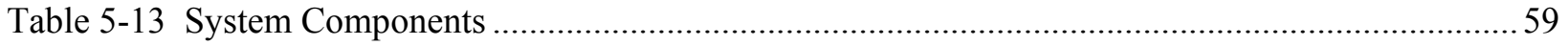

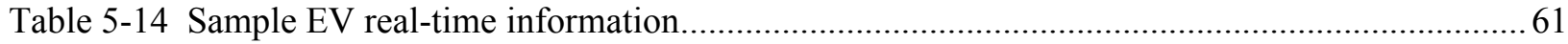

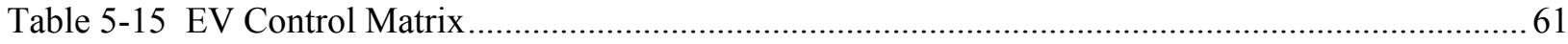




\section{LIST OF FIGURES}

Figure 2-1 System configuration of grid-connected distributed energy generation system...................... 8

Figure 3-1 Global solar radiation on tilted surface [online: www.greenrhinoenergy.com] ...................... 12

Figure 3-2 Declination angle, hour angle, latitude [online: www.powerfromthesun.net] ........................ 14

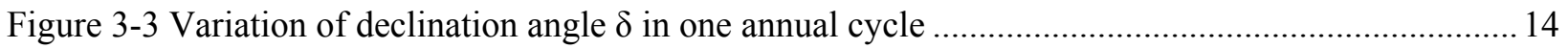

Figure 3-4 Variation of hour angle (solar time and local time: Jan 1, Longitude -81 ${ }^{\circ}$, GMT-5).............. 15

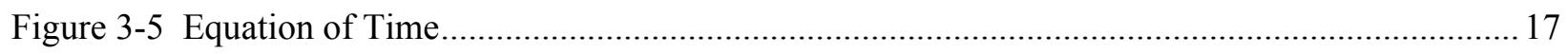

Figure 3-6 Wind speed vs power output of a Bergey $7.5 \mathrm{~kW}$ wind turbine generator............................. 20

Figure 3-7 Capacity curve of the Trojan J150 battery ......................................................................... 27

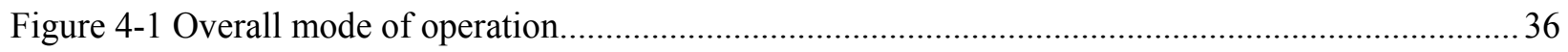

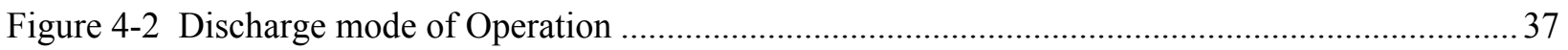

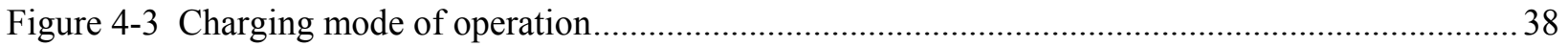

Figure 5-1 Load profile of low demand residential Unit 1 on a typical day in summer (Aug 24)............40

Figure 5-2 Load profile of low demand residential Unit 1 on a typical day in winter (Dec 22).............. 41

Figure 5-3 Load profile of high demand residential Unit 2 on a typical day in summer (Aug 24) ...........41

Figure 5-4 Load profile of high demand residential Unit 2 on a typical day in winter (Dec 22).............42

Figure 5-5 Load profile of small office Unit 3 on a typical day in summer (Aug 24) .......................... 42

Figure 5-6 Load profile of small office Unit 3 on a typical day in winter (Dec 22) .............................43

Figure 5-7 Load profile of commercial Unit 4 (restaurant) on a typical day in summer (Aug 24)..........43

Figure 5-8 Load profile of commercial Unit 4 (restaurant) on a typical day in winter (Dec 22)..............44

Figure 5-9 Power output of $7.5 \mathrm{~kW}$ Bergey wind turbine on Aug 24 (inverter $\eta=0.93$ ).................... 45

Figure 5-10 Power output of 7.5 kW Bergey wind turbine on Dec 22 (inverter $\eta=0.93$ ) ..................46

Figure 5-11 Power output of 42 solar panels of Panasonic's HIT Power 240S on Aug 24 (inverter

$\eta=0.93)$

Figure 5-12 Power output of 42 solar panels of Panasonic's HIT Power 240S on Dec 22 (inverter

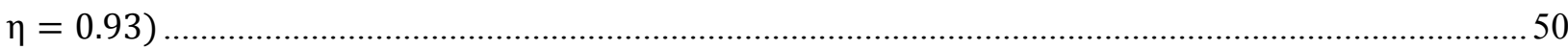

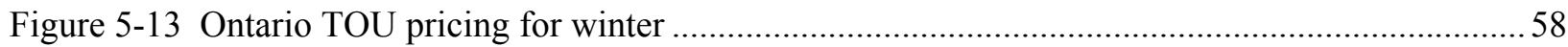

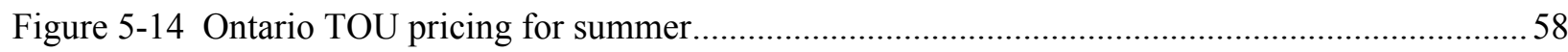

Figure 6-1 Electricity demand vs supply for residential Unit 1 on a typical summer day ........................64

Figure 6-2 Electricity demand vs supply for residential Unit 1 on a typical winter day.........................64 
Figure 6-3 Electricity demand vs renewable energy supply for residential Unit 1 on a typical summer day

Figure 6-4 Electricity demand vs renewable energy supply for residential Unit 1 on a typical winter day

Figure 6-5 Electricity demand vs energy supply for residential Unit 1 without the EVs on a typical summer day.....

Figure 6-6 Electricity demand vs energy supply for residential Unit 1 without the EVs on a typical winter day.

Figure 6-7 Electricity demand vs supply for residential Unit 2 on a typical summer day

Figure 6-8 Electricity demand vs supply for residential Unit 2 on a typical winter day.....

Figure 6-9 Performance of wind turbine installed at residential Unit 2 on a typical summer day............ 70

Figure 6-10 Performance of wind turbine installed at residential Unit 2 on a typical winter day ............. 70

Figure 6-11 Performance of solar panels installed at residential Unit 2 on a typical summer day ........... 71

Figure 6-12 Performance of solar panels installed at residential Unit 2 on a typical winter day.............. 71

Figure 6-13 Electricity demand vs renewable energy supply for residential Unit 2 on a typical summer day

Figure 6-14 Electricity demand vs renewable energy supply for residential Unit 2 on a typical winter day

Figure 6-15 Electricity demand vs supply for residential Unit 2 without the EVs on a typical summer day

Figure 6-16 Electricity demand vs supply for residential Unit 2 without the EVs on a typical winter day

Figure 6-17 Electricity demand vs supply for small office Unit 3 on a typical summer day................... 75

Figure 6-18 Electricity demand vs supply for small office Unit 3 on a typical winter day ..................... 75

Figure 6-19 Electricity demand vs supply for a full-service restaurant (Unit 4) on a typical summer day 76

Figure 6-20 Electricity demand vs supply for a full-service restaurant (Unit 4) on a typical winter day.. 76 


\section{LIST OF APPENDICES}

Appendix A: Sharp Solar Panel Data Sheet............................................................................................ 83

Appendix B: Bergey BWC Excel Wind Turbine Power Curve .......................................................... 84

Appendix C: Trojan J150 Battery Data Sheet...................................................................................... 85

Appendix D: 6-kW / 7-kW Generator Data Sheet................................................................................. 86 


\section{INTRODUCTION}

\subsection{Distributed Energy Resources}

Distributed energy resources (DER) are smaller-size (1 kW to $10 \mathrm{MW})$ power generating or storage units that can be connected directly to the customer's building and/or interconnected to the grid. They can also be used in remote areas where it is not economically feasible to connect to the traditional electric grid. In areas with access to the grid, the DER system connected to the customer's building is interconnected to the grid to assure a reliable supply of power. Some of the alternative sources of energy that can be used to build a distributed energy system are wind, solar, fuel cell (FC), geothermal, natural gas, diesel, biomass and micro turbines. The performance of wind turbine generators (WTG) and photovoltaic (PV) panels are dependent on weather conditions but the complementary nature of wind and sun energy make them ideal candidates to form a hybrid system. Wind speeds are usually low in periods when the sun radiation is highest and vice versa. A photovoltaic energy system alone cannot provide 24hour power to the load because of the absence of the sun during the night and during cloudy days. Moreover, shadows from nearby structures reduce the performance of PV panels. A wind energy system alone cannot provide 24-hour load coverage because of fluctuations in wind speed throughout the day. Individually installed, a large and expensive energy storage system would be required to satisfy the energy requirement of the local load. Together as a hybrid system, the size of the energy storage device can be significantly reduced. The storage device used in a distributed energy system that uses wind and solar energy can be a battery bank, a superconducting magnetic energy storage (SMES), a supercapacitor bank, or a fuel cell-electrolyzer system [2]. Among the aforementioned storage devices, the battery bank is the most commonly used storage technology. Recent developments in electric vehicle (EV) and plug-in hybrid electric vehicle (PHEV) storage technology hold a promising option to supply electricity to a customer's building (V2B) or into the grid (V2G) [24]. 


\subsection{Renewable Energy Sources}

Among the various renewable energy sources, wind and solar power are the most promising and are already widely used and researched [3-11]. Wind and solar technologies are used in individual buildings and in farms to supply the power needs of a community. Reference [3] presented a Simulink model of a small-scale variable speed wind turbine system equipped with a synchronous generator and a closed loop dc-dc converter for maximum power point tracking and fault detection. In [4] the accuracy of the electrical model of a wind turbine system that uses a permanent magnet alternator was validated using an actual wind turbine installed on the premises. A fixed-pitch angle wind turbine model with an induction generator is simulated in [5] to analyze the effect of wind velocity to the mechanical power and torque output. An MPPT strategy to extract the maximum power from a variable speed stand-alone wind turbine with a permanent magnet synchronous generator is presented in [6] as well as a control strategy for the bidirectional dc-dc converter used to charge the battery bank. Research on different ground-mounted flatplate solar array designs are analyzed in [9] and the optimum module and array mechanical and electrical circuit configurations that minimizes the total PV system life-cycle energy cost is presented. The lifecycle energy cost includes the cost of repairing and replacing failed cells and modules. Reference [11] shows that modeling the performance of a PV panel is not as simple as modeling the I-V characteristics of a single cell and then multiplying that by the number of cells in the panel. The authors presented an approximation model to calculate the output of a PV panel at a given temperature and irradiation. For engineering applications, $[14,20]$ uses the power efficiency model to predict the performance of PV arrays under changing climate conditions.

Because the power outputs of renewable energies do not always coincide with the time durations of load demands, storage systems are required to balance out the irregularities in their power outputs. Lead acid battery is the preferred storage technology for this type of application. The ampere-hour counting method is the widely used technique in predicting battery behavior because it can be easily implemented 
with satisfactory results $[14,20]$. The ampere-hour counting method is characterized by the battery's state of charge (SOC) or its opposite, the state of discharge (DOD).

\subsection{Sizing of Components}

Setting up a distributed energy system that includes renewable energy sources with high installation costs such as wind and solar technologies requires proper sizing of the system components to satisfy the load demand. The optimum hybrid configuration cannot be obtained without designing a control strategy to maximize the potential of the renewable resources. Different approaches and techniques to optimal sizing of renewable energy systems have been covered in various literature [14-20]. Optimal sizing of a hybrid system that takes into consideration the charge/discharge rate, cycles and current of the battery and the complementary nature of wind and solar while minimizing the fluctuations of the power injected into the grid is presented in [14]. Multi-objective optimization - minimizing system cost and minimizing $\mathrm{CO}_{2}$ emission - is used in $[15,17]$. Single-objective optimization - minimizing cost - is presented in $[16,18$, 19, 20]. Linear programming technique is used in [20] to calculate the optimal size of a hybrid wind, solar and battery set that uses diesel generator or the grid to guarantee a reliable supply of power while reducing the cost of electricity for a community. Results are expressed in optimum total area of solar panels, the total wind turbine rotor area, total battery size and total generator size. Reference [29] provides a review of the different research made on optimal sizing of stand-alone hybrid solar-wind power generation systems.

\subsection{Power Management}

The integration of distributed energy resources that uses solar and wind power into the grid poses challenges because solar and wind energy cannot be dispatched in the same way as nuclear, hydro and fossil fuels to match supply to demand. Adding to the challenge is the fact that the intermittent production 
of solar and wind energy does not always coincide with peak demand times. To manage the power flows of the DER system, the individual components are modeled first and then their power outputs combined to meet the load demand. To reduce the size of the storage battery and minimize power fluctuations injected into the grid, [14] proposed an optimization model for a dc-linked wind-solar-battery hybrid system that can be connected to the grid or as stand-alone. The computer model utilizes the HOMER software for the pre-processing of data needed by the optimization routine. A power management strategy for a stand-alone, ac-linked hybrid wind-PV-fuel cell system that can supply 5 homes is proposed in [2]. Reference [20] presented two control policies for its power management model: renewablesbattery-generator and renewable-generator-battery for an autonomous system. The grid replaces the generator if the system is interconnected to the grid. Their model can give the production cost, energy available from each component, unmet and dumped energies and battery charge and discharge losses and the environmental credit of the system.

Simulation programs are the most common tools used to analyze and verify the performance of a DER system after the component sizes have been selected and a power management strategy has been designed. The various simulation programs commercially available are HOMER, HYBRID2, HOGA and HYBRIDS.

\subsection{Motivation, Objective and Report Organization}

Traditionally, power is generated far from the centers of consumption and transmission lines are used to reach these consumers. Over the last few decades, the electric power industry has been marked by high load growth, an aging transmission system and skyrocketing cost of energy. Large-scale generation projects are hindered by inadequate and under-invested transmission systems due to land availability, property value issues, aesthetics and licensing concerns [34]. Society is not open to the idea of building transmission lines that pass through their backyards, so to speak. One of the solutions to this dilemma is 
to bring the source of power close to where the demand is. This concept is called distributed energy resources.

The energy industry and academic scholars are scrambling to come up with the next-generation technologies of producing energy that will not harm and instead improve the standard of life of future generations. This project is an attempt to contribute to that endeavor.

Distributed energy system is one of the solutions that has taken root and is being slowly adopted worldwide. The complexity of designing and analyzing a distributed energy system that includes renewable resources (whether stand-alone or hybrid), energy storage and conventional energy sources makes it difficult without the use of a computer system. In this project, a computer model is developed that monitors the energy available from each component of the distributed energy resource system and controls the balance of power by maximizing the potential of the renewable energy sources before taking advantage of the available power from electric vehicles, the battery and from the conventional sources.

The aim of the proposed computer model is not to calculate the optimal size of the various energy sources based on the lowest investment cost possible or lowest carbon footprint. The proposed computer model is designed to manage the daily power flows among the different energy sources and the storage systems to help reduce peak electric demand and purchase the least amount of power from the grid. The network is always connected to the grid to provide an uninterrupted supply of power.

The modeling software proposed in this project can be used as a tool during the feasibility and design stage to analyze and build a distributed energy system that includes renewable energy resources, storage devices (battery and electric vehicle) and conventional energy sources. The software model can also be used to verify the results of optimal sizing methodologies that use single renewable technology or hybrid wind-solar-battery power systems. By comparing the performances and energy production costs of different configurations, the optimum configuration can be found. The author hopes that it will fill a shortage of an intuitive software tool where any type of load profile can be used and users can select the appropriate system components to supply the load. 
The proposed system can model the following configurations:

Load Units:

- Residential

- Office

- Commercial

- Industrial
Power Sources:

- Photovoltaic

- Wind turbine

- Natural gas generator

- Utility grid
Storage Devices:

- Battery bank

- Electric vehicle battery pack

WTG and PV panels are the primary energy sources and a battery bank is used as a permanent storage system. EVs (if the load unit has charging stations) can be used to provide additional power to the load unit or can act as loads themselves. A small-size natural gas generator and the utility grid serve as the conventional energy sources. The battery and the conventional sources of energy ensure a reliable supply of electricity. The computer model can provide an overview of the components' performances and compare the practicality of different configurations in terms of cost and energy savings. The software provides a graphical user interface (GUI) to make it easy to set up and operate.

This report is organized as follows. Chapter 2 explains the system configuration chosen. Chapter 3 describes the performance models used to estimate the outputs of each distributed energy resource available at the modeler's disposal. Chapter 4 explains the power flow strategies used by the computer model. Chapter 5 presents the case cases used to validate the models and test the control strategy. It also details the process used in this project to select the component sizes. Chapter 6 analyzes and explains the results of the case study used to verify the accuracy and performance of the system. In Chapter 7 a conclusion is drawn from the results and lessons learned from the project. 


\section{SYSTEM CONFIGURATION}

The network architecture of a hybrid system can be classified according to the connection bus: dcbus, ac-bus and hybrid bus [1]. Each configuration has its own advantages and disadvantages. The dcbus architecture is widely used in small-scale implementations of distributed power generation for its convenient control and easy integration of renewable energy sources to the system. The dc-bus architecture has the following additional advantages [1]: fewer power converters, higher overall system efficiency and the absence of frequency stability and reactive power issues, skin effect and ac losses. The proposed computer model uses the dc-bus architecture as shown in Fig. 2-1. The PV panels and wind turbine generator(s) are connected to the dc bus by a charge controller-dc/dc converter and a charge controller-ac/dc converter, respectively. These converters also provide the maximum power point tracking (MPPT) function for the PV and wind turbine generators. The scope of the project assumes that these maximum power point trackers will keep the WTG and PV panels operating at their optimal power operating points. MPPT models of the wind and PV energy conversion systems can be found in [6] and [13]. The solar charge controller is used to disconnect the solar panels from the battery bank when it is fully charged to prevent damage to the battery. The wind turbine charge controller is used to disconnect the wind turbine from the battery bank when it is fully charged and at the same time divert the power to the dump load to prevent damage to the wind turbine. A bidirectional dc/dc converter connects the battery bank to the dc bus. The battery bank can be made up of many battery modules connected in series and/or parallel to provide the necessary voltage and power. A bidirectional inverter converts the dc voltage to ac voltage to supply power to the load and the ac voltage to dc in situations when the grid and/or the natural gas generator are needed to charge the battery bank. EVs have the power electronics capable of drawing and producing $60 \mathrm{~Hz}$ ac power and are therefore connected to the ac bus. The power generated by the wind, solar and EV batteries provides the primary power source to satisfy the demand of the local load. 
The battery will be used to supply the load demand when there is not enough wind, solar and EV power. The natural gas generator and utility grid serve as the backups to provide a reliable source of electricity.

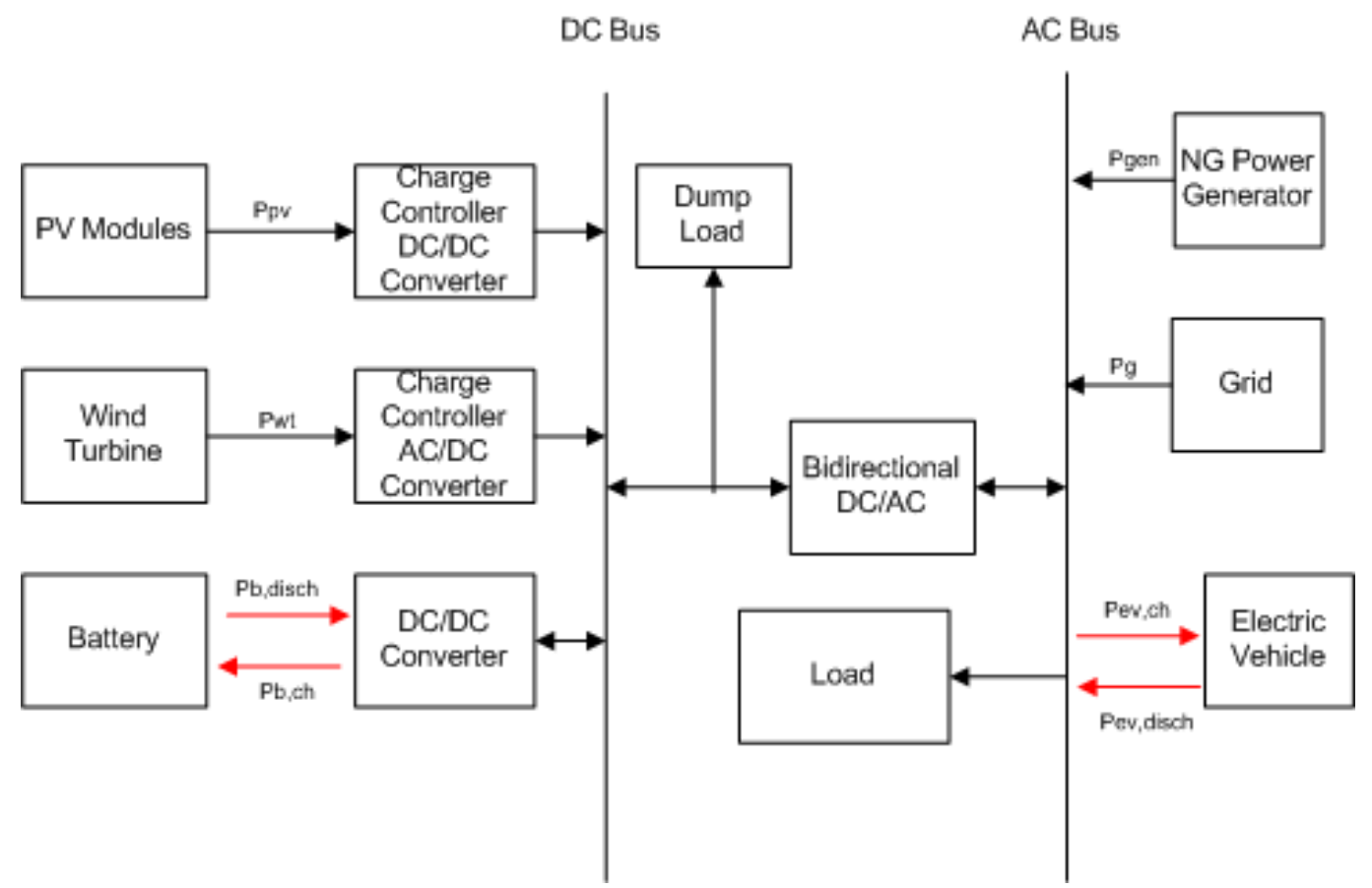

Figure 2-1 System configuration of grid-connected distributed energy generation system

If energy buy back is implemented, the excess energy produced by the wind and solar technologies can be transferred into the utility grid by means of a step up transformer. In this project, buy back is not considered. Any excess energy produced by the renewable energy sources is diverted to the dump load as shown in Fig. 2-1 to maintain voltage stability and prevent damage to the wind turbine.

To estimate the power output of different types of wind turbine generators and PV panels, the software program uses the hourly weather data in the form provided in the Canadian Weather for Energy Calculations (CWEC) data sets. The CWEC files contain twelve Typical Meteorological Months selected from 30 years of Canada Weather Energy and Engineering Data Sets (CWEEDS) [27] with each month in the dataset as being the best representative of that particular month. These data sets include solar 
radiation, wind speed and ambient temperature and are convertible into Excel spreadsheets. Weather data can be requested for different meteorological locations in Canada. 


\section{MATHEMATICAL MODEL OF COMPONENTS}

When designing a distributed energy system, the performances of the individual components used in the DER system are modeled first and their combination analyzed and evaluated to match the load demand. In this section, the models used to estimate the performance of the different technologies used in the proposed computer model are presented.

\subsection{Photovoltaic Power Generation Model}

PV generators convert the energy of the sun into electrical power. The output of the PV system is a function of the solar radiation that hits the surface of the PV panels and the operating temperature of the panels. Below is a discussion of the model used to obtain the solar irradiance and the operating temperature.

The total ground radiation at the earth's surface is called the global solar radiation and is composed of three components: the beam radiation coming directly from the sun, the diffuse component that is scattered everywhere (from the sky and from the surroundings) and the radiation reflected from the surroundings (ground or sea) depending on the local "albedo" (reflection coefficient).

In this project, the irradiance on a titled surface is calculated using the direct beam and diffuse components only $[10,27]$. Reflected radiation does not contribute much to the sunlight striking the surface of solar panels because the panels are usually tilted away from the direction of reflected light. In very snowy areas however, reflected radiation can provide a significant amount of sunlight striking the solar panels. For this project the total ground radiation is expressed only as:

$$
G(t)=B(t)+D(t)
$$


where $G(t)$ is the hourly values of global irradiance on an inclined surface, $B(t)$ is the hourly direct or beam irradiance on an inclined surface and $D(t)$ is the hourly diffuse irradiance on an inclined surface.

The direct beam irradiance on an inclined surface (in $W / \mathrm{m}^{2}$ ) is expressed in $[10,27]$ as:

$$
\begin{aligned}
B(t)=D N I(t) & {[\sin (\delta) \sin (\varphi) \cos (\beta)} \\
& -\sin (\delta) \cos (\varphi) \sin (\beta) \cos (\gamma) \\
& +\cos (\delta) \cos (\varphi) \cos (\beta) \cos (\omega) \\
& +\cos (\delta) \sin (\varphi) \sin (\beta) \cos (\psi) \cos (\omega) \\
& +\cos (\delta) \sin (\beta) \sin (\gamma) \sin (\omega)]
\end{aligned}
$$

where $D N I(t)$ is the time step value of the direct solar radiation on a surface normal to the direction of the beam, $\delta$ is the solar declination angle in degrees, $\varphi$ is the latitude of the location in degrees, $\gamma$ is the module azimuth in degrees and $\omega$ is the hour angle of the sun in degrees.

The diffuse irradiance on an inclined surface $\left(\right.$ in $\left.\mathrm{W} / \mathrm{m}^{2}\right)$ is expressed in $[8,12]$ as:

$$
D(t)=D H I(t)\left(\frac{1+\cos (\beta)}{2}\right)
$$

where $\operatorname{DHI}(t)$ is the time step diffuse irradiation on a horizontal surface. Eq. (3) is derived from the simple isotropic sky model. The simple isotropic model assumes that the intensity of diffuse radiation is uniform across the sky. Both $D N I$ and $D H I$ values are obtained from the CWEC data set.

In Fig. 3-1, the PV module is tilted at angle $\beta$ and facing azimuth $\gamma$ to collect direct beam and diffuse radiation at a site located in the northern hemisphere. The optimum module tilt $\beta$ is usually set to the latitude of the site to get the same amounts of sunlight during summer and winter. To get the maximum power, module tilt can be set to the site's latitude less $15^{\circ}$. For roof-mounted PV arrays, the tilt angle is 
limited by the building's roof pitch. Roof pitch is the degree of steepness of the roof typically expressed in the rise in a run of 12 units. For example, if a roof rises 4' in a length of 12', the roof pitch is 4/12. In [26] the tilt angles for various roof pitches is given in Table 3-1.

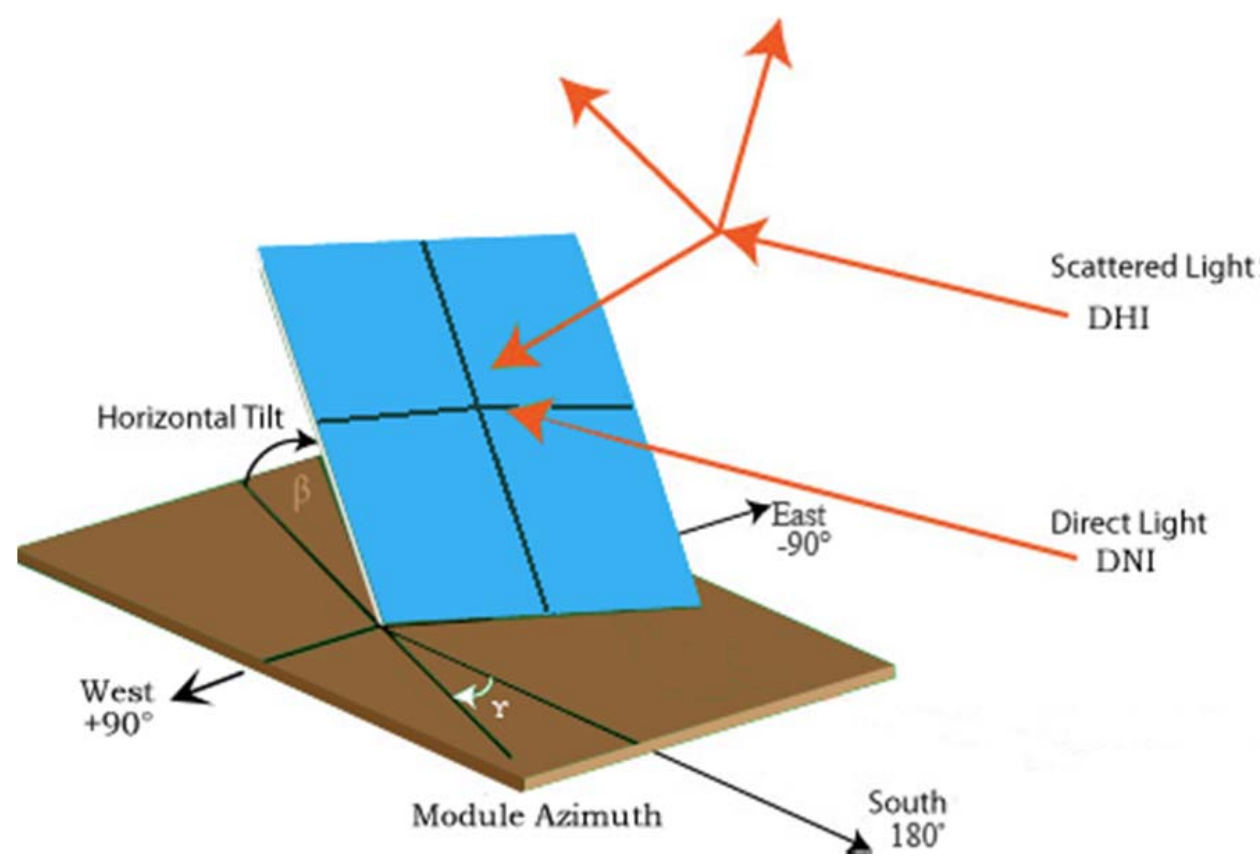

Figure 3-1 Global solar radiation on tilted surface [online: www.greenrhinoenergy.com]

Table 3-1 PV array tilt angle by roof pitch [26]

\begin{tabular}{|l|l|}
\hline Roof Pitch & Tilt Angle $\left.^{(}{ }^{\circ}\right)$ \\
\hline $4 / 12$ & 18.4 \\
\hline $5 / 12$ & 22.6 \\
\hline $6 / 12$ & 26.6 \\
\hline $7 / 12$ & 30.3 \\
\hline $8 / 12$ & 33.7 \\
\hline $9 / 12$ & 36.9 \\
\hline $10 / 12$ & 39.8 \\
\hline $11 / 12$ & 42.5 \\
\hline $12 / 12$ & 45.0 \\
\hline
\end{tabular}


For a PV system mounted in a fixed position, usually on a roof, the module azimuth specifies the angle that the surface of the PV array should be facing from the true north in a clockwise direction. For a single-axis azimuth-tracking PV system, the azimuth angle is the angle of the axis of rotation from the true north in a clockwise direction. The module azimuth angle does not apply to a sun-tracking PV system with two axes of rotation. An azimuth value $+90^{\circ}$ is facing due west, $-90^{\circ}$ is facing due east. To gather the most sun, the ideal azimuth angle for locations in the northern hemisphere is $180^{\circ}$ (south-facing) and $0^{\circ}$ (north-facing) for locations in the southern hemisphere. Since this is not always possible, the roof space nearest to the ideal azimuth is chosen. In the northern hemisphere, increasing the azimuth angle captures more sun in the afternoon, and decreasing the azimuth angle captures more solar energy in the morning. The opposite is true for the southern hemisphere [26].

Fig. 3-2 shows a celestial sphere depicting the declination angle $\delta$, hour angle $\omega$ and the latitude $\varphi$. The earth tilts on its axis while it rotates around the sun causing the solar declination $\delta$ to vary every season. If the earth were not tilted on its axis of rotation, the declination angle would always be $0^{\circ}$. The variation of the declination angle $\delta$ over a year is illustrated in Fig. 3-3. The solar declination can be defined as the distance (expressed in degrees) of the sun north or south of the equator viewed from the center of the earth and can be approximated as:

$$
\delta=23.45^{\circ} \sin \left[\frac{360}{365}(284+d)\right]
$$

where $d$ is the day of the year ( 1 to 365 ) and $23.45^{\circ}$ is the earth's axial tilt. The earth's axial tilt is the angle between the earth's rotational axis and a line perpendicular to the earth's orbit and is virtually constant. Its current value is approximately $23^{\circ} 26^{\prime}$. 


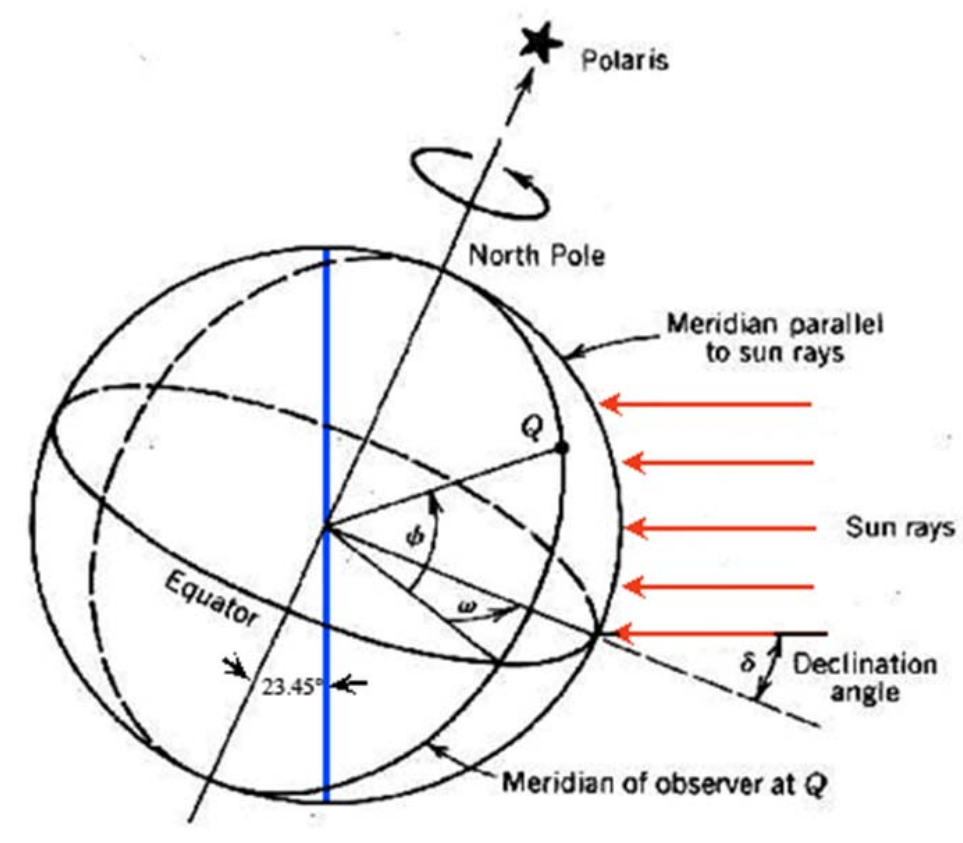

Figure 3-2 Declination angle, hour angle, latitude [online: www.powerfromthesun.net]

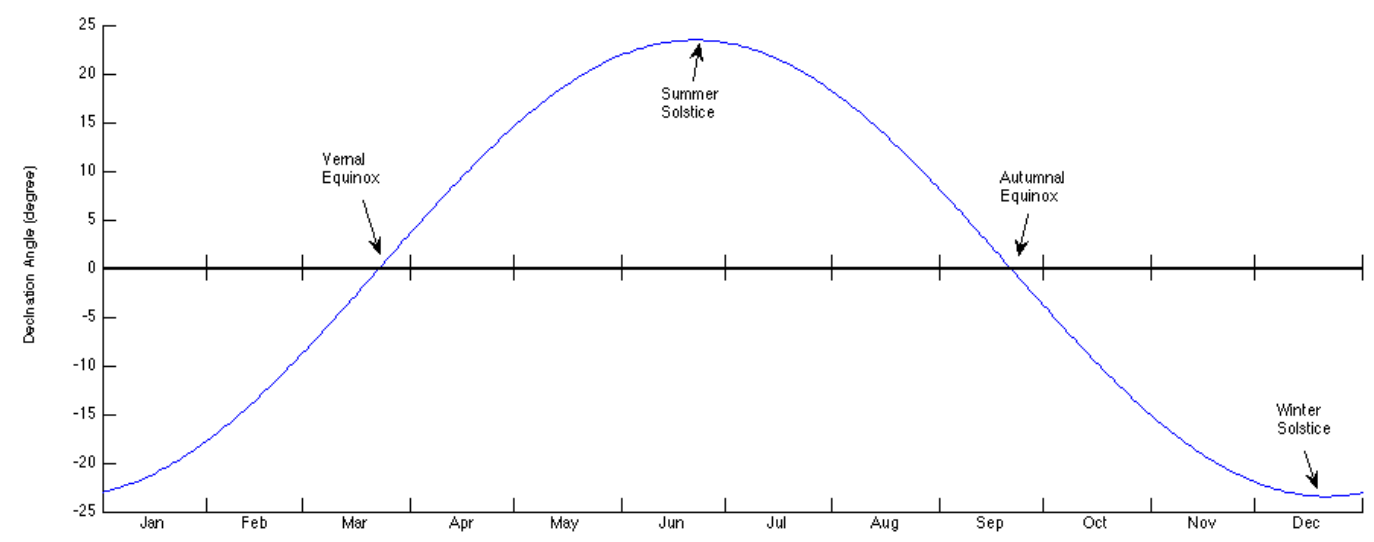

Figure 3-3 Variation of declination angle $\delta$ in one annual cycle

Equations relating to solar radiation use solar time while climate data obtained from the meteorological stations are recorded using the local standard time of the weather station. The next set of 
equations will require the location, day of the year and the local clock settings to convert local time to solar time.

The solar hour angle $\omega$ is a measure of time, expressed in degrees, from the solar noon. As shown in Fig. 3-4, the hour angle is $0^{\circ}$ at solar noon, at the observer's longitude on earth and each hour away from the solar noon is equivalent to a $15^{\circ}$ (the earth rotates on its axis $\frac{360^{\circ}}{24}$ each hour) motion of the sun in the sky with morning being negative and afternoon being positive. The hour angle $\omega$ is calculated as:

$$
\omega=\frac{360}{24}^{\circ}(L S T-12)
$$

where LST is the local solar time. Local clock time differs from local solar time because the earth's distance from the sun is never the same day to day and because of human adjustments to time, i.e., time zones and daylight savings time.

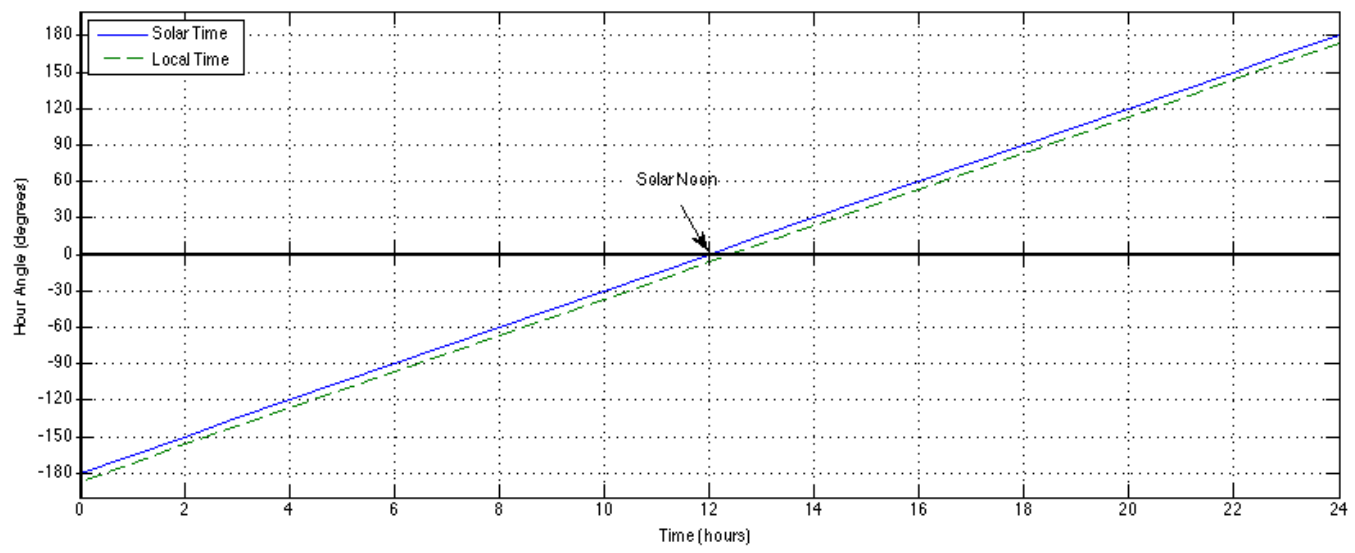

Figure 3-4 Variation of hour angle (solar time and local time: Jan 1, Longitude -81 ${ }^{\circ}$, GMT-5)

Local solar time (in hours) is expressed as: 


$$
L S T=L C T+\frac{T C}{60}
$$

where LCT is the local clock time expressed in 24-hour format, TC is the Time Correction factor in minutes and the factor is 60 is introduced to convert TC to hours.

The Time Correction factor takes care of the variations of the Local Solar Time (LST) within a given time zone and the variations of the earth's orbit around the sun. TC is expressed as follows:

$$
T C=4 *(\text { longitude }- \text { LSTM })+E o T
$$

where longitude is the longitude of the site where the solar panels are installed and LSTM is the Local Standard Time Meridian. The factor 4 is due to the earth rotating on its axis $1^{\circ}$ every 4 minutes. The Local Standard Time Meridian is the longitude of a time zone's reference meridian in relation to the Greenwich Mean Time. Since the time in each time zone changes by one hour every $15^{\circ}$ east (one hour forward) or west (one hour backward) of the Greenwich Meridian, LSTM is calculated as:

$$
L S T M=15^{\circ} \Delta T_{G M T}
$$

The Equation of Time is the discrepancy between two kinds of solar time: apparent or true solar time and the mean or "fictitious" solar time. Fig. 3-5 shows this difference. It is expressed in [8] as:

$$
\begin{gathered}
E o T=229.2[0.000075+0.001868 \cos (B)-0.032077 \sin (B)-0.014615 \cos (2 B) \\
-0.04089 \sin (2 B)]
\end{gathered}
$$

where $B$ is given by: 


$$
B=(d-1) \frac{360}{365}
$$

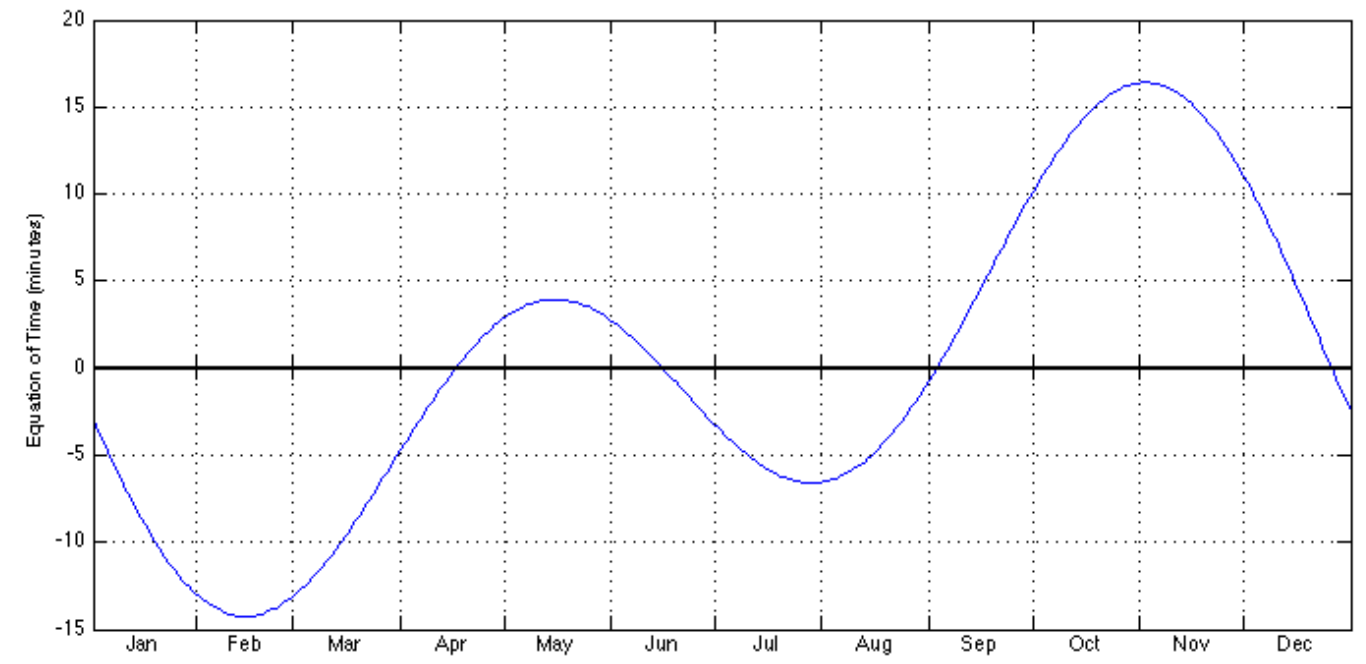

Figure 3-5 Equation of Time

The above calculations were used by [8] and can also be found in [28] for estimating the solar radiation on inclined surfaces.

In addition to the effect of solar radiation on PV performance, the temperature at which the cells operate also affects the efficiency of the PV system. Solar panels are more efficient at low temperatures and energy output goes down at high temperatures. Using the climate data obtained from the CWEC data set and the manufacturer's datasheet, the cell temperature (in ${ }^{\circ} \mathrm{C}$ ) can be derived using the following equation:

$$
T_{c}(t)=T_{a}(t)+\frac{T_{c, \text { noct }}}{T_{a, \text { noct }}} G_{c, \text { noct }}
$$


where $T_{a}(t)$ is the hourly air temperature in ${ }^{\circ} \mathrm{C}$ obtained from the weather data, $T_{c, \text { noct }}$ is the nominal operating cell temperature obtained from the solar panel manufacturer, $T_{a, \text { noct }}$ is the ambient temperature at which the nominal cell temperature (NOCT) is defined $\left(20^{\circ} \mathrm{C}\right.$ as per industry standard) and $G_{c, n o c t}$ is the solar radiation at which NOCT is defined $\left(800 \mathrm{~W} / \mathrm{m}^{2}\right.$ as per industry standard).

Using the manufacturer's data sheet, the solar panel output power (in Watts) at any time interval can be calculated according to the expression [1]:

$$
P_{P V}(t)=P_{m, s t c} f_{P V} \frac{G(t)}{G_{s t c}}\left[1+\propto_{T}\left(T_{c}(t)-T_{c, s t c}\right)\right]
$$

where $P_{m, s t c}$ is the rated output in $W_{P}$ at standard test condition (STC), $f_{P V}$ is the derating factor estimated based on the location of the solar panels, $G(t)$ is the global solar radiation on an inclined surface in $\mathrm{W} / \mathrm{m}^{2}$ calculated using Eq. (1), $\propto_{T}$ is the temperature coefficient of maximum power in $\% /{ }^{\circ} \mathrm{C}$ taken from the manufacturer's data sheet, $T_{c(t)}$ is the cell temperature in the current time step calculated using Eq. (11), $G_{s t c}$ is the incident radiation at standard test conditions $\left(1000 \mathrm{~W} / \mathrm{m}^{2}\right)$ and $T_{c, s t c}$ is PV cell temperature at standard test conditions $\left(25^{\circ} \mathrm{C}\right.$ industry standard). The derating factor is a scaling factor introduced to account for physical and environmental conditions such as wiring losses, dust/dirt, shading, mismatch, age, snow cover and other foreign matters that causes the power output of the PV system to deviate from its rated output at standard conditions.

The power supplied to the load by the PV system is further reduced by the inverter's efficiency and is calculated as:

$$
P_{P V-\text { out }}(t)=S_{n} P_{P V}(t) \eta_{\text {inv }}
$$


where $S_{n}$ is the number of solar panels, $P_{P V}$ is the output power of the solar panel calculated using Eq. (12) and $\eta_{i n v}$ is the efficiency of the inverter.

When charging the battery, the PV array output does not pass through the inverter, therefore, the power available from the PV array that can be used to charge the battery is calculated without the inverter losses:

$$
P_{P V-b a t t}(t)=S_{n} P_{P V}(t)
$$

\subsection{Wind Power Generation Model}

Wind turbines transform the kinetic energy of the wind into electricity. The wind speed data obtained from the CWEC data set and the wind turbine power curve obtained from the manufacturer are used to estimate the power output of a wind turbine generator. The power curve is the manufacturer's guarantee of performance of its wind turbine at standard air density. It illustrates the expected power output of the wind turbine at certain wind speeds. Power output performance curves usually vary for different types of wind turbines. The wind turbine's power curve does not exactly represent the power output of the wind turbine because instantaneous wind speed variations are ignored. However, calculating the power outputs of wind turbines based on actual wind speed variations is time consuming and sometimes impossible [22].

Fig. 3.1 shows the output power curve of a Bergey $7.5 \mathrm{~kW}$ wind turbine generator. At the cut-in speed $V_{c i}$ of $4 \mathrm{~m} / \mathrm{s}$, enough force hits the blades to rotate the generator shaft and generate power. The wind turbine reaches its rated power or nameplate output at the rated wind speed $V_{r}$ of $11 \mathrm{~m} / \mathrm{s}$. The Bergey wind turbine can produce a maximum power output of $8 \mathrm{~kW}$ at wind speeds of $12-14 \mathrm{~m} / \mathrm{s}$. Some small wind turbine models have a furling mechanism to slow it down. The furling speed of the Bergey wind 
turbine starts at $15 \mathrm{~m} / \mathrm{s}$ and if the wind speed exceeds the cut-out speed $V_{c o}$ of $20 \mathrm{~m} / \mathrm{s}$ the wind generator stops running to protect its electrical and mechanical components.

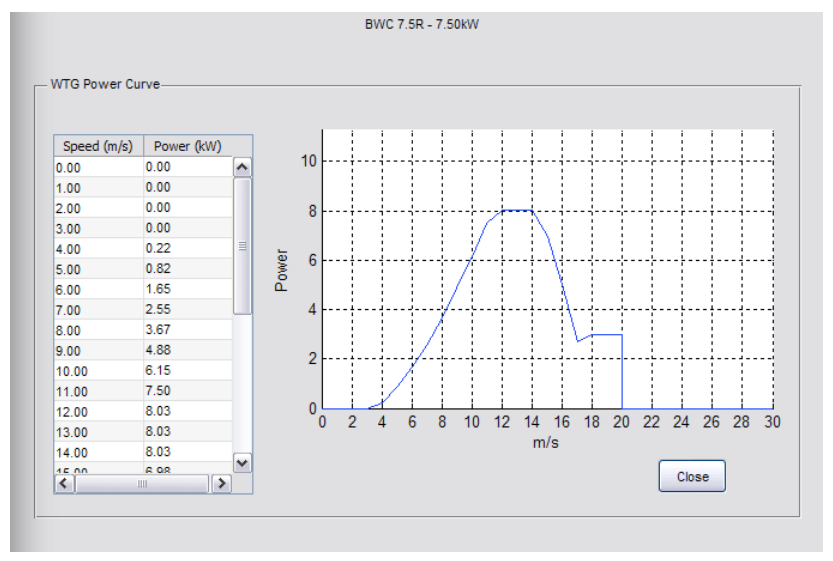

Figure 3-6 Wind speed vs power output of a Bergey $7.5 \mathrm{~kW}$ wind turbine generator

The power output of a wind turbine generator can be mathematically written as follows:

$$
P_{w}= \begin{cases}0, & v_{w}<V_{c i} \text { or } v_{w}>V_{c o} \\ P_{w, r} \frac{v_{w}-V_{c i}}{v_{r}-V_{c i},}, & V_{c i} \leq v_{w} \geq V_{r} \\ P_{w, r}, & V_{r} \leq v_{w} \leq V_{c o}\end{cases}
$$

where $v_{w}$ is the wind speed at the hub height, $V_{r}$ is the rated wind speed, $V_{c i}$ is the cut-in wind speed, $V_{c o}$ is the cut-out wind speed and $P_{w, r}$ is the rated output power of the wind turbine generator. It should be noted that the measured power curve is usually different from the calculated version.

Wind speed data provided in the CWEC data set were taken at a height of 10 meters. If the wind turbine hub height is different, the wind data can be approximated using the power law engineering approximation [4]: 


$$
v_{1}=v_{0}\left(\frac{H_{1}}{H_{o}}\right)^{\alpha}
$$

where $v_{1}$ is the wind speed at hub height $H_{1}, v_{o}$ is the recorded wind speed at height $H_{o}$ and $\alpha$ is the power law exponent that varies from 0.1 to 0.6 depending upon the stability and surface roughness of the atmosphere. Some wind turbine manufacturers like Bergey provide the value of $\alpha$. If the power law exponent is not available, the commonly assumed value of $\alpha$ in wind resource assessments is $1 / 7$ or 0.143 because the difference between the two heights (usually less than $50 \mathrm{~m}$ ) are not high enough to produce significant errors into the estimates [7].

Using the adjusted wind speed, the output of the wind turbine can be interpolated from the manufacturer's power curve with the assumption that the power curve was generated at standard air density. Two derate factors are applied to the power output of the wind turbine: turbulence factor to account for air turbulence, site variability and other performance-influencing factors and air density factor to account for the reduction from sea-level performance. Some wind turbine models include the turbulence factor in their data sheet, others incorporate it in the power curve. According to [33], for identical systems, the simple payback is almost $14 \%$ longer at 5,000 feet compared to systems installed at sea level. The authors recommend a $1.4 \%$ reduction in power output for every 500 feet $(152.4 \mathrm{~m})$. For wind turbine models that do not include the air density factor in their data sheets, $1.4 \%$ is used to calculate the reduction from sea level-performance. The power output of the wind turbine (in Watts) is therefore calculated as:

$$
P_{w t}(t)=P_{v w}(t)\left[\left(1-f_{\text {turbulence }}\right)\left(1-\frac{\text { Altitude }}{152.4 \mathrm{~m}} f_{\text {airdensity }}\right]\right.
$$


where $P_{v w}(t)$ is the power curve intercept at the corresponding wind speed, $f_{\text {turbulence }}$ is the turbulence factor to account for air turbulence and site variability, Altitude is the elevation of the site and $f_{\text {airdensity }}$ is the air density factor to account for the reduction from sea-level performance.

The power available from the wind turbine that can be used to supply the load is calculated as:

$$
P_{w t-o u t}(t)=W_{n} P_{w t}(t) \eta_{i n v}
$$

where $W_{n}$ is the number of wind turbines installed, $P_{w t}$ is the output power of the wind turbine calculated using Eq. (17) and $\eta_{i n v}$ is the efficiency of the inverter.

When charging the battery, the power from the wind turbine does not go through the inverter, therefore, the power available from the wind turbine that can be used to charge the battery is calculated without the inverter losses:

$$
P_{w t-b a t t}(t)=W_{n} P_{w t}(t)
$$

\subsection{Electric Vehicle Model}

The primary purpose of the EV battery pack is to supply the energy needed by the car for driving. However, recent advances in vehicle to building (V2B) technology [30,31] have made the concept of integrating plug-in electric vehicles as an additional source of energy for commercial and residential buildings a market reality [32]. The proposed modeling software introduced in this report uses the EV model and data reported in [24].

To meet the driving requirements of the car, this project assumes that EV charging stations are available at home, in the work place and in shopping malls and that the charging schedule is managed by 
a local controller installed within the premises. The charging power and time are used to model the charging requirements of the EV battery pack. To tap the energy stored in EV batteries, a simplified approach to the driving pattern of vehicle owners is adopted. The driving pattern is modeled using the following information:

- Initial state of charge for the first trip of each day

- Arrival and departure time in each location

- Distance to next destination

- Safety factor provided to ensure car has enough reserve power to reach its next destination

- Efficiency of the EV battery in terms of power required per kilometer

- Flag to indicate if the EV owner will allow the vehicle battery to be discharged.

The power in $\mathrm{kW}$ required to reach the driver's next destination is calculated using:

$$
P_{D+1}=\eta_{e v} D
$$

where $\eta_{e v}$ is the efficiency of the battery pack in $\frac{\mathrm{kW}}{\mathrm{km}}$ and $D$ is the distance to the next destination in $\mathrm{km}$. The EV battery power (in $\mathrm{kW}$ ) at each time step is calculated using the equation:

$$
P_{\text {ev-out }}(t)=P_{\text {avail }}(t)-P_{D+1}(t) \cdot f_{e v}
$$

where $P_{\text {avail }}$ is current state of charge of the battery pack in $\mathrm{kW}, P_{D+1}$ is the power required to reach the driver's next destination and $f_{e v}$ is a safety factor added to the power required to reach the driver's next destination. $P_{e v-o u t}$ is positive if it has excess energy to give away and negative if it needs charging. 
Reference [24] uses an internal transfer of power that pools together the excess battery power of EVs whose owners allow discharging to charge the EVs that need power. The EV model uses the following setup:

1. EVs are categorized into two sets: charging-only EVs and V2B EVs. Charging-only EVs include only EVs that charge their battery but do not allow discharging. V2B EVs include EVs that allow charging and discharging of their battery.

2. Maximum allowable rate of discharge for each $\mathrm{EV}$ is limited to $5 \mathrm{~kW}$ per hour.

3. Each EV with excess energy can provide power to an EV that needs charging up to the maximum allowable rate of discharge.

4. Each EV can accept as much power it needs from multiple EVs without exceeding the battery pack's maximum capacity or the power needed to reach the driver's next destination including the safety factor.

5. EVs leaving the premises do not have to be fully charged.

After the internal transfer of power is completed and there are still EVs that need charging, the local controller will request power from the renewable sources, generator and/or grid. Each EV can only request a maximum of $5 \mathrm{~kW}$ per hour or the power required to reach it's next destination whichever is less. It is calculated as follows:

$$
P_{\text {net }}=\sum P_{\text {ev-out }}
$$

subject to:

$$
P_{D+1} \geq P_{e v-o u t} \leq P_{\text {ev,trate }}
$$

where $P_{\text {ev,trate }}$ is the maximum transfer rate (set at $5 \mathrm{~kW}$ per hour).

If no EV requires charging, the net power output is the sum of the excess power of all EVs that allow their battery to be discharged subject to the maximum allowable rate of discharge. 
Table 3-2 is an example of how the transfer of power is facilitated by the local controller. In the table $\mathrm{EV}_{1}, \mathrm{EV}_{3}$ and $\mathrm{EV}_{4}$ are V2B EVs. EV2 is a charge-only EV and it needed $27 \mathrm{~kW}$ to reach its next destination including the safety factor. $\mathrm{EV}_{1}$ can give $19 \mathrm{~kW}$ and still be able to arrive at its next destination while $\mathrm{EV}_{3}$ has an excess of $4 \mathrm{~kW}$ only. The local controller calculated that $\mathrm{EV}_{1}$ can be discharged for 3 hours at the maximum allowable rate of discharge $P_{e v \text {,disch }}$ of $5 \mathrm{~kW}$ per hour to charge $\mathrm{EV}_{2} . \mathrm{EV}_{3}$ 's battery pack was also discharged by $4 \mathrm{~kW}$ to charge $\mathrm{EV}_{2}$. The local controller requested power from the external source (renewable, generator or grid) to charge $\mathrm{EV}_{2}$ for 2 hours. At time interval $t_{3}, E_{2}$ has enough capacity to reach its next destination including the safety factor. At time interval $t_{4}$ and $t_{5}, \mathrm{EV}_{1}$ was discharged to supply power to the load. At time interval $\mathrm{t}_{4}, \mathrm{EV}_{4}$ came online and also provided power to the load.

Table 3-2 Sample EV Charge/Discharge Schedule

\begin{tabular}{|c|c|c|c|c|c|c|}
\hline $\begin{array}{c}\text { EV/ } \\
\text { Time } \\
\text { Interval }\end{array}$ & $t_{0}$ & $t_{1}$ & $\mathrm{t}_{2}$ & $t_{3}$ & $t_{4}$ & $t_{5}$ \\
\hline $\mathrm{EV}_{1}$ & $+19 \mathrm{~kW}$ & $+14 \mathrm{~kW}$ & $+9 \mathrm{~kW}$ & $+6 \mathrm{~kW}$ & $+1 \mathrm{~kW}$ & 0 \\
\hline $\mathrm{EV}_{2}$ & $-27 \mathrm{~kW}$ & $\begin{array}{r}\mathrm{EV}_{1}=5 \\
\mathrm{EV}_{2}=4 \\
\mathrm{Ext}=5\end{array}$ & $\begin{aligned} \mathrm{EV}_{1} & =5 \\
\mathrm{Ext} & =5\end{aligned}$ & $\mathrm{EV}_{1}=3$ & 0 & 0 \\
\hline & & $\begin{array}{r}14 \\
-27+14=-13 \mathrm{~kW}\end{array}$ & $\begin{array}{r}10 \\
-13+10=-3 \mathrm{~kW}\end{array}$ & $\begin{array}{r}3 \\
-3+3=0\end{array}$ & & \\
\hline $\mathrm{EV}_{3}$ & $+4 \mathrm{~kW}$ & 0 & 0 & 0 & 0 & 0 \\
\hline $\mathrm{EV}_{4}$ & & & & & $5 \mathrm{~kW}$ & 0 \\
\hline $\begin{array}{l}\text { External } \\
\text { Power } \\
\text { Source }\end{array}$ & & $-5 \mathrm{~kW}$ & $-5 \mathrm{~kW}$ & & & \\
\hline Load & & & & & $+5 \mathrm{~kW}$ & $+6 \mathrm{~kW}$ \\
\hline
\end{tabular}

\subsection{Battery Bank Model}

The battery bank is made up of one or more batteries connected in series and/or parallel to provide the necessary voltage and power required by the system. The battery bank is modeled using its maximum 
capacity, minimum capacity, charge time and discharge time. The model does not consider the effects of temperature on the condition of the battery and assumes that the properties of the battery do not change over its lifetime.

When supplying power to the load, the maximum allowable rate of discharge of the battery bank is calculated using the expression:

$$
P_{b, \text { maxdisch }}=\frac{E_{b, c a p}}{t_{\text {disch }} / 60}
$$

where $P_{b, \text { maxdisch }}$ is the maximum power (in $\mathrm{kW}$ ) that can be drawn from the battery in 1 hour, $E_{b, c a p}$ is the battery capacity in $\mathrm{kWh}$ (deep-cycle battery capacity is usually quoted at the 20-hour rate) and $t_{\text {disch }}$ is the minimum discharge time in minutes. The factor 60 is used to convert minutes into hours. To prolong the life of the battery, the model caps the amount energy that can be drawn from the battery to the minimum capacity specified by the user (usually $80 \%$ depth of discharge). Decreasing $t_{\text {disch }}$ will allow constant power to be drawn from the battery at a high power level but for a shorter period of time. At high discharge rates, the battery energy is depleted quickly.

The battery bank is charged at any time when it falls below its rated capacity. The maximum allowable rate of charge of the battery is calculated using the expression:

$$
P_{b, \operatorname{maxch}}=\frac{E_{b, c a p}}{t_{c h} / 60}
$$

where $P_{b, \text { maxch }}$ is the maximum power (in $\mathrm{kW}$ ) that can be injected to charge the battery in 1 hour, and $t_{c h}$ is the maximum charge time in minutes. The battery cannot be charged above its maximum capacity. To preserve the life of the battery, the state of charge of the battery is kept at $50 \%$ of rated capacity every cycle. If at any time interval the state of charge is below $50 \%$, the battery is recharged first and is not 
allowed to discharge until the available energy is above $50 \%$.

The battery is charged in 3 stages: 1) at the maximum allowable rate until its state of charge reaches $80 \%$ of its maximum capacity, 2) at half the maximum allowable rate until its state of charge is $95 \%$ and 3) float or trickle charge until the battery reaches its maximum charge.

To calculate the energy remaining in the battery after it is charged or discharged, the battery's capacity curve is used. This capacity curve can be derived using the manufacturer's data sheet. Fig. 3.2 shows the capacity curve of a Trojan J150 deep-cycle lead-acid battery. Appendix C shows the battery's datasheet. The data points show the capacity of the battery in ampere-hours if discharged at a constant current. A polynomial of the $3^{\text {rd }}$ order is used to get the best fit curve. Using the total current discharged from the battery, the model uses the capacity curve to interpolate the remaining capacity of the battery.

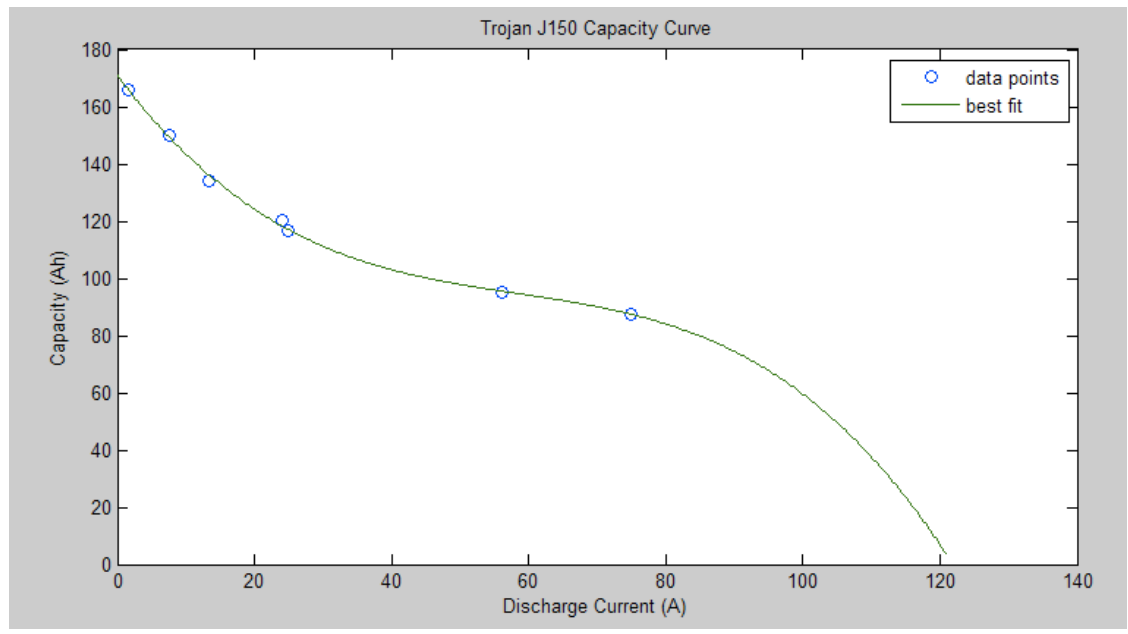

Figure 3-7 Capacity curve of the Trojan J150 battery

The energy drawn from the battery in kWh to supply the unmet load demand at each time step is calculated as:

$$
P_{b, \operatorname{disch}}(t)=\frac{P_{D}(t)}{\eta_{\text {inv }}}
$$


subject to:

$$
0 \leq P_{b, \operatorname{disch}}(t) \leq P_{b, \max d i s c h}
$$

where $P_{D}$ is the unmet load demand.

\subsection{Natural Gas Power Generation Model}

Generators can be classified according to its mode of operation: continuous, prime or stand-by. Continuous power generators are used to provide power continuously or for extended periods of time at consistent load. Prime power generators, like the continuous power generators, are also used to provide power for extended periods of time but with a variable load. Stand-by generators are sometimes called emergency generators because they are used in case of an outage from the utility grid. Standby power generators can be used in a distributed energy system that has solar-wind-battery components since they are not expected to be run often. The generator model used in this project is taken from [25]. It is modeled after an off-the-shelf generator sold commercially. This particular generator does not have any defined startup, shutdown, minimum or maximum runtimes, and can be dispatched at any time based on the power flow strategy described in Section 4. The only property used by the model is the generator's maximum power rating. Minimum power rating is set to 0 . The power in $\mathrm{kW}$ that can be drawn from the generator to supply the load is expressed as:

$$
P_{n g-o u t}=P_{D}
$$

subject to:

$$
0 \leq P_{n g-\text { out }} \leq P_{n g-\text { rating }}
$$


where $P_{n g, \text { rating }}$ is the generator name plate rating.

Energy sources that produce ac voltage must use the bidirectional inverter when charging the battery to convert the voltage to dc. If the generator is used to charge the battery, the power drawn from the generator should take into account the inverter efficiency:

$$
P_{n g-b a t t}=\frac{P_{D}}{\eta_{\text {inv }}}
$$

\subsection{Grid Power Generation Model}

The model and assumptions made in [25] are used in this project. Like the generator, the grid is modeled as a dispatchable power source. Any amount of power can be drawn from the grid at any time and it does not have a startup, shutdown, minimum or maximum run time. The power that can be purchased from the grid to supply the load is expressed as:

$$
P_{\text {grid }}=P_{D}
$$

subject to:

$$
0 \leq P_{\text {grid }} \leq \infty
$$

If the grid is used to charge the battery, the power purchased from the grid must pass through the bidirectional inverter to convert the AC voltage to DC. The power purchased from the grid to charge the battery must take into consideration the inverter efficiency:

$$
P_{\text {grid-batt }}=\frac{P_{D}}{\eta_{\text {inv }}}
$$




\section{POWER FLOW STRATEGY}

The computer model presented here uses time-series simulation to match the required energy demand to the total energy available from the different sources. Although the meteorological input data has a resolution of 1-hr intervals, the distributed energy system's behavior is simulated on 15-minute intervals. Because of the presence of electric vehicles, two strategies are needed. The first scenario is when the EVs act as a power source that can be exploited to supply the local load and the second scenario is when the EVs become part of the load when the car's battery capacity is not enough to reach its next destination. In both strategies, the natural gas generator and utility grid serve as the backups to ensure a reliable supply of electricity. This section explains the two operational strategies.

\subsection{EV as Power Source}

The wind and solar technologies always have the priority in satisfying the load demand:

$$
P_{L}(t) \geq P_{w t-o u t}(t)+P_{p v-o u t}(t)
$$

where $P_{L}(t)$ is the electric energy consumption of the load unit, $P_{w t-o u t}$ is power output of the wind turbine and $P_{p v-o u t}$ is the power output of the PV panels, at any instant of time.

If wind and solar energy is not enough to supply the load, power from the EVs is used if they have extra power to give:

$$
P_{L}(t) \geq P_{w t-o u t}(t)+P_{p v-o u t}(t)+P_{\text {ev-out }}(t)
$$

where $P_{e v \text {-out }}$ is the power output of the EV battery packs subject to the maximum discharge rate imposed on the each EV. 
The energy in the battery bank will be used to supply the load demand when there is not enough renewable and $\mathrm{EV}$ power and is represented by the equation:

$$
P_{L}(t) \geq P_{w t-o u t}(t)+P_{\text {pv-out }}(t)+P_{\text {ev-out }}(t)+P_{b, \text { disch }}(t)
$$

where $P_{b, \text { disch }}$ is the power supplied by the battery bank at the same instant of time. The power discharged by the battery is subject to the maximum allowable rate of discharge and DOD limit set by the user.

If the wind turbine, PV array, EV and battery bank do not have enough power, the natural gas generator will be dispatched to supply the shortage:

$$
P_{L}(t) \geq P_{w t-o u t}(t)+P_{p v-o u t}(t)+P_{\text {ev-out }}(t)+P_{b, \text { disch }}(t)+P_{n g-o u t}(t)
$$

where $P_{n g-o u t}$ is the power provided by the natural gas generator.

If the combined wind turbine, PV array, battery bank, EV and natural gas generator do not have enough power to meet the demand, power will be purchased from the grid. The power needed from the grid will be:

$$
P_{\text {grid }}(t)=P_{L}(t)-\left[P_{w t-o u t}(t)+P_{\text {pv-out }}(t)+P_{\text {ev-out }}(t)+P_{b, \text { disch }}(t)+P_{n g-o u t}(t)\right]
$$

If the total power generated by the renewable technologies is more than the load demand, the simplex method is used to calculate how much power from each of the renewable resources will be used to supply the load with the objective of minimizing the total cost of producing power. In this project, the cost of using renewable energy sources is defined as: 


$$
\mathrm{C}(\mathrm{t})=\sum_{i} P_{i-o u t}(t) C_{i}
$$

Subject to the constraint that the total energy extracted from the renewable resources cannot exceed the instantaneous electrical energy demand:

$$
\begin{aligned}
& \sum_{i} P_{\text {i-out }}(t) \leq P_{L}(t) \text { and } \\
& P_{\text {i-out }}(t) \geq 0
\end{aligned}
$$

where $i$ is the renewable technology indicator, $P_{i-\text { out }}(t)$ is the power output of the renewable technology at time $t$ in $\mathrm{kW}$ and $C_{i}$ is the cost of energy of the $i^{\text {th }}$ technology in $\phi / \mathrm{kWh}$. Time $t$ is every 15 minutes. Cost of energy for each technology used is explained in the section on Unit Sizing.

Any excess power will be used to charge the storage battery. The power in excess of the maximum allowable rate of charge or the power unused after the battery is fully charged will be dumped:

$$
P_{b, c h}(t)=\left[P_{w t-o u t}(t)+P_{p v-o u t}(t)\right]-P_{L}(t)-P_{d u m p}(t)
$$

subject to:

$$
\left[P_{b, \max }-P_{b}(t)\right] \geq P_{b, c h}(t) \leq P_{b, \max c h}
$$

where $P_{b, c h}$ is the power used to charge the battery, $P_{d u m p}$ is the excess power, $P_{b, \max }$ is the battery's maximum power and $P_{b}(t)$ is the power remaining in the battery at time $t$.

If the generator is used to charge the battery the proposed computer model uses the cycle-charging strategy. The battery is charged whenever it falls below its maximum capacity. If the battery needs charging and the energy from the renewable source(s) is not enough, the generator will operate to charge 
the storage battery up to its maximum charging limit or up to the generator's maximum power limit. Power received by the battery is calculated using the expression:

$$
P_{b, c h}(t)=\left[P_{n g-o u t}(t)+P_{w t-o u t}(t)+P_{p v-o u t}(t)\right]-P_{L}(t)
$$

subject to:

$$
\begin{aligned}
& P_{b, c h}(t) \leq P_{b, \text { maxch }} \text { and } \\
& P_{n g-\text { out }}(t) \leq P_{n g-\text { rating }}
\end{aligned}
$$

The generator is operated as a dispatchable resource with a maximum power equal to its rated power $P_{n g-\text { rating }}$ and is treated as always operating.

If the battery still needed charging and there is not enough power from all the other energy sources (EVs excluded), power will be purchased from the grid to charge the battery bank. The grid is operated as a dispatchable resource with an infinite capacity and is treated as always operating. Power drawn from the grid is calculated as:

$$
P_{\text {grid }}(t)=P_{L}(t)+P_{b, c h}(t)-\left[P_{w t-o u t}(t)+P_{p v-o u t}(t)+P_{n g-o u t}(t)\right]
$$

Figs. 4-1 to 4-4 show the block diagrams of the control strategy used by the computer model with the EVs as source of power.

\subsection{EV as Load}

Satisfying the electrical load of the unit using the renewable energy sources has priority over the electric vehicle:

$$
P_{L}(t) \geq P_{w t-o u t}(t)+P_{p v-o u t}(t)
$$


If the energy output of the renewable technologies is more than the load, $P_{L}(t)<P_{w t-o u t}(t)+$ $P_{p v-o u t}(t)$, the excess power will be used to charge the EVs using the equation:

$$
P_{L}(t)+P_{e v, c h}(t) \geq P_{w t-o u t}(t)+P_{p v-o u t}(t)
$$

where $P_{e v, c h}$ is the power requested by the local controller managing the EV charging stations.

The battery will be used to supply the load demand and the EV requirement if there is not enough wind and solar power:

$$
P_{L}(t)+P_{e v, c h}(t) \geq P_{w t-o u t}(t)+P_{p v-o u t}(t)+P_{b, d i s c h}(t)
$$

If the total power generated by the renewable energy sources is more than the load demand and the EV requirement, the simplex method is used to calculate how much power from each of the renewable resources will be used with the objective of minimizing the total cost of producing electricity. The optimization problem is the same as Eqns. (39), (40) and (41). $P_{L}(t)$ would be the sum of the electrical load and the EV requirement.

The excess power will be used to charge the battery. The power in excess of the maximum allowable rate of charge or the power left the battery is fully charged will be dumped. Below is the equation used to calculate the power used to charge the battery:

$$
P_{b, c h}(t)=\left\{\left[P_{w t-o u t}(t)+P_{p v-o u t}(t)\right]-\left[P_{L}(t)+P_{e v, c h}(t)\right]\right\} / \eta_{\text {inv }}-P_{\text {dump }}(t)
$$

subject to:

$$
\left[P_{b, \max }-P_{b}(t)\right] \geq P_{b, c h}(t) \leq P_{b, \operatorname{maxch}}
$$


If the wind turbines, PV panels and battery bank cannot produce enough power for the load unit and EVs, the natural gas generator will supply the shortage:

$$
\left.P_{L}(t)\right)+P_{e v, c h}(t) \geq P_{w t-o u t}(t)+P_{p v-o u t}(t)+P_{b, \text { disch }}(t)+P_{n g-o u t}(t)
$$

At any time, if the battery charge is not at its maximum limit, the generator is used to charge the battery up to its maximum charge limit or up to the generator's maximum power limit. The generator is operated as a dispatchable resource with a maximum capacity equal to its rated capacity and is treated as always available at any instant it is needed. The proposed computer model uses the cycle-charging strategy when charging the battery using the generator. The battery is charged whenever it falls below its maximum capacity. This is represented in the equation:

$$
\begin{aligned}
& P_{b, c h}(t)=\left\{\left[P_{n g-\text { out }}(t)+P_{w t-o u t}(t)+P_{p v-\text { out }}(t)\right]-\left[P_{L}(t)+P_{\text {ev }, \text { ch }}(t)\right]\right\} / \eta_{\text {inv }} \\
& \text { subject to: }
\end{aligned}
$$

$$
\begin{aligned}
& P_{b, c h}(t) \leq P_{b, \text { maxch }} \text { and } \\
& P_{n g-\text { out }}(t) \leq P_{n g-\text { rating }}
\end{aligned}
$$

If the battery still needed charging or there is not enough energy to meet the load and EV demands, power will be purchased from the grid to cover the deficit. The grid is operated as a dispatchable resource with a maximum capacity equal to the maximum demand of the load and is treated as always operating. Power drawn from the grid is calculated as follows:

$$
P_{\text {grid }}(t)=\left\{\left[P_{L}(t)+P_{b, c h}(t)+P_{\text {ev }, \text { ch }}(t)\right]-\left[P_{\text {wt-out }}(t)+P_{\text {pv-out }}(t)+P_{\text {ng-out }}(t)\right]\right\} / \eta_{\text {inv }}
$$




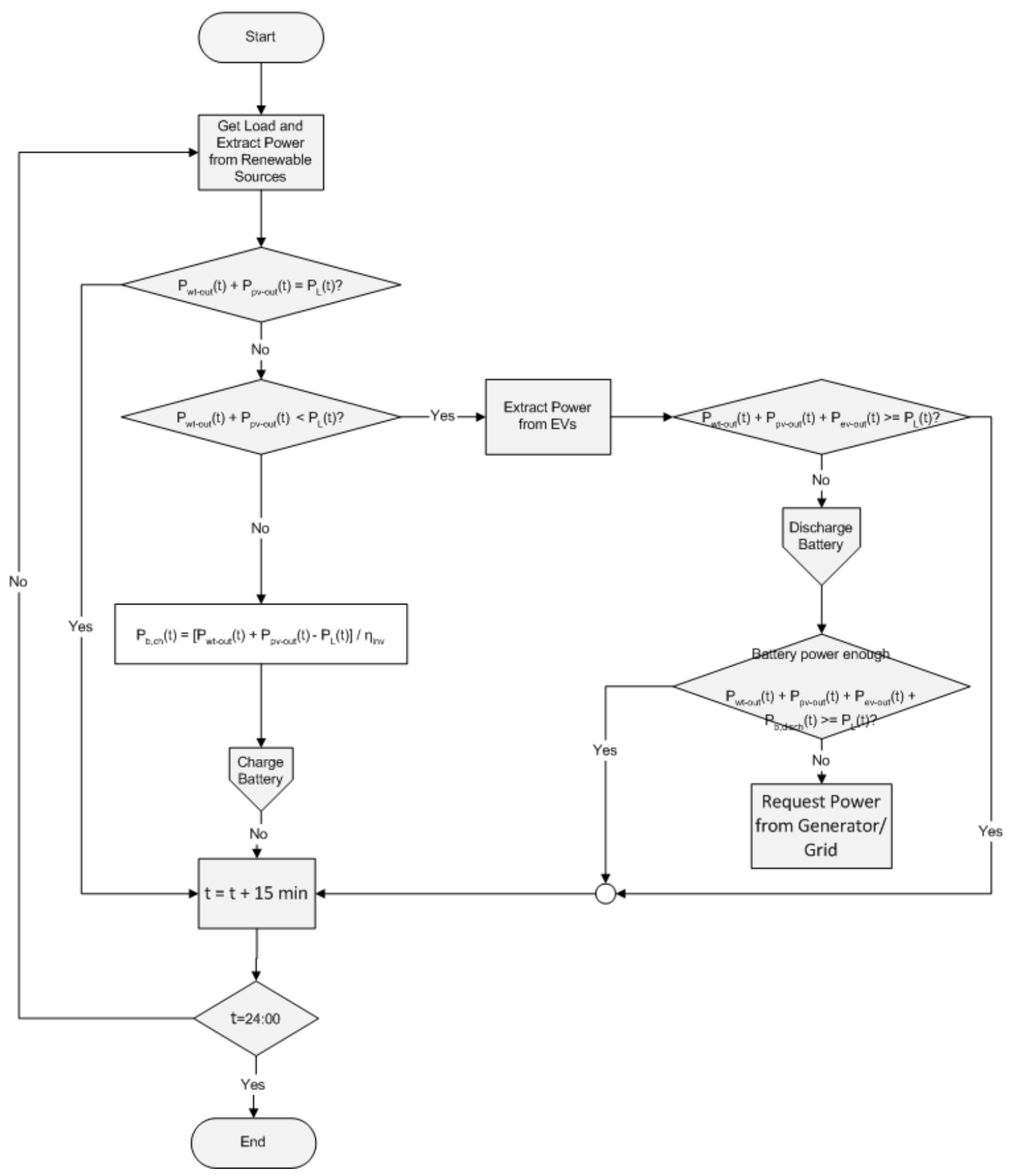

Figure 4-1 Overall mode of operation 


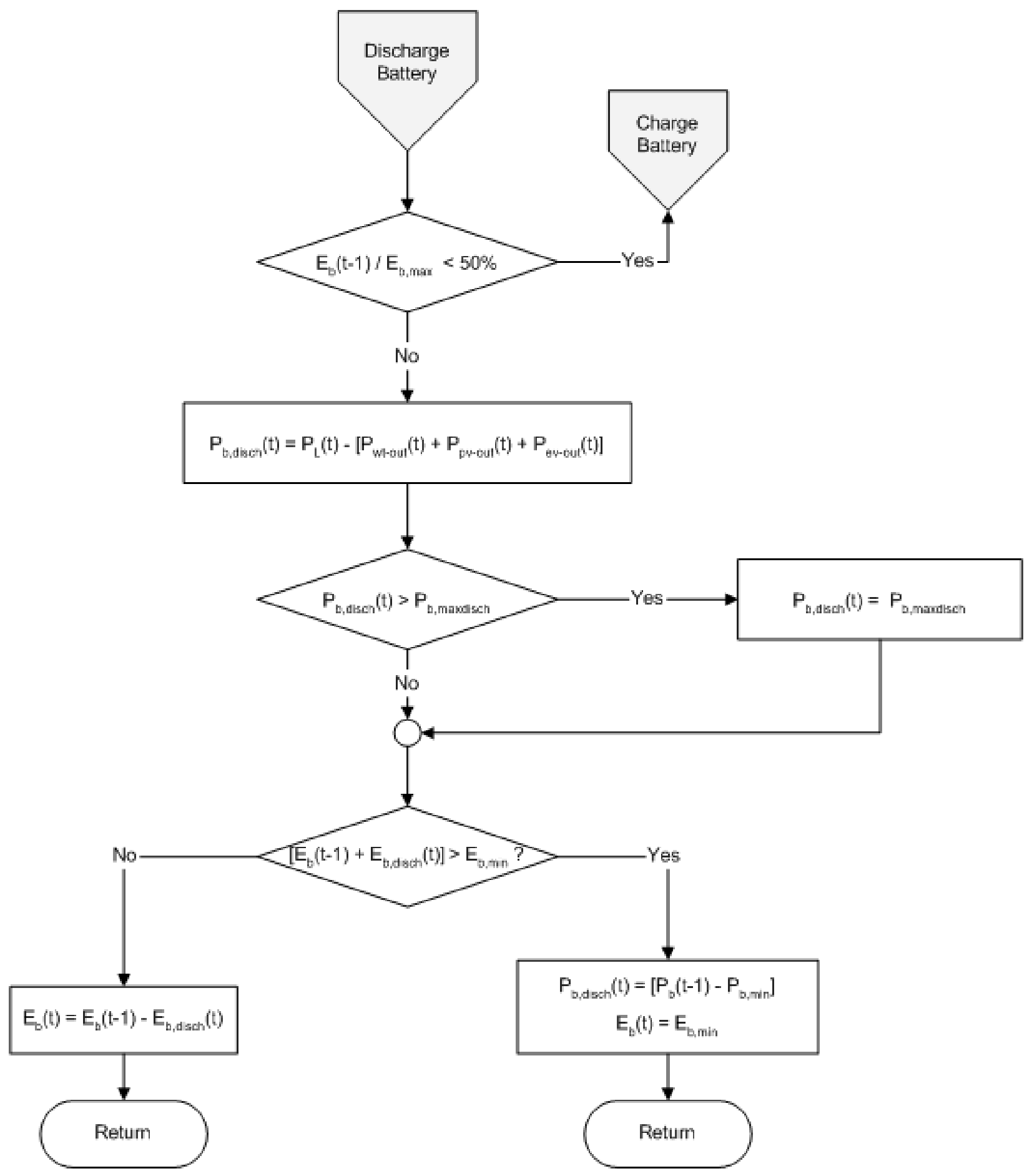

Figure 4-2 Discharge mode of Operation 


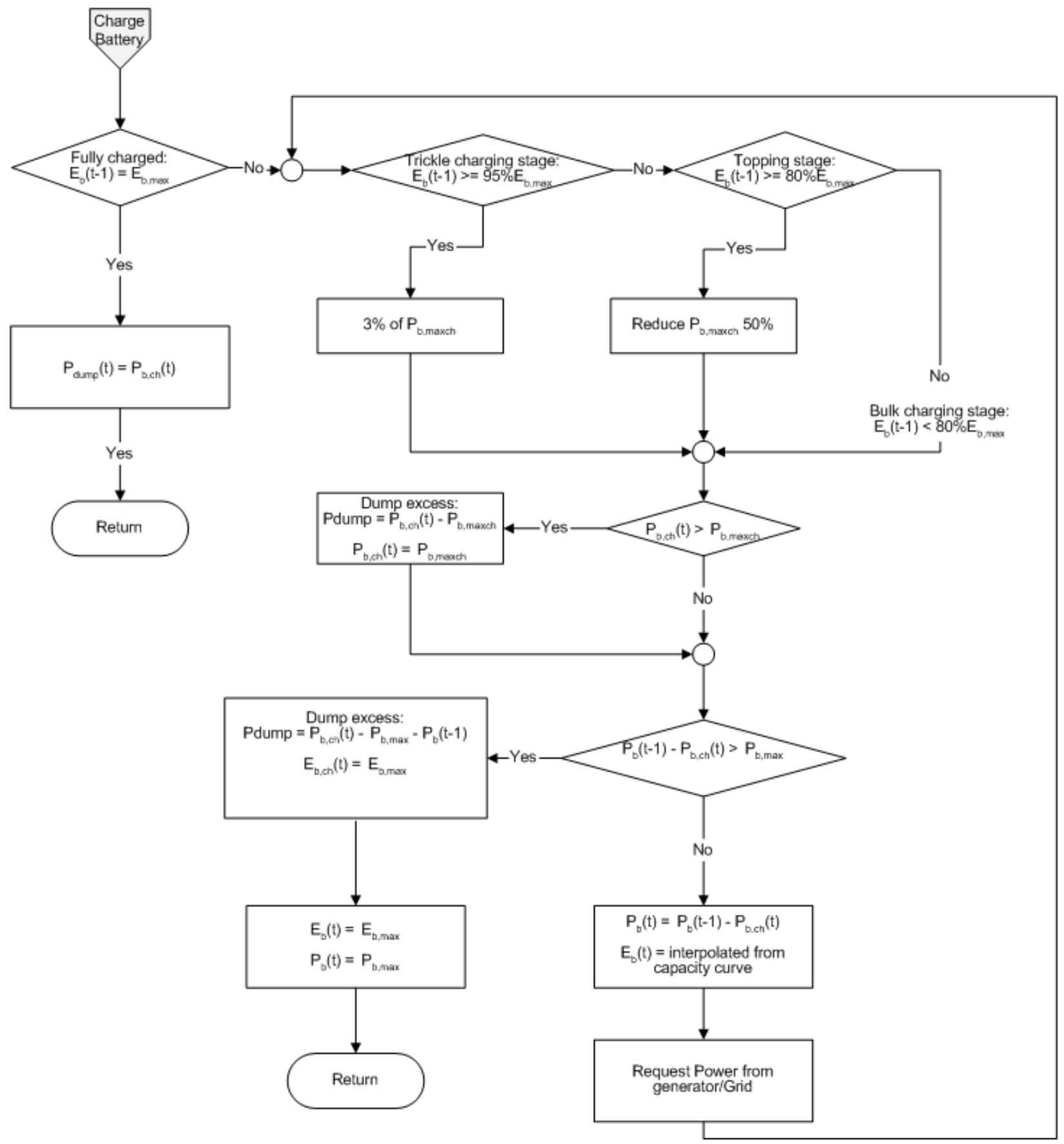

Figure 4-3 Charging mode of operation 


\section{CASE STUDY}

The proposed computer model is an Excel-based power management system. All inputs to the computer model are taken from MS Excel files. All outputs are also stored in an excel file. The CWEC data set for London, Ontario is converted into an Excel file with only the relevant data extracted. The datasheets are pulled from the manufacturers' website and the data required by the proposed system entered into an Excel spreadsheet. Designers can choose any components as long as the specifications are entered in the spreadsheets.

The test site is assumed to be located in London, Ontario (latitude $43.03^{\circ}$, longitude $-81.15^{\circ}$, elevation $278 \mathrm{~m}$ above sea level). Table 5-1 shows the types of loads used in the case study. The four load profiles reported in [23] are used to verify the performance and reliability of the computer model. To test different cases, the load units are given different configurations. In the next sections the different components available to each load unit are identified, modeled, analyzed, chosen and sized. The power that EVs provide or require is not taken into consideration when component sizes are calculated because EV arrival times, charging periods and number of EVs that will arrive are not known in advance.

Table 5-1 Load units used in the case study

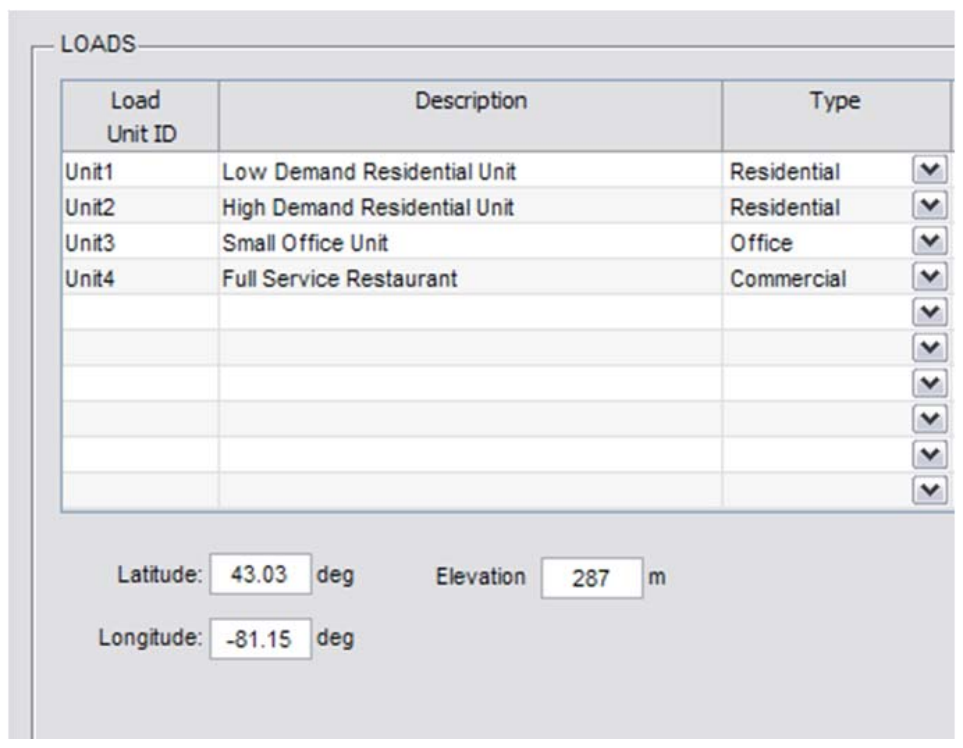




\subsection{Electricity Demand Profile}

In [23] four load units are set up: a residential unit with low power consumption, another residential unit with high power consumption, a small office unit, and a full service restaurant to represent a commercial unit. The electrical devices such as appliances, machineries and lighting equipment available in each unit and their operating schedule are stored in an Excel spreadsheet and can be controlled by the user. The power consumption is calculated based on the following parameters: average outside temperature, thermostat setting, the power rating of the electrical devices available inside the load unit and the operating schedule of the devices. The heating and cooling equipment are controlled by the temperature settings. The load profiles have a resolution of 15-minute intervals over a 24-hour period. Figs. 5-1 to 5-8 show the load profiles of each load unit for a typical summer and typical winter. The curve of the load demand is shown as constant during each 15-minute period. According to the CWEC data set, August 24-30 is a typical summer week and December 22-28 is a typical winter week. For purposes of this study, August 24 and December 22 are chosen as the test days.

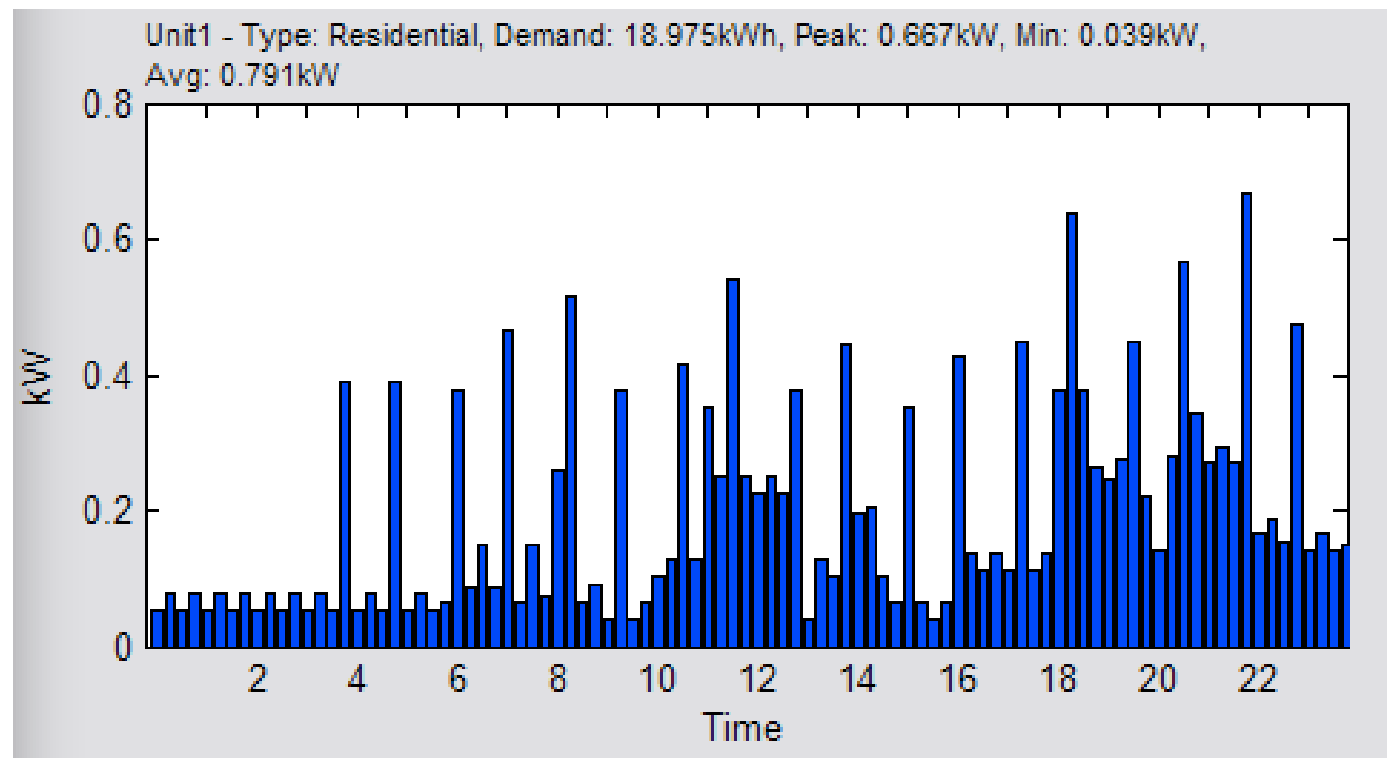

Figure 5-1 Load profile of low demand residential Unit 1 on a typical day in summer (Aug 24) 


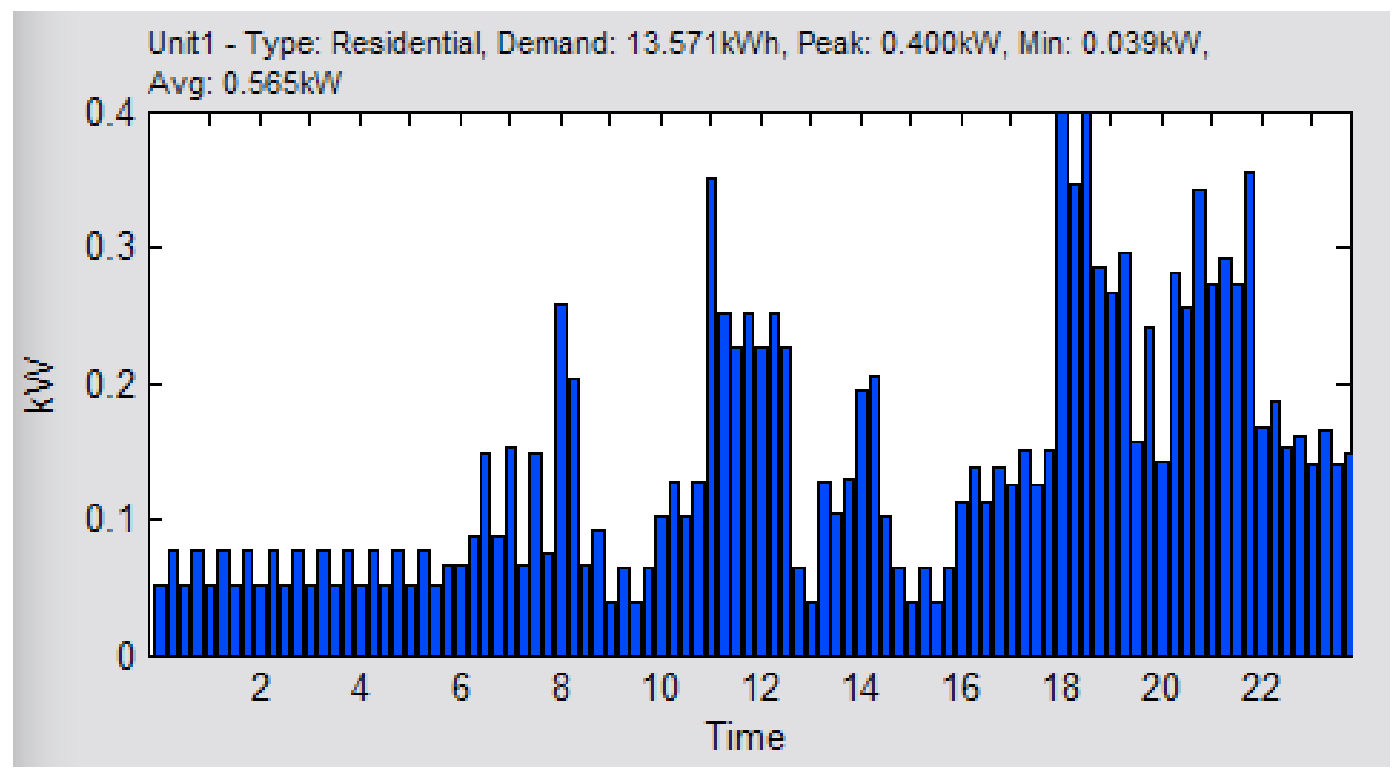

Figure 5-2 Load profile of low demand residential Unit 1 on a typical day in winter (Dec 22)

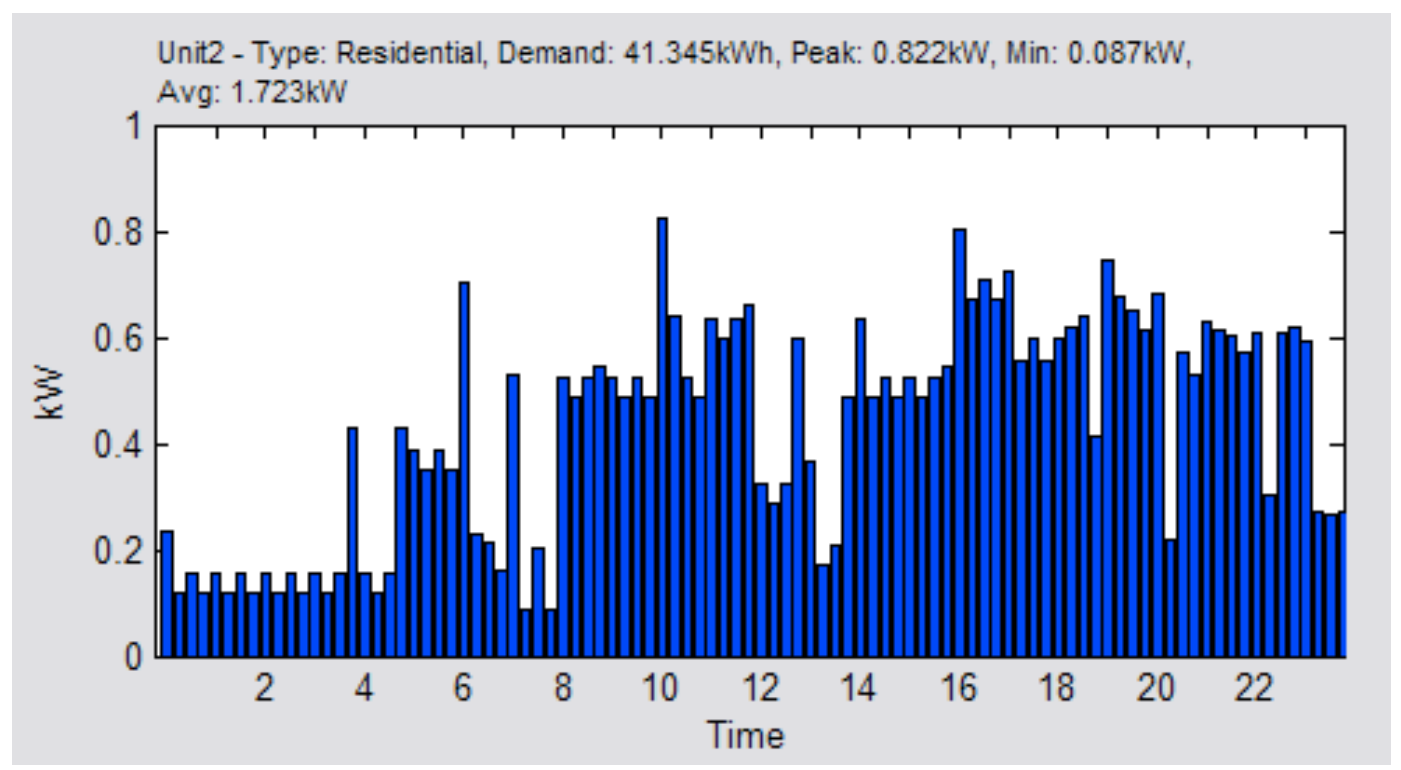

Figure 5-3 Load profile of high demand residential Unit 2 on a typical day in summer (Aug 24) 


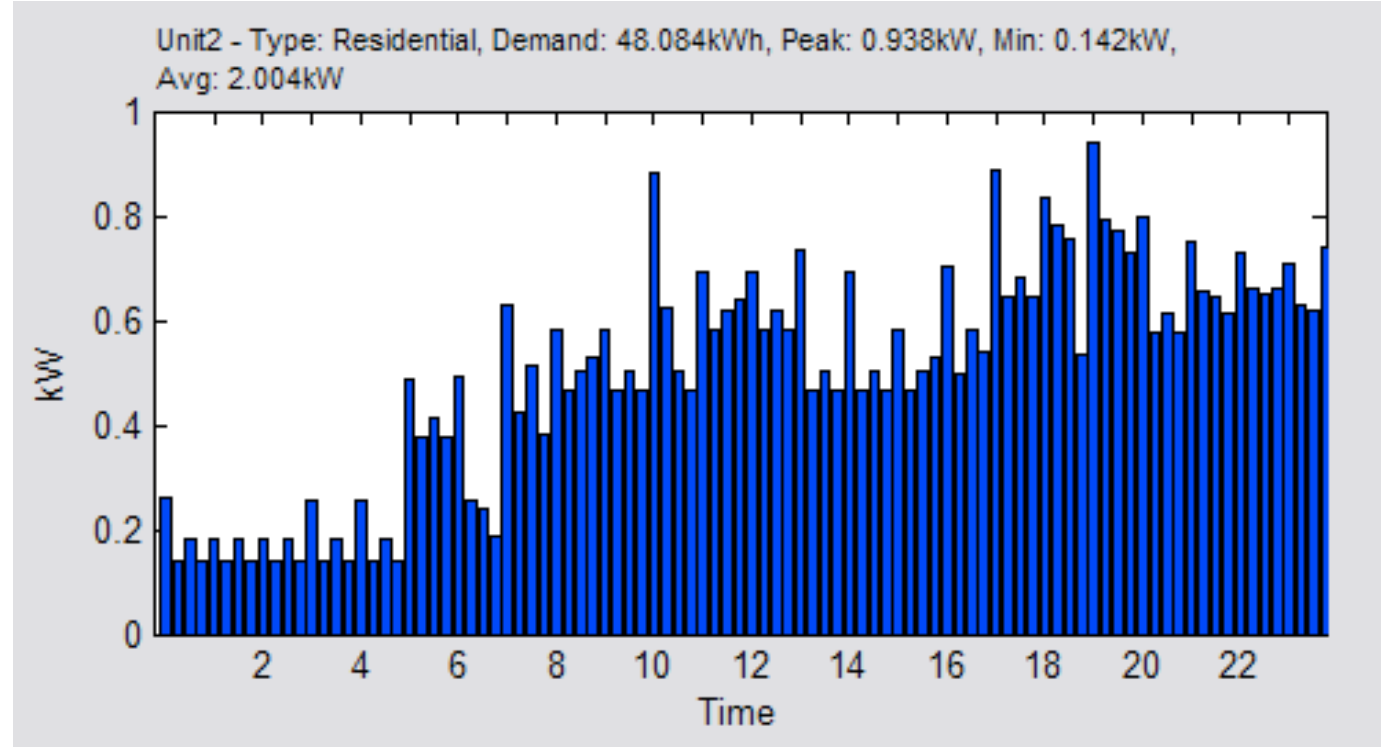

Figure 5-4 Load profile of high demand residential Unit 2 on a typical day in winter (Dec 22)

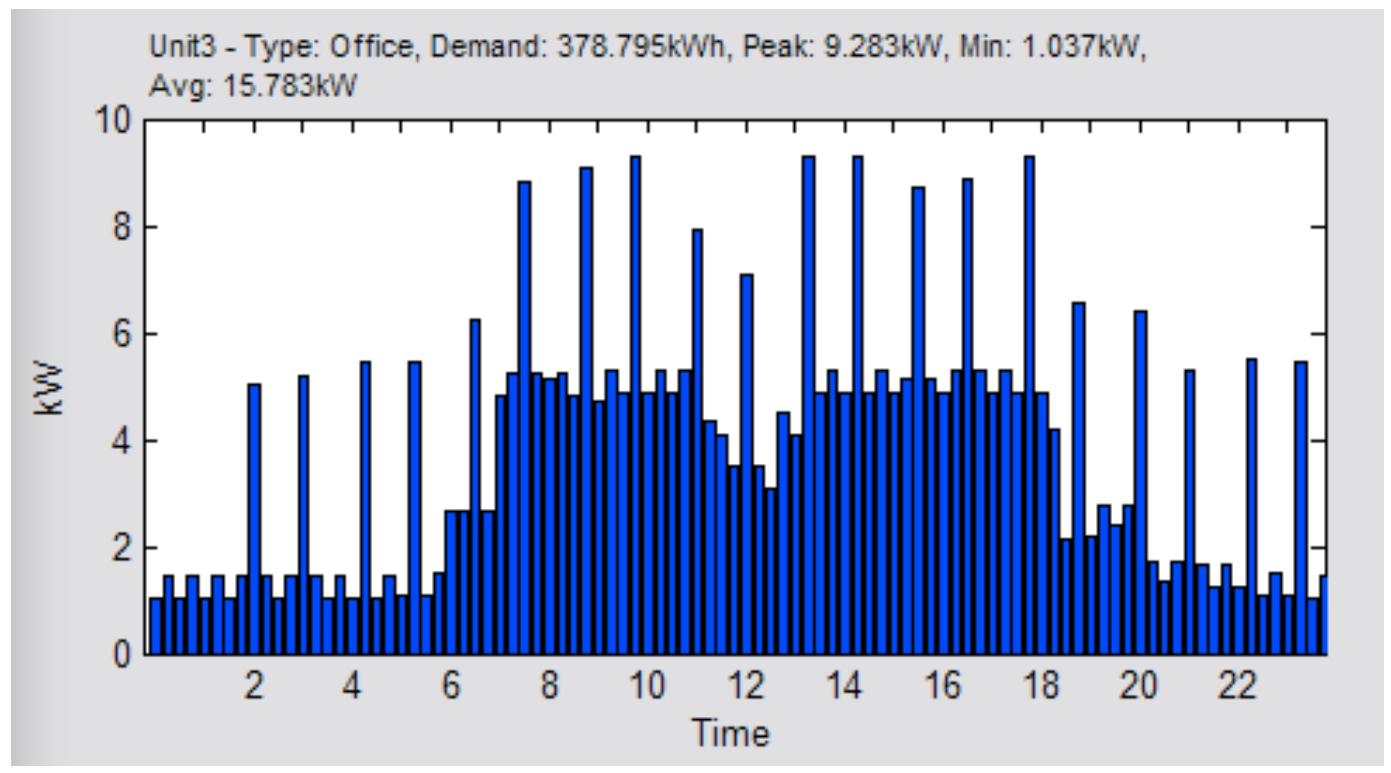

Figure 5-5 Load profile of small office Unit 3 on a typical day in summer (Aug 24) 


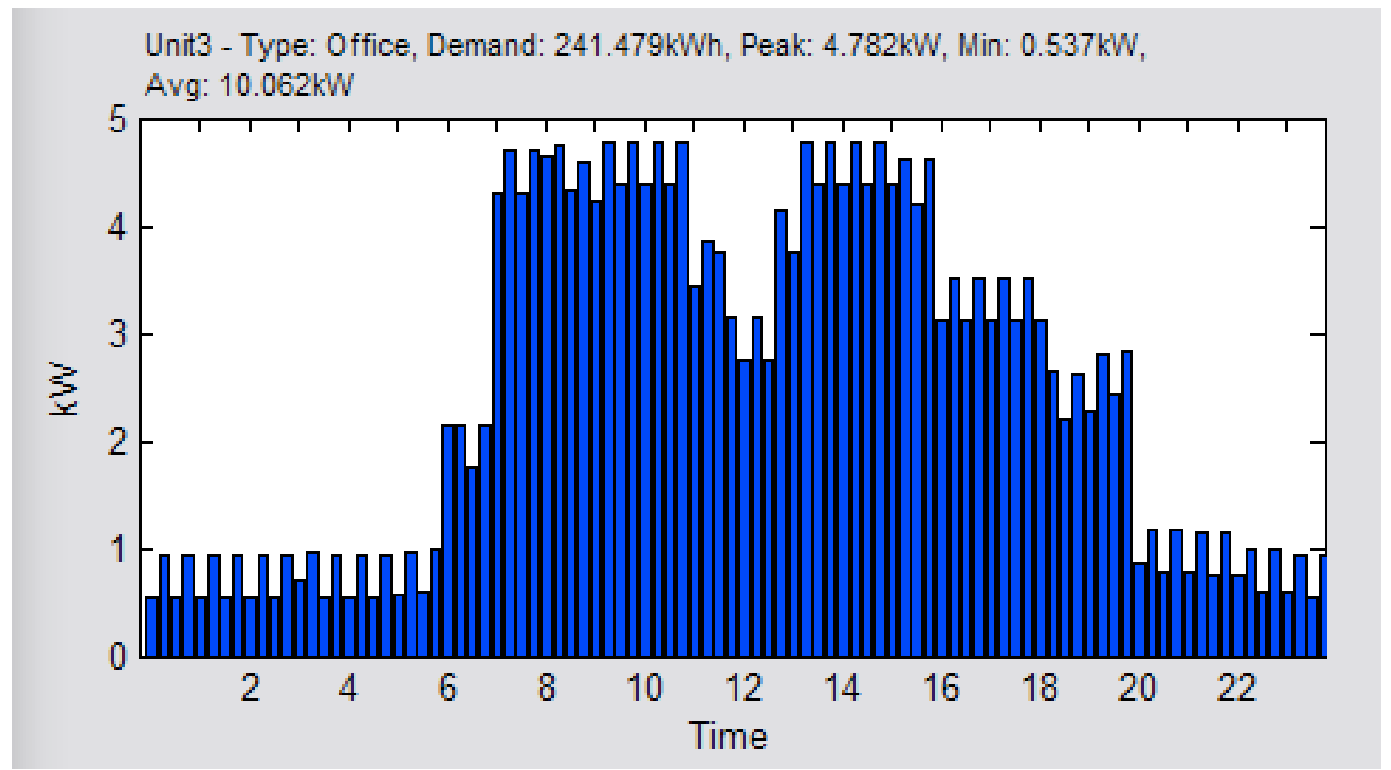

Figure 5-6 Load profile of small office Unit 3 on a typical day in winter (Dec 22)

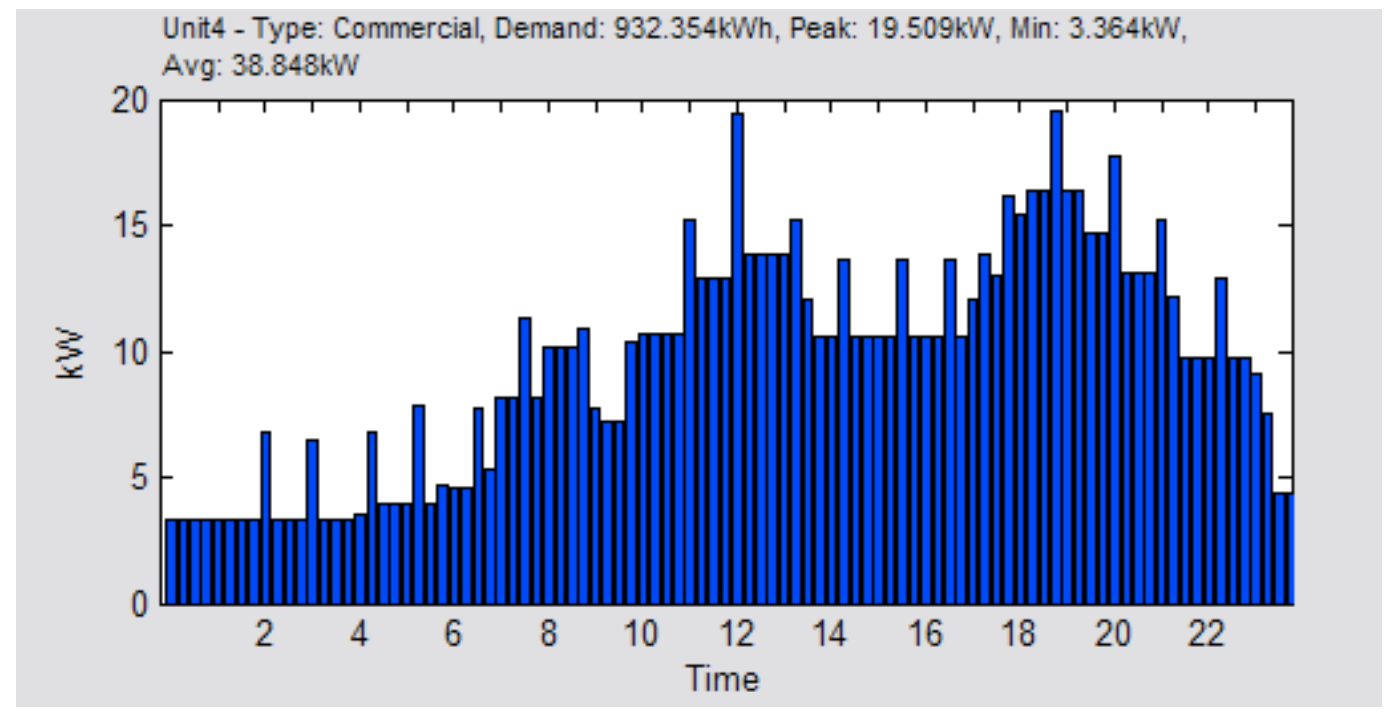

Figure 5-7 Load profile of commercial Unit 4 (restaurant) on a typical day in summer (Aug 24) 


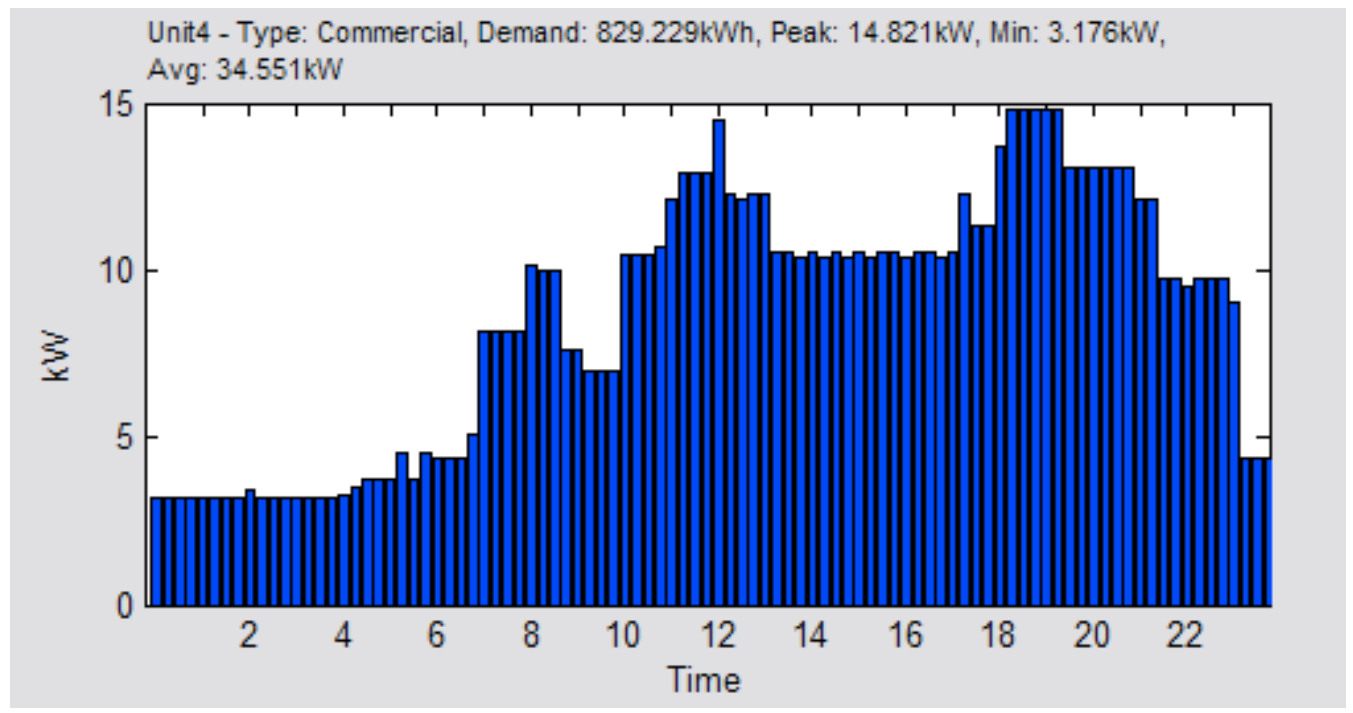

Figure 5-8 Load profile of commercial Unit 4 (restaurant) on a typical day in winter (Dec 22)

\subsection{Unit Sizing}

Table 5-2 compares the average demands of each unit reported in (23) for the typical summer and winter day chosen. All the load units, except for residential Unit 2, have higher power demands in summer. Where feasible, energy components are sized to satisfy the highest power requirements. In this project, commercially available PV panels, wind turbines, batteries, inverters and generators are used. The manufacturer's datasheet containing the component's output at standard test conditions is used to approximate the output under normal operating conditions.

Table 5-2 Demand of each load unit during summer and winter

\begin{tabular}{|c|l|r|r|r|r|r|r|}
\hline \multirow{2}{*}{ Load Unit ID } & \multirow{2}{*}{ Type } & \multicolumn{2}{|c|}{ Energy (Wh) } & \multicolumn{2}{c|}{ Average Power (W) } & \multicolumn{2}{c|}{ Peak Power (W) } \\
\cline { 3 - 8 } & & Summer & Winter & Summer & Winter & Summer & Winter \\
\hline Unit 1 & Residential & 18,975 & 13,571 & 791 & 565 & 667 & 400 \\
\hline Unit 2 & Residential & 41,345 & 48,084 & 1,723 & 2,004 & 822 & 938 \\
\hline Unit 3 & Small Office & 378,795 & 241,479 & 15,783 & 10,062 & 9,283 & 4,782 \\
\hline Unit 4 & $\begin{array}{l}\text { Commercial } \\
\text { (restaurant) }\end{array}$ & 932,354 & 829,229 & 38,848 & 34,551 & 19,509 & 14,821 \\
\hline
\end{tabular}




\subsubsection{Wind Turbine Size}

Using the wind speed data obtain from the CWEC data set for December 22 and August 24 and the manufacturer's datasheet for a $7.5 \mathrm{~kW}$ Bergey wind turbine (see Appendix B), the proposed modeling software calculated the average power output of the wind turbine with an inverter efficiency of $93 \%$ to be $573 \mathrm{~W}$ and 534 W for August 24 and December 22, respectively. Figs. 5-9 and 5-10 show the power outputs of the $7.5 \mathrm{~kW}$ wind turbine using the wind speed data for the two typical days used in the case study.

Table 5-3 shows the wind turbines available to the load units. Residential Unit 1 does not have a wind turbine installed. The rate for on-shore wind power for all sizes through Ontario's FIT/microFIT program as of Aug 26, 2013 is $11.5 \mathrm{c} / \mathrm{kWh}$ [29]. This project uses this rate as the cost of energy for the wind turbines selected.

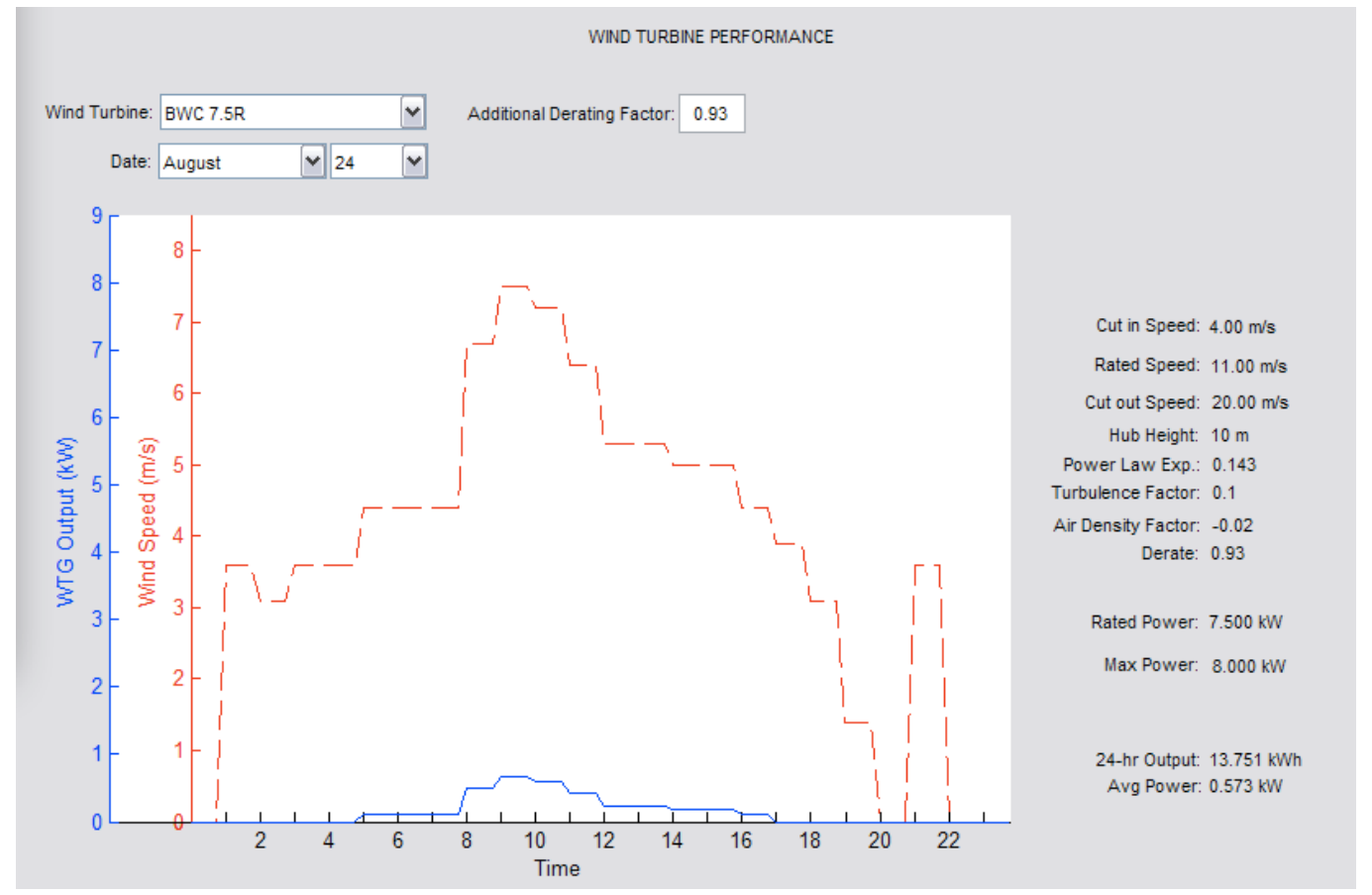

Figure 5-9 Power output of $7.5 \mathrm{~kW}$ Bergey wind turbine on Aug 24 (inverter $\eta=0.93$ ) 


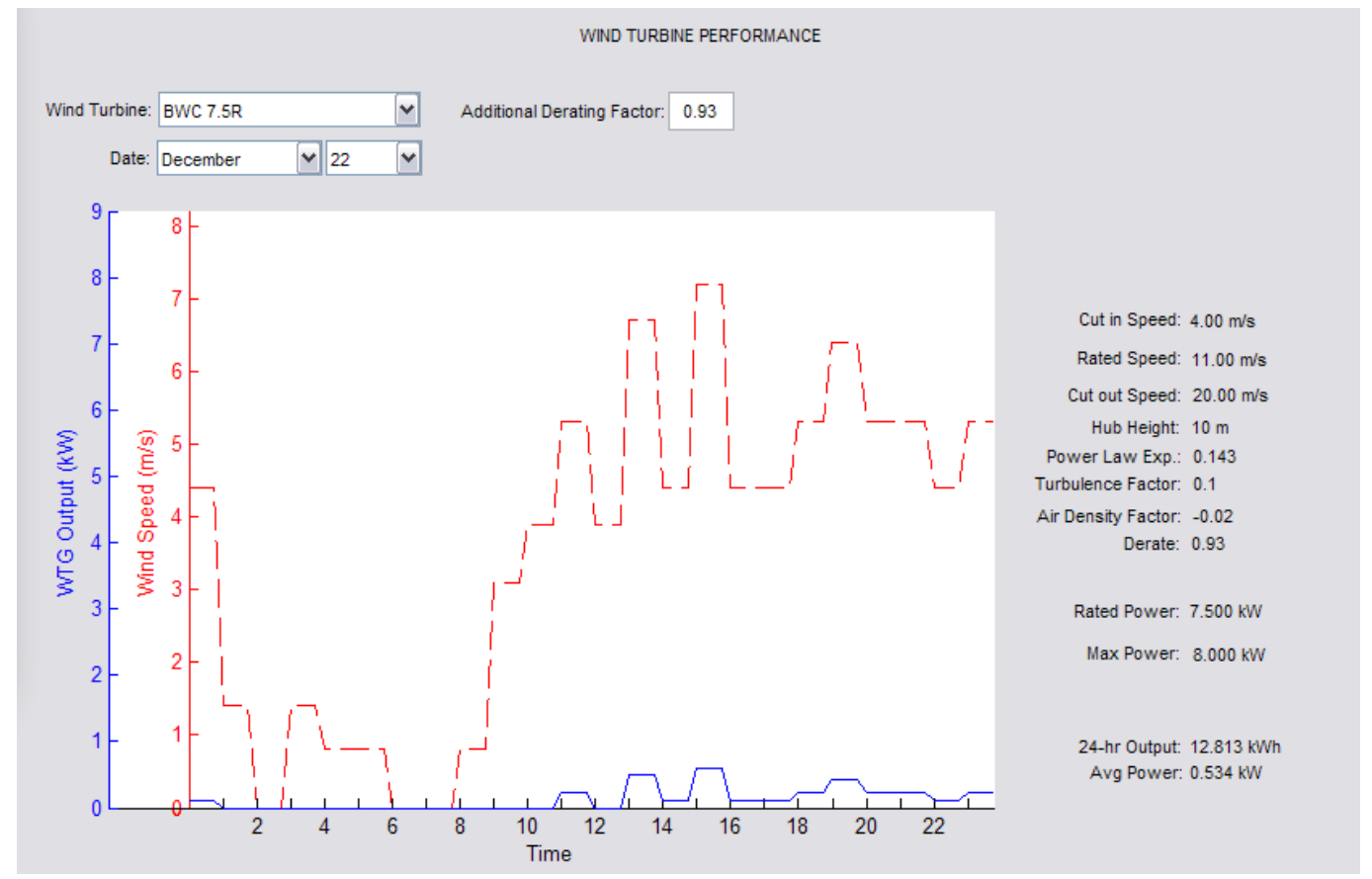

Figure 5-10 Power output of $7.5 \mathrm{~kW}$ Bergey wind turbine on Dec 22 (inverter $\eta=0.93$ )

Table 5-3 Wind turbines available to each load unit

\begin{tabular}{|c|c|c|c|c|c|}
\hline & \multicolumn{5}{|c|}{ WIND TURBINE GENERATOR } \\
\hline $\begin{array}{l}\text { Load } \\
\text { Unit ID }\end{array}$ & \multicolumn{2}{|c|}{ Model } & $\begin{array}{c}\text { Rated } \\
\text { Power }(\mathrm{kW})\end{array}$ & Qty & $\begin{array}{c}\text { Cost of } \\
\text { Energy }(\$ / k W h)\end{array}$ \\
\hline Unit1 & & $v$ & & & \\
\hline Unit2 & BWC $5 \mathrm{~kW}$ & $v$ & 5 & 1 & 0.1150 \\
\hline Unit3 & BWC 7.5R & $\checkmark$ & 7.5000 & 2 & 0.1150 \\
\hline Unit4 & BWC 7.5R & $v$ & 7.5000 & 2 & 0.1150 \\
\hline$<$ & & II & & & \\
\hline
\end{tabular}




\subsubsection{PV Array Size}

The proposed computer system can model fixed-mounted solar panels only. The available roof area that is facing the desired direction limits the number of fixed roof-mounted solar panels that can be installed. For the residential units in the test site, it is assumed that the maximum roof area available that faces, S, SW and/or W is $600 \mathrm{ft}^{2}$ or $55 \mathrm{~m}^{2}$ (average for a $2000 \mathrm{ft}^{2}$ house). For the other types of loads, it is assumed that there will be enough real estate to install any number of solar panels required. Depending on the local environment, solar panels can also be installed facing due east to maximize the morning sun or if there are obstacles that will reduce the output if facing due S, SW and/or W. For this study the solar panels available to the load units will be installed facing south.

In the PV industry, a derating factor is applied to the components to account for losses in the PV system installed. Reference [26] describes the following derate factors:

- PV module nameplate DC rating: Indicates how much the manufacturer's nameplate rating deviates from the measured output during testing. A derate factor of 0.95 , for example, indicates that power measurements at STC during testing were 5\% less than the manufacturer's nameplate rating.

- PV module mismatch: PV modules of the same size and even from the same manufacturer can have slightly different current-voltage characteristics. Connected in series, the energy output of the system will be that of the lowest performing module. A value of 0.98 means that $2 \%$ of the module's power is wasted due to module mismatch.

- Diodes and connections: The system suffers losses due to voltage drops across diodes that are used to block the reverse flow of current to protect the solar cells. This factor also accounts for the resistive losses across the electrical connections.

- Shading: Accounts for the times during the day when some or all panels are shaded by nearby buildings, objects or other PV modules. A value of 1.00 is used if there is no shading and the PV modules are producing the optimal power. 
- DC wiring: Accounts for the wiring losses between modules and between the PV array and the inverter.

- Soiling: Accounts for foreign matter, such as dirt, snow, leaves and animal droppings on the surface of the PV module blocking the solar radiation from striking the solar cells. It can be minimal or severe depending on the location. Losses could be high in areas with lots of pollution and few rainy days. In the northern hemisphere, output of the solar panels is also affected by how long snow stays on the PV module.

- Age: Accounts for performance degradation as the panels age. The degradation is usually estimated at $1 \%$ per year.

- System availability: Accounts for the non-availability of solar power when the system is turned off for maintenance. A value of 0 means that maintenance is scheduled for the whole day.

Inverter efficiency is not included as one of the derates by the proposed computer model because it is accounted for separately at a later stage (during the delivery of de power to the ac load) as shown in Eq. (13).

Table 5-4 shows the derate factors used in [26] for the components of the PV system and the allowed ranges. Except for the losses in the AC components (the proposed system uses a dc-bus network), these same factors and ranges are used in this project. The overall derate factor is obtained by multiplying all the individual factors together.

Table 5-4 PV derate factors and ranges [26]

\begin{tabular}{|l|l|}
\hline Component Derate Factors & \multicolumn{1}{|c|}{ Range } \\
\hline PV module nameplate rating & $0.80-1.05$ \\
\hline PV module mismatch & $0.97-0.995$ \\
\hline Diodes and connections & $0.99-0.997$ \\
\hline DC wiring & $0.97-0.99$ \\
\hline Soiling & $0.30-0.995$ \\
\hline Shading & $0.00-1.00$ \\
\hline Age & $0.70-1.00$ \\
\hline System availability & $0.00-0.995$ \\
\hline
\end{tabular}


Choosing a high-rated solar panel in the database (see Panasonic HIT Power 240S datasheet in Appendix A) and using the solar radiation and ambient temperature for London, Ontario from the CWEC data set, the proposed modeling software calculated that residential Unit 1 can fit 42 solar panels facing south for total area of $52.96 \mathrm{~m}^{2}$ and total rated power of $10.08 \mathrm{~kW}$. With a tilt of $35^{\circ}$ (assuming roof pitch of 8/12) and total derating factor of 0.88 (overall derate of 0.96 and inverter efficiency of $92 \%$ ), the modeling software calculated the average power output on August 24 to be $1.23 \mathrm{~kW}$ and $0.36 \mathrm{~kW}$ on December 22. Fig. 5-11 and Fig. 5-12 show the power outputs given the ambient temperature and ground radiations for a surface tilted at $35^{\circ}$ for the two representative days.

Table 5-5 shows the PV components available to each load unit and the derate factors used to estimate the power output of the PV system. Commercial Unit 4 does not have solar panels installed.

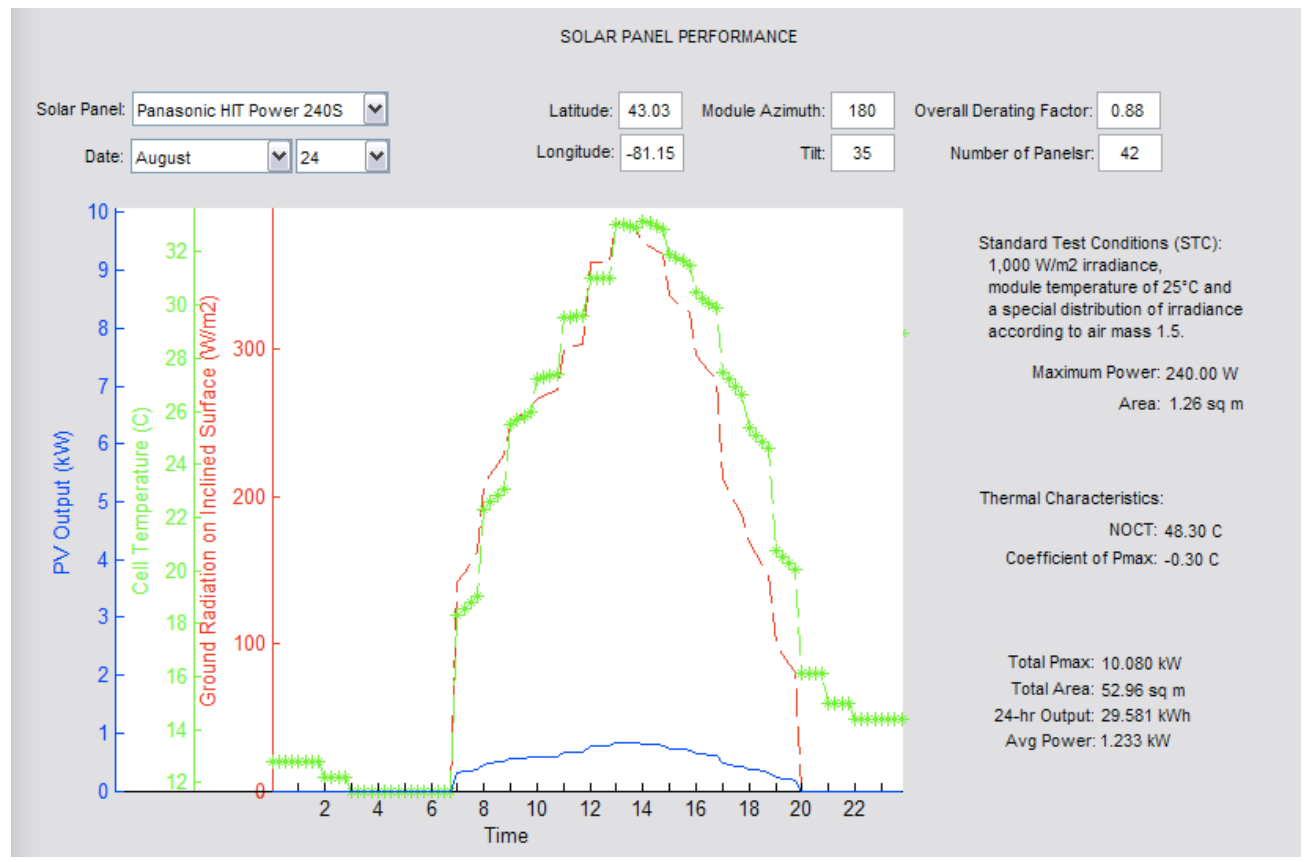

Figure 5-11 Power output of 42 solar panels of Panasonic's HIT Power 240S on Aug 24 (inverter $\eta=0.93$ ) 


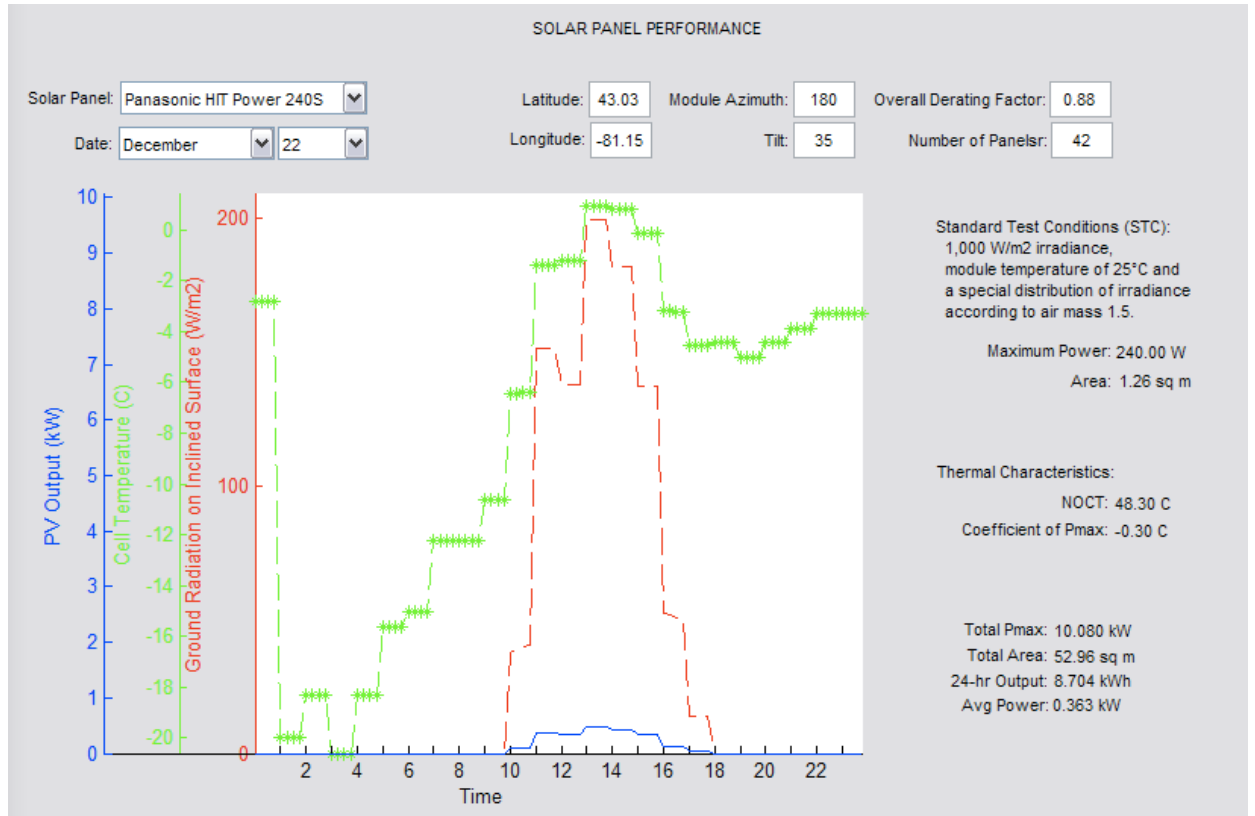

Figure 5-12 Power output of 42 solar panels of Panasonic's HIT Power 240S on Dec 22 (inverter $\eta=0.93$ )

Table 5-5 PV panels available to the load units and the derate factors applied

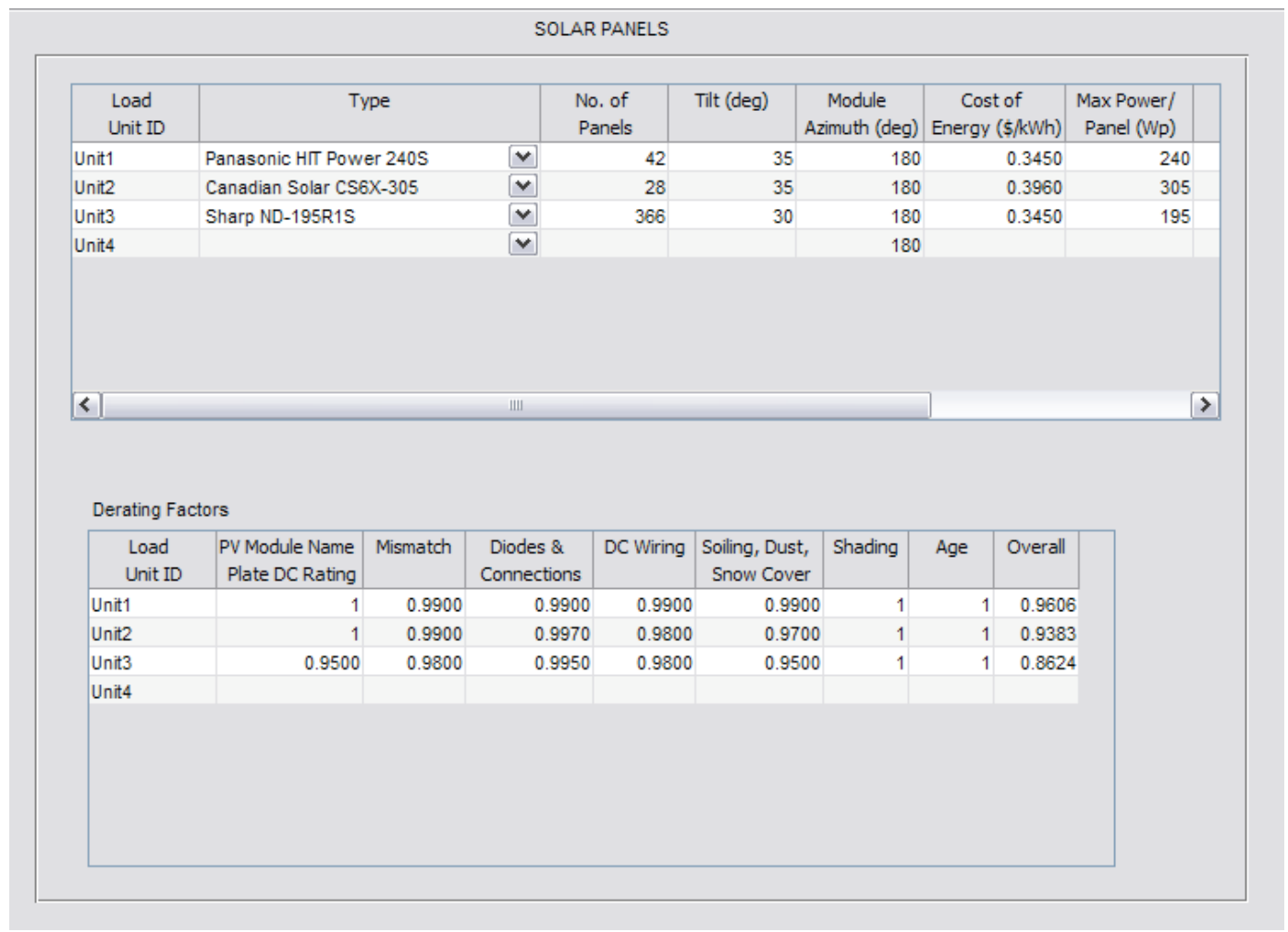


Table 5-6 lists the rates for roof-mounted PV systems through Ontario's FIT/microFIT program [29]. These rates will be used as the cost of producing energy from the PV array.

Table 5-6 FIT/microFIT Price Schedule as at Aug 26, 2013

\begin{tabular}{|l|l|}
\hline Project size & Price $(\mathbf{c} / \mathbf{k W h})$ \\
\hline$\leq 10 \mathrm{~kW}$ & 39.6 \\
\hline $\begin{array}{l}>10 \mathrm{~kW} \\
\leq 100 \mathrm{~kW}\end{array}$ & 34.5 \\
\hline$>100 \mathrm{~kW}$ & 32.9 \\
\hline
\end{tabular}

Table 5-7 shows the wind turbine and PV array sizes given to each load unit, the power available to the load during summer and winter and the power deficit or surplus. Based on the power outputs calculated by the proposed computer model, it can be seen that the energy $(29.6 \mathrm{kWh})$ produced by a $10-\mathrm{kW}$ PV system alone is supposed to be able to supply the power requirements $(19 \mathrm{kWh})$ of the low demand residential house (Unit1) during summer with plenty of surplus energy $(10.6 \mathrm{kWh})$. As will be shown in the simulation results in Chapter 6 , this is not the case because the generation of renewable energy does not always coincide with the time of the demand. A 5-kW Bergey wind turbine and 28 panels of Canadian Solar CS6X-305 installed in residential Unit 2 will result in an energy surplus of $6.2 \mathrm{kWh}$ in summer and a deficit of $19.9 \mathrm{kWh}$ in winter. Office Unit 3 still needed additional source of power even with two 7.5-kW Bergey wind turbines and 366 panels of Sharp ND195R1S tilted at $30^{\circ}$. The shortfall can be supplied by EVs (if available), by the battery bank, generator and/or the grid in that order. The full service restaurant (Unit 4) has a huge unmet power requirement in summer and winter with only 2 wind turbines installed. 
Table 5-7 Wind and PV Component Sizes, Power Outputs and Deficits/Surplus

\begin{tabular}{|c|c|c|c|c|c|c|c|c|c|c|c|}
\hline \multirow{3}{*}{$\begin{array}{c}\text { Load } \\
\text { Unit ID }\end{array}$} & \multirow{3}{*}{ Type } & \multirow{2}{*}{\multicolumn{2}{|c|}{$\begin{array}{l}\text { Average Power/ } \\
\text { Energy Demand }\end{array}$}} & \multicolumn{3}{|c|}{ PV Power } & \multicolumn{3}{|c|}{ Wind Power } & \multirow{2}{*}{\multicolumn{2}{|c|}{ Deficit }} \\
\hline & & & & \multirow{2}{*}{$\begin{array}{l}\text { Size } \\
(W)\end{array}$} & \multicolumn{2}{|c|}{$\begin{array}{c}\text { Average Power / } \\
\text { Energy }\end{array}$} & \multirow{2}{*}{$\begin{array}{l}\text { Size } \\
(W)\end{array}$} & \multicolumn{2}{|c|}{$\begin{array}{l}\text { Average Power/ } \\
\text { Energy }\end{array}$} & & \\
\hline & & $\begin{array}{c}\text { Summer } \\
(\mathrm{W} / \\
\text { Wh) }\end{array}$ & $\begin{array}{c}\text { Winter } \\
\text { (W / } \\
\text { Wh) }\end{array}$ & & $\begin{array}{c}\text { Summer } \\
\text { (W/ } \\
\text { Wh) }\end{array}$ & $\begin{array}{c}\text { Winter } \\
\text { (W / } \\
\text { Wh) }\end{array}$ & & $\begin{array}{c}\text { Summer } \\
(\mathrm{W} / \\
\text { Wh) }\end{array}$ & $\begin{array}{c}\text { Winter } \\
\text { (W/ } \\
\text { Wh) } \\
\end{array}$ & $\begin{array}{c}\text { Summer } \\
(\mathbf{W} / \\
\text { Wh) }\end{array}$ & $\begin{array}{c}\text { Winter } \\
\text { (W/ } \\
\text { Wh) } \\
\end{array}$ \\
\hline \multirow{2}{*}{ Unit 1} & \multirow{2}{*}{ Residential } & 791 & 565 & \multirow{2}{*}{10,080} & 1,233 & 363 & \multirow{2}{*}{\multicolumn{3}{|c|}{ None }} & -442 & 202 \\
\hline & & 18,975 & 13,571 & & 29,581 & 8,704 & & & & $-10,606$ & 4,867 \\
\hline \multirow{2}{*}{ Unit 2} & \multirow{2}{*}{ Residential } & 1,723 & 2,004 & \multirow{2}{*}{8,540} & 1,033 & 314 & \multirow{2}{*}{5,000} & 827 & 860 & -257 & 830 \\
\hline & & 41,345 & 48,084 & & 24,784 & 7,533 & & 19,858 & 20632 & $-6,160$ & 19,919 \\
\hline \multirow{2}{*}{ Unit 3} & \multirow{2}{*}{ Small office } & 15,783 & 10,062 & \multirow{2}{*}{71,370} & 8,483 & 2,542 & \multirow{2}{*}{15,000} & 1,146 & 1,068 & 6,154 & 6,452 \\
\hline & & 378,795 & 241,479 & & 203,597 & 61,015 & & 27,502 & 25,626 & 145,696 & 154,838 \\
\hline \multirow{2}{*}{ Unit 4} & \multirow{2}{*}{$\begin{array}{l}\text { Full service } \\
\text { restaurant }\end{array}$} & 38,848 & 34,551 & \multirow{2}{*}{\multicolumn{3}{|c|}{ None }} & \multirow{2}{*}{15.00} & 1,146 & 1,068 & 37,702 & 33,483 \\
\hline & & 932,354 & 829,229 & & & & & 27,502 & 25,626 & 904,852 & 803,603 \\
\hline
\end{tabular}

\subsubsection{Distributed Battery Bank Size}

The wind turbine and/or solar panels will not be able to meet the load demand of the building at all hours of the day. Additional power from EVs (if available) may not be enough during peak hours. A battery bank connected to the dc bus as shown in Fig. 2-1 will supply all or part of the unmet demand during these times. The battery storage capacity $B_{w h}$ needed by the system is calculated using the equation used in [3]:

$$
B_{w h}=\frac{E_{L} A D}{\eta_{i n v} \eta_{B} D O D}
$$

where $E_{L}$ is the energy deficit (kWh/day), $A D$ is the daily autonomy (days), $\eta_{\text {inv }}$ is the efficiency of the inverter, $\eta_{B}$ is the efficiency of the battery and $D O D(\%)$ is the depth of discharge. The daily autonomy is the required 
number of days that the battery will be able to supply power to the load in the absence of power from the renewable sources.

The energy cost of the battery is calculated as follows:

$$
C O E_{\text {batt }}=\frac{\text { Price }}{\text { Capacity } * \text { No of cycles }}
$$

Batteries used in PV and wind turbine systems are deep-cycle batteries designed to take advantage of any available energy by requiring only very little current for charging. These batteries normally have very high charge and discharge efficiencies (90 to 95\%). In this study, deep cycle lead acid batteries are used because they offer the best price-to-power ratio among other new technologies.

Table 5-8 shows the battery sizes calculated for each load unit given the energy deficits, the daily autonomy, the efficiency of the inverter used, the assumed battery efficiency and the desired depth of discharge. In this case study, it is assumed that the battery will be discharged continuously for 5 hours a day for all types of loads. Any further deficit can be covered by the natural gas generator (if the unit has one) and the grid. To prolong the battery's life, a lower depth of discharge can be chosen but this would result in more batteries and increased cost to the system.

Table 5-8 Calculated battery sizes required by the load units

\begin{tabular}{|l|c|r|c|c|c|c|r|}
\hline $\begin{array}{c}\text { Load } \\
\text { Unit ID }\end{array}$ & Season & $\begin{array}{r}\text { Deficit } \\
(\mathrm{Wh})\end{array}$ & $\mathrm{AD}$ & $\begin{array}{c}\eta_{\text {inv }} \\
(\%)\end{array}$ & $\begin{array}{c}\eta_{B} \\
(\%)\end{array}$ & $\begin{array}{c}\text { DOD } \\
(\%)\end{array}$ & $B_{W h}$ \\
\hline Unit1 & Winter & 4,867 & $0.21(5 \mathrm{hrs})$ & 92 & 90 & 80 & 1,531 \\
\hline Unit2 & Winter & 19,919 & $0.21(5 \mathrm{hrs})$ & 93 & 90 & 80 & 6,197 \\
\hline Unit3 & Winter & 154,838 & $0.21(5 \mathrm{hrs})$ & 93 & 90 & 80 & 48,175 \\
\hline Unit4 & Summer & 904,852 & $0.21(5 \mathrm{hrs})$ & 93 & 90 & 80 & 281,528 \\
\hline
\end{tabular}


Table 5-9 shows the battery sizes available to each load unit. Assuming a dc bus voltage of $48 \mathrm{~V}$ and a battery terminal voltage of $12 \mathrm{~V}, 4$ batteries will be connected in series. To come up with the required power, sets of 4 batteries connected in series are connected in parallel. A 12V Trojan J150 battery (see datasheet in Appendix C) that cost around \$250 is chosen. The "Capacity@C20" column is the rating of the battery when discharged continuously for 20 hours. Deep cycle batteries are normally quoted using the 20 -hour rate. According to the manufacturer's datasheet, the Trojan J150 battery has a 20-hour rate of 150Ah. Office Unit 3 and commercial Unit 4 are tested using 20 batteries for a total capacity of $36 \mathrm{kWh}(150 \mathrm{Ah} \cdot 48 \mathrm{~V} \cdot 5 \mathrm{sets}$ in parallel) each. The Minimum Capacity column is the DOD beyond which the battery cannot be discharged further. In all the load units, the batteries are not allowed to discharge below $20 \%$ of its rated capacity. Cost of energy is derived using Eq (58). With a capacity of $1.44 \mathrm{kWh}(120 \mathrm{Ah} \cdot 12 \mathrm{~V}$ for a constant rate of discharge for 5 hours) and 2000 cycles for DOD of $80 \%$, the COE for each battery comes out to $8.68 ф / \mathrm{kWh}$. "Discharge Time" and "Charge Time" are used by the battery model to calculate the maximum allowable discharge and charge rates of the battery, respectively.

Table 5-9 Battery bank available to each load units.

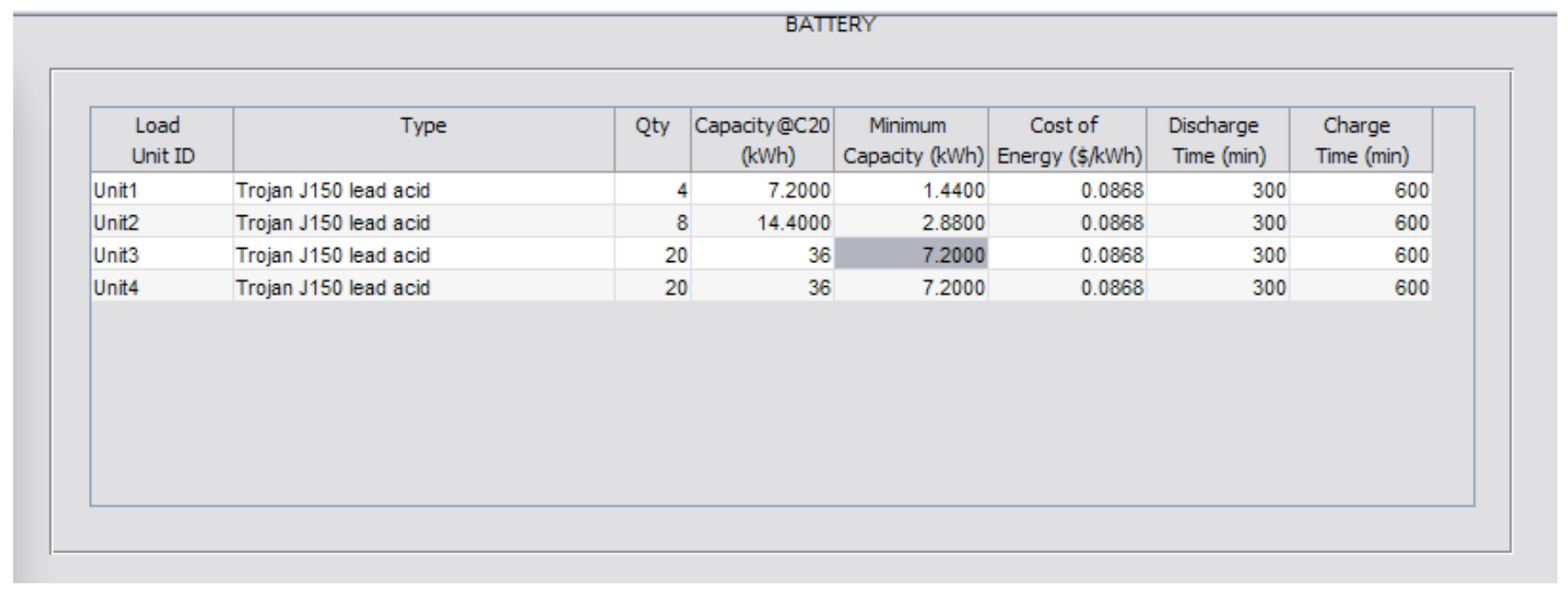


A system that uses a battery bank should have a charge controller to protect the battery from extreme overcharging and deep discharging. The charge controller will disconnect the battery from the load when its DOD is reached and disconnect the battery from the dc bus when the maximum state of charge (SOC) is reached.

The voltage of the battery and the output power of the wind turbine determine the ratings of the charge controller chosen. The same is true for the other charge controller connecting the PV system and the battery bank. The proposed computer model presented here communicates with the battery and the generator/grid computer model of [25] by providing it with the deficit power after solar, wind and EV energy are exhausted or by providing it with the surplus renewable energy that can be used to charge the battery. In the case of a renewables shortfall, the computer model will provide information on how much power is taken individually from the battery, the generator and/or the grid and the cost of extracting power from each of these sources to supply the unmet demand. If surplus renewable power is given to the battery model, it will provide information on how much was used to charge the storage battery. If the battery needed further charging, the model will provide information on how much power was taken individually from the generator and the grid and the costs involved.

\subsubsection{Inverter Size}

In a dc-bus architecture, an inverter is required to convert the dc voltage of the PV system, wind turbines and battery bank to ac. A system that involves a storage system, generator, grid and/or EVs must have a bidirectional inverter. The inverter will act as a rectifier when needed to convert the ac voltage from the ac source to dc when charging the battery.

Usually, the power rating of the inverter chosen is based on the peak demand of the load unit multiplied by a factor of $30 \%$ or more for safety reasons. The presence of EVs complicates the situation since it is not known how many EVs will be requiring power at any time. For purposes of this study, the rating of the inverter required is calculated as: 


$$
P_{\text {inv }}=P_{L, p k} \cdot 300 \%
$$

Table 5-10 shows the calculated minimum inverter sizes that should be installed in each load unit that needed one. Table 5-11 shows the inverters given to each load unit and their efficiency ratings. Efficiency is the only inverter property required by the computer model and is assumed to be constant throughout the life of the inverter.

Table 5-10 Calculated minimum inverter sizes

\begin{tabular}{|l|l|r|r|r|}
\hline $\begin{array}{c}\text { Load Unit } \\
\text { ID }\end{array}$ & Type & \multicolumn{2}{|c|}{ Peak Power (W) } & \multirow{2}{*}{$\begin{array}{c}\text { Inverter } \\
\text { Size (W) }\end{array}$} \\
\cline { 3 - 4 } & & Summer & Winter & Siz \\
\hline Unit 1 & Residential & 667 & 400 & 2001 \\
\hline Unit 2 & Residential & 822 & 938 & 2466 \\
\hline Unit 3 & Office & 9,283 & 4,782 & 27849 \\
\hline Unit 4 & Commercial & 19,509 & 14,821 & 58527 \\
\hline
\end{tabular}

Table 5-11 Inverters available to each load unit.

\begin{tabular}{|c|c|c|}
\hline \multicolumn{3}{|c|}{ INVERTER } \\
\hline $\begin{array}{l}\text { Load } \\
\text { Unit ID }\end{array}$ & Type & $\begin{array}{c}\text { Efficiency } \\
\%\end{array}$ \\
\hline Unit1 & Xantrex Freedom 458 - $2 \mathrm{~kW}$ & 92 \\
\hline Unit2 & Xantrex Freedom $458-2.5 \mathrm{~kW}$ & 93 \\
\hline Unit3 & Victron Energy Quattro - 30kW & 93 \\
\hline Unit4 & Victron Energy Quattro - 60kW & 93 \\
\hline
\end{tabular}




\subsubsection{Natural Gas Power Generator Size}

A $6-\mathrm{kW}$ or a 7-kW air-cooled natural gas generator is used for the different load units. Table 5-12 shows the natural gas generator available to each load unit. Reference [25] uses a fixed fuel cost for the generator and calculates the fuel cost using the fuel consumption of the generator at full load. The generator data sheet provides a full load consumption of $3.4 \mathrm{~m}^{3} / \mathrm{hr}$. At $10 \$ / \mathrm{m}^{3}$ for natural gas (local utility rate), the cost of energy for the 6 $\mathrm{kW}$ generator is $\frac{3.4 \mathrm{~m}^{3}}{\mathrm{hr}} \frac{0.10 \AA}{\mathrm{m}^{3}} \frac{1}{6 \mathrm{~kW}}=5.67 \mathrm{\$} / \mathrm{kWh}$ and $4.86 \mathrm{\$} / \mathrm{kWh}$ for the $7-\mathrm{kW}$ generator.

As described in the Battery Size section, the computer model developed in [25] will give a breakdown of the power and the cost of energy taken from the battery, generator and grid to fill the renewables shortfall.

Table 5-12 Natural gas generators available to each load unit

\begin{tabular}{|c|c|c|c|c|}
\hline \multicolumn{5}{|c|}{ GENERATOR } \\
\hline $\begin{array}{l}\text { Load } \\
\text { Unit ID }\end{array}$ & Type & Qty & Capacity (kW) & $\begin{array}{c}\text { Cost of } \\
\text { Energy }(\$ / \mathrm{kWh})\end{array}$ \\
\hline Unit1 & Natural gas & 1 & 6 & 0.0567 \\
\hline Unit2 & Natural gas & 1 & 6 & 0.0567 \\
\hline Unit3 & Natural gas & 1 & 7 & 0.0486 \\
\hline Unit4 & Natural gas & 1 & 6 & 0.0567 \\
\hline
\end{tabular}

\subsubsection{Grid}

The grid is utilized by the proposed computer model in such a way that the maximum load demand including EV requirement is the maximum amount of power that can be drawn from the grid. Time-of-Use (TOU) rates are in effect in [25]. Time of the day is important to determine energy costs, as well as weekends and holidays. Figs. 
5-13 and 5-14 show the TOU pricing of Ontario Hydro for winter and summer, respectively. All these data are entered in an Excel file.

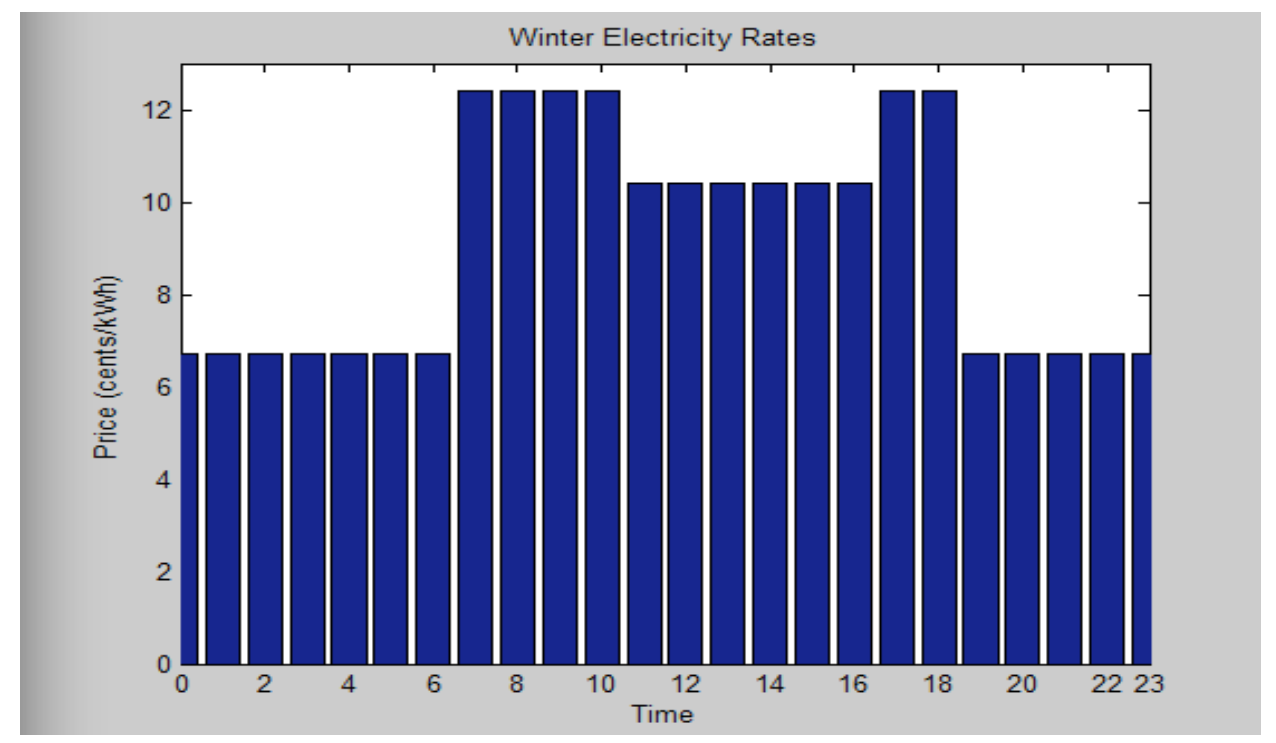

Figure 5-13 Ontario TOU pricing for winter

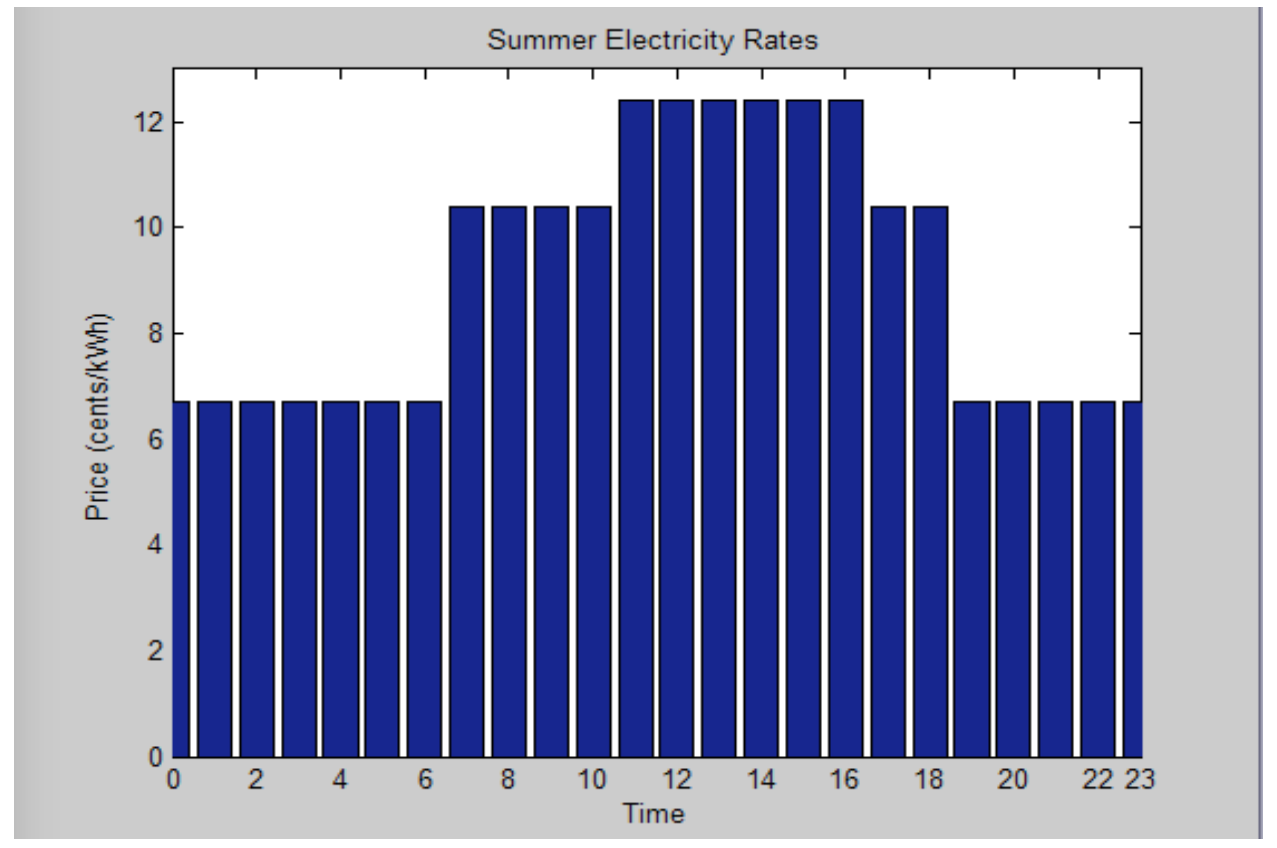

Figure 5-14 Ontario TOU pricing for summer 


\subsubsection{Summary of System Components}

Table 5-13 is a summary of the system components available to each of the load units used in the case study.

Table 5-13 System Components

\begin{tabular}{|c|c|c|c|}
\hline \multicolumn{2}{|c|}{ UNIT 1 - Residential } & \multicolumn{2}{|c|}{ UNIT 2 - Residential } \\
\hline \multicolumn{2}{|c|}{ Wind Turbine } & \multicolumn{2}{|l|}{ Wind Turbine } \\
\hline Type & None & Type & Bergey 5 \\
\hline Rated Power & & Rated Power & $5 \mathrm{~kW}$ \\
\hline Quantity & & Quantity & 1 \\
\hline Cut-in Speed & & Cut-in Speed & $2.5 \mathrm{~m} / \mathrm{s}$ \\
\hline Rated Speed & & Rated Speed & $12.5 \mathrm{~m} / \mathrm{s}$ \\
\hline Cut-off Speed & & Cut-off Speed & $20 \mathrm{~m} / \mathrm{s}$ \\
\hline Cost of Energy & & Cost of Energy & $11.5 \varnothing / \mathrm{kWh}$ \\
\hline \multicolumn{2}{|l|}{ PV } & \multicolumn{2}{|l|}{ PV } \\
\hline Type & Panasonic HIT 204S & Type & $\begin{array}{l}\text { Canadian Solar CS6X- } \\
305\end{array}$ \\
\hline Number of Modules & 42 & Number of Modules & 28 \\
\hline $\begin{array}{l}\text { Power rating/Total } \\
\text { Power }\end{array}$ & $240 \mathrm{Wp} / 10.08 \mathrm{~kW}$ & $\begin{array}{l}\text { Power rating / Total } \\
\text { Power }\end{array}$ & $305 \mathrm{~W} / 8.540 \mathrm{~kW}$ \\
\hline Cost of Energy & $34.5 \notin / \mathrm{kWh}$ & Cost of Energy & $39.6 \notin / \mathrm{kWh}$ \\
\hline \multicolumn{2}{|l|}{ Battery } & \multicolumn{2}{|l|}{ Battery } \\
\hline Type & Trojan J150 & Type & Trojan J150 \\
\hline Capacity & $7.20 \mathrm{kWh}$ & Capacity & $14.4 \mathrm{kWh}$ \\
\hline Quantity & 4 & Quantity & 8 \\
\hline Minimum Charge & $1.144 \mathrm{kWh}$ & Minimum Charge & $2.88 \mathrm{kWh}$ \\
\hline Cost of Energy & $8.68 \notin / \mathrm{kWh}$ & Cost of Energy & $8.68 \phi / \mathrm{kWh}$ \\
\hline \multicolumn{2}{|l|}{ Inverter } & \multicolumn{2}{|l|}{ Inverter } \\
\hline Type & Xantrex Freedom 458 & Type & Xantrex Freedom 458 \\
\hline Capacity & $2 \mathrm{~kW}$ & Capacity & $2.5 \mathrm{~kW}$ \\
\hline Efficiency & $92 \%$ & Efficiency & $93 \%$ \\
\hline \multicolumn{2}{|l|}{ Generator } & \multicolumn{2}{|l|}{ Generator } \\
\hline Type & Natural Gas & Type & Natural Gas \\
\hline Quantity & 1 & Quantity & 1 \\
\hline $\begin{array}{l}\text { Rated Power / Total } \\
\text { Power }\end{array}$ & $6 \mathrm{~kW} / 6 \mathrm{~kW}$ & $\begin{array}{l}\text { Rated Power / Total } \\
\text { Power }\end{array}$ & $6 \mathrm{~kW} / 6 \mathrm{~kW}$ \\
\hline Cost of Energy & $5.67 \notin / \mathrm{kWh}$ & Cost of Energy & $5.67 \notin / \mathrm{kWh}$ \\
\hline
\end{tabular}




\begin{tabular}{|c|c|}
\hline \multicolumn{2}{|c|}{ UNIT 3 - Office } \\
\hline \multicolumn{2}{|l|}{ Wind Turbine } \\
\hline Type & Bergey 7.5 \\
\hline Rated Power & $7.5 \mathrm{~kW}$ \\
\hline Quantity & 2 \\
\hline Cut-in Speed & $4.0 \mathrm{~m} / \mathrm{s}$ \\
\hline Rated Speed & $11.0 \mathrm{~m} / \mathrm{s}$ \\
\hline Cut-off Speed & $20 \mathrm{~m} / \mathrm{s}$ \\
\hline Cost of Energy & $11.5 \notin / \mathrm{kWh}$ \\
\hline \multicolumn{2}{|l|}{ PV } \\
\hline Type & Sharp ND-195R1S \\
\hline Number of Modules & 366 \\
\hline $\begin{array}{lll}\text { Power rating / Total } \\
\text { Power }\end{array}$ & $195 \mathrm{~W} / 71.370 \mathrm{~kW}$ \\
\hline Cost of Energy & $34.5 \phi / \mathrm{kWh}$ \\
\hline \multicolumn{2}{|l|}{ Battery } \\
\hline Type & Trojan J150 \\
\hline Capacity & $36 \mathrm{kWh}$ \\
\hline Quantity & 20 \\
\hline Minimum Charge & $7.2 \mathrm{kWh}$ \\
\hline Cost of Energy & $8.68 \phi / \mathrm{kWh}$ \\
\hline \multicolumn{2}{|l|}{ Inverter } \\
\hline Type & Victron Energy Quattro \\
\hline Capacity & $30 \mathrm{~kW}$ \\
\hline Efficiency & $93 \%$ \\
\hline \multicolumn{2}{|l|}{ Generator } \\
\hline Type & Natural Gas \\
\hline Quantity & 1 \\
\hline $\begin{array}{l}\text { Rated Power / Total } \\
\text { Power }\end{array}$ & $7 \mathrm{~kW} / 7 \mathrm{~kW}$ \\
\hline Cost of Energy & $4.86 \notin / \mathrm{kWh}$ \\
\hline
\end{tabular}

\begin{tabular}{|c|c|}
\hline \multicolumn{2}{|c|}{ UNIT 4 - Full Service Restaurant } \\
\hline \multicolumn{2}{|l|}{ Wind Turbine } \\
\hline Type & Bergey 7.5 \\
\hline Rated Power & $7.5 \mathrm{~kW}$ \\
\hline Quantity & 2 \\
\hline Cut-in Speed & $4.0 \mathrm{~m} / \mathrm{s}$ \\
\hline Rated Speed & $11 \mathrm{~m} / \mathrm{s}$ \\
\hline Cut-off Speed & $20 \mathrm{~m} / \mathrm{s}$ \\
\hline Cost of Energy & $11.5 \phi / \mathrm{kWh}$ \\
\hline \multicolumn{2}{|l|}{ PV } \\
\hline Type & None \\
\hline \multicolumn{2}{|l|}{ Number of Modules } \\
\hline \multicolumn{2}{|l|}{$\begin{array}{l}\text { Power rating / Total } \\
\text { Power }\end{array}$} \\
\hline \multicolumn{2}{|l|}{ Cost of Energy } \\
\hline \multicolumn{2}{|l|}{ Battery } \\
\hline Type & Trojan J150 \\
\hline Capacity & $36 \mathrm{kWh}$ \\
\hline Quantity & 20 \\
\hline Minimum Charge & $7.2 \mathrm{kWh}$ \\
\hline Cost of Energy & $8.68 \phi / \mathrm{kWh}$ \\
\hline \multicolumn{2}{|l|}{ Inverter } \\
\hline Type & Victron Energy Quattro \\
\hline Capacity & $60 \mathrm{~kW}$ \\
\hline Efficiency & $93 \%$ \\
\hline \multicolumn{2}{|l|}{ Generator } \\
\hline Type & Natural Gas \\
\hline Quantity & 1 \\
\hline $\begin{array}{l}\text { Rated Power / Total } \\
\text { Power }\end{array}$ & $6 \mathrm{~kW} / 6 \mathrm{~kW}$ \\
\hline Cost of Energy & $5.67 ф / \mathrm{kWh}$ \\
\hline
\end{tabular}




\subsubsection{Electric Vehicle/Plug-in Hybrid Electric Vehicles}

Table 5-14 shows the data taken from [24]. Six vehicles are assumed to be available. The "Supply Power" column indicates if the owner will allow the car battery to be discharged (value ' 1 ') to supply power to other EVs and to the local load. If the owner does not allow the battery pack to be discharged, the "Supply Power" column has a value of ' 0 '.

Table 5-14 Sample EV real-time information

\begin{tabular}{|c|r|r|r|r|r|}
\hline $\begin{array}{l}\text { Vehicle } \\
\text { ID }\end{array}$ & $\begin{array}{c}\text { Power } \\
\text { Available } \\
(\mathrm{kW})\end{array}$ & $\begin{array}{c}\text { Power } \\
\text { Consumption } \\
(\mathrm{kW} / \mathrm{km})\end{array}$ & $\begin{array}{c}\text { Distance Left } \\
\text { to Travel } \\
(\mathrm{km})\end{array}$ & $\begin{array}{l}\text { Allow Vehicle } \\
\text { to Discharge }\end{array}$ & $\begin{array}{c}\text { Safety } \\
\text { Limit } \\
(\%)\end{array}$ \\
\hline 10000 & 30 & 0.6 & 15 & 1 & 1.2 \\
\hline 10001 & 45 & 0.6 & 100 & 1 & 1.2 \\
\hline 10002 & 12 & 0.6 & 20 & 1 & 1.2 \\
\hline 10003 & 12 & 0.6 & 6 & 1 & 1.2 \\
\hline 10004 & 150 & 0.6 & 22 & 1 & 1.2 \\
\hline 10005 & 150 & 0.6 & 22 & 1 & 1.2 \\
\hline
\end{tabular}

Table 5-15 shows a part of the control matrix from [24] adopted in this project. It shows where the electric vehicle is at any 15 -minute period. For example, at $12 \mathrm{mn}$, residential Unit 1 has 3 EVs connected to its charging stations while commercial Unit 4 has 2.

Table 5-15 EV Control Matrix

\begin{tabular}{|l|l|l|l|l|l|l|l|l|l|l|l|l|}
\hline $\begin{array}{l}\text { Vehicle } \\
\text { ID } \\
\text { Xime }\end{array}$ & $00: 00$ & $00: 15$ & $00: 30$ & $00: 45$ & $01: 00$ & $01: 15$ & $01: 30$ & $01: 45$ & & $23: 15$ & $23: 30$ & $23: 45$ \\
\hline 10000 & Unit1 & Unit1 & Unit1 & Unit1 & Unit1 & Unit1 & Unit1 & Unit1 & $\ldots$ & Unit1 & Unit1 & Unit1 \\
\hline 10001 & Unit1 & Unit1 & Unit1 & Unit1 & Unit1 & Unit1 & Unit1 & Unit1 & $\ldots$ & Unit1 & Unit1 & Unit1 \\
\hline 10002 & & & & & & & & & $\ldots$ & Unit1 & Unit1 & Unit1 \\
\hline 10003 & Unit1 & Unit2 & Unit2 & Unit2 & Unit2 & Unit2 & Unit2 & Unit2 & $\ldots$ & Unit2 & Unit2 & Unit2 \\
\hline 10004 & Unit4 & Unit4 & Unit4 & Unit4 & Unit4 & Unit4 & Unit4 & Unit4 & $\ldots$ & Unit4 & Unit4 & Unit4 \\
\hline 10005 & Unit4 & Unit4 & Unit4 & Unit4 & Unit4 & Unit4 & Unit4 & Unit4 & $\ldots$ & & & \\
\hline
\end{tabular}


The proposed computer model interfaces with the computer model developed in [24] by querying it for the status of the EVs connected to the charging stations every 15 minutes. The EV computer model will respond with the net power it needs or the net power it has available for all the EVs in a load unit. The power requested by the EVs will first be provided using the excess power from the renewables (after the load demand is satisfied) as expressed in Eq. (49). If there is not enough renewable energy, the computer model of [25] will be given the task of distributing the unfilled EV requirement to the battery, generator or grid, in that particular order, as formulated in Eqs. (50) to (53) and Eq. (57). At any time interval, if the EV computer model says it has net excess power from the EVs, the excess power will be used to supply the portion of the load demand that the renewable technologies are not able to fill as expressed in Eq. (35). The EV computer model is then informed of how much power is taken from or given to the EVs. It should be noted that the EV model of [24] does not consider the cost of discharging. 


\section{SIMULATION RESULTS AND ANALYSIS}

Figs. 6-1 to 6-2 illustrate how the various distributed energy resources are operated to satisfy the electrical requirements of the residential Unit 1 as well as the EVs. The demand-supply balance is illustrated for summer and winter days. The left side of the figures shows a table of the electrical demand of the load unit (excluding EV demand) every 15 minutes. The top bar chart shows the balance of power between demand and supply. The top pie chart shows the share of each technology in the electricity supply. The bottom bar chart shows the times when the battery was charged and the contribution of each energy source in charging it. The bottom pie chart shows the share of each technology in the costs incurred to supply power to the load and the EVs and to charge the battery bank. The renewable energy costs reflected in the figures is the cost of producing power regardless of whether it is used or dumped. The right panel of the figures shows additional information such as:

- The load unit type, the 24-hour demand, peak demand and minimum demand

- The energy sources available to the load unit, the types/models, rated outputs and the cost of producing energy.

- The energy spent by the renewable technologies, generator and grid to charge the battery. The battery model does not distinguish the source of renewable energy it used to charge the battery, thus the figure only shows the total energy from all renewable resources that was used to charge the battery.

- The unused renewable energy that was dumped.

It can be seen from Fig. 6-1 (typical summer day) that from midnight to 2:15am the electrical demand of the residential unit is only $0.636 \mathrm{kWh}$ and the rest of the demand is from the $3 \mathrm{EVs}$ being charged. The net charging rate of the EVs is set to $5 \mathrm{~kW}$ per hour per EV. Because of the absence of solar energy the sources of power are the generator and the battery. Based on the discharge time provided to the battery model, a maximum of 1.152 $\mathrm{kW}$ can be drawn from the battery per hour or $0.288 \mathrm{~kW}$ per 15 minutes. The generator had to be dispatched to provide the extra power needed to charge the EVs. Starting at 2:15am, EVs connected to the system have extra energy to spare for the residential unit. The battery was continuously charged at a constant rate when it was not 


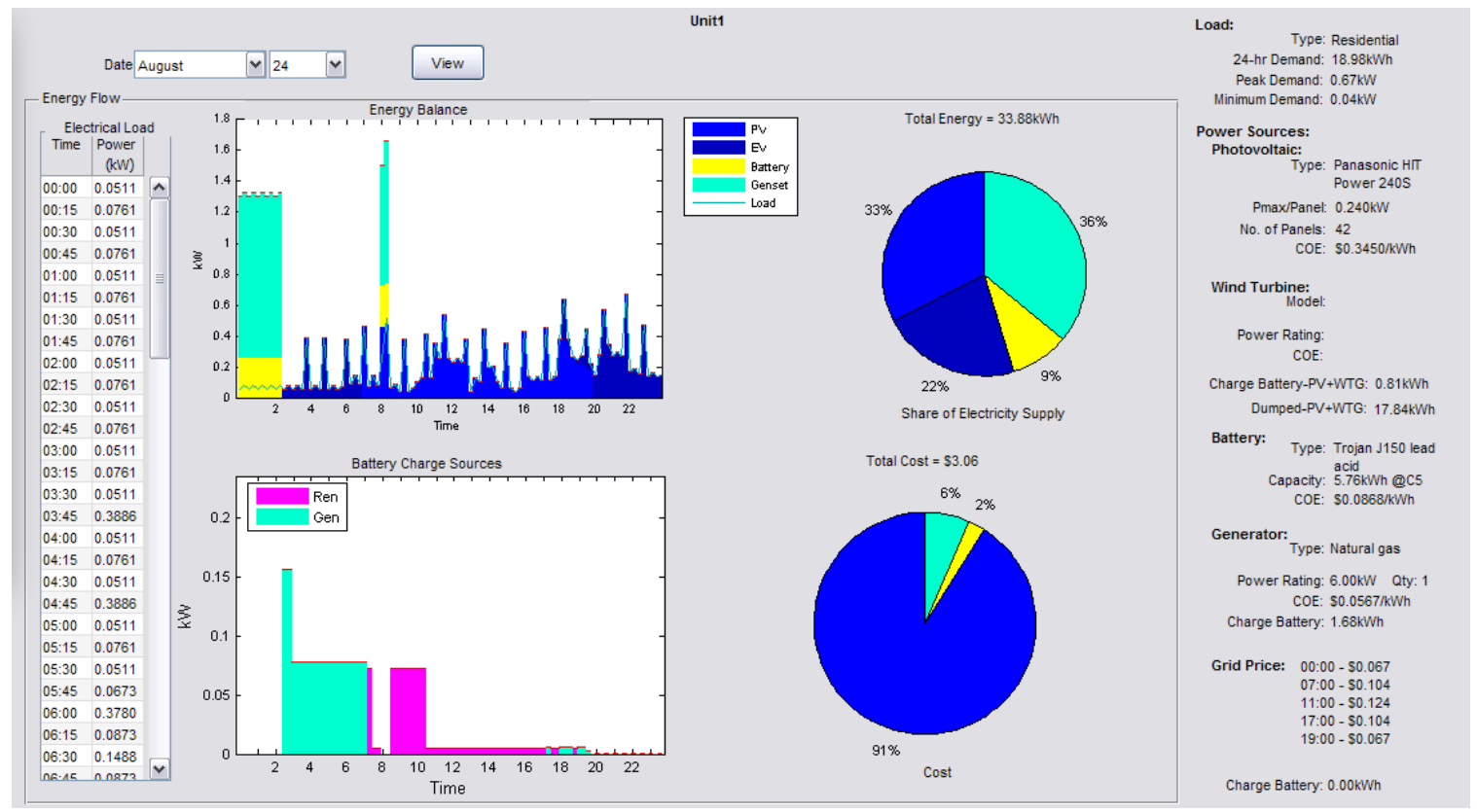

Figure 6-1 Electricity demand vs supply for residential Unit 1 on a typical summer day

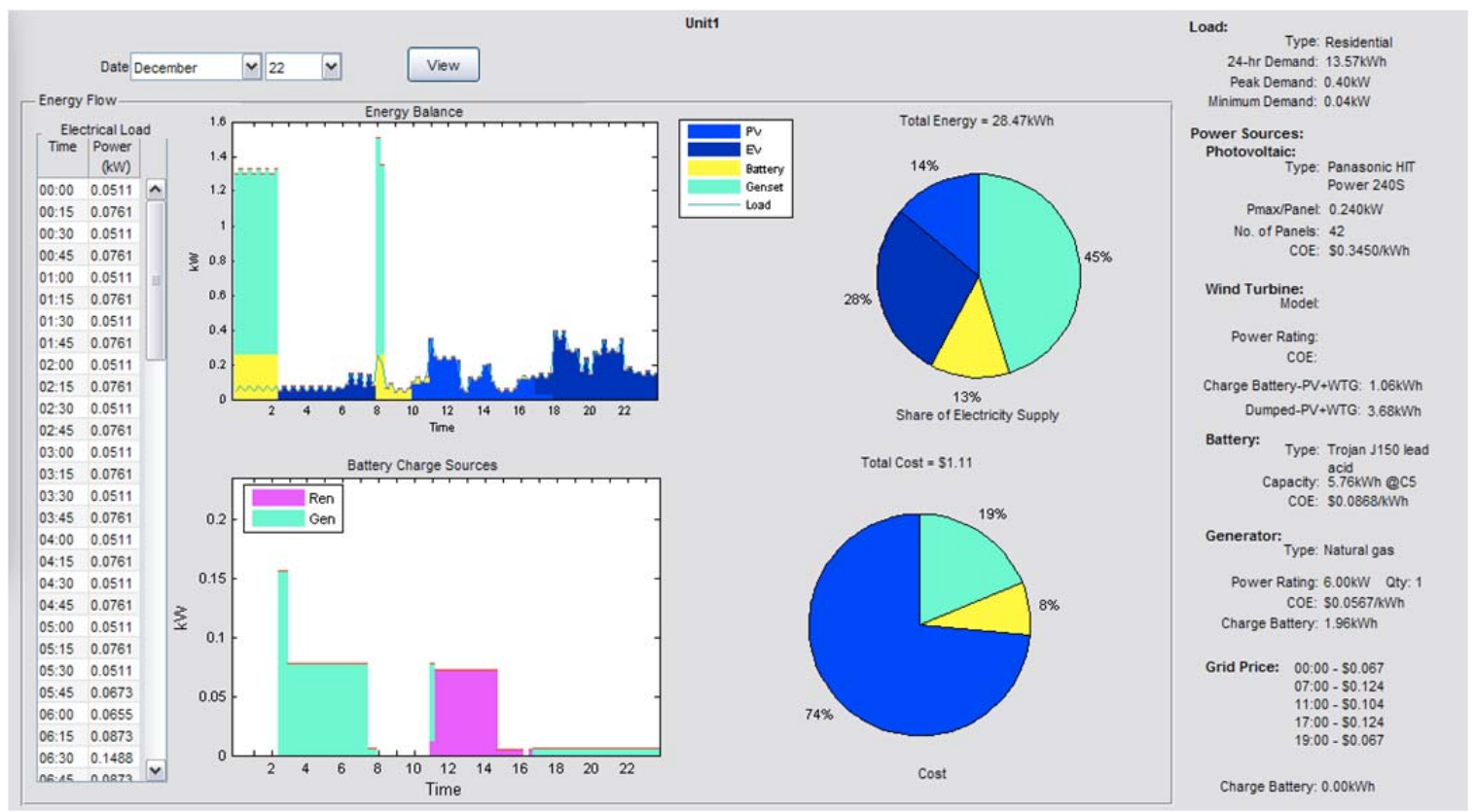

Figure 6-2 Electricity demand vs supply for residential Unit 1 on a typical winter day 
supplying power. At 2:45am, when the battery capacity reached $80 \%$ SOC, the topping charge stage began and the power given to the battery was reduced. Starting at 7:15am, solar energy was available to provide power to the load and at the same time take over the generator in charging the battery. At 7:30am, the trickle or floating charge stage began as the battery capacity reached $95 \%$. 7:45am to 8:15am showed a spike in EV demand again and both load and EV demands were met by the PV system, the battery and generator. Solar energy was enough to charge the battery at a constant rate while supplying power to the load from 8:15am to $5 \mathrm{pm}$. At 2:45pm, trickle or floating charge was applied to the battery. The PV system alone was able to supply power to the residential unit until 6:30pm. From 6:30 pm to 8pm, excess EV power was used. EVs provided the energy requirement from 8pm to 12 midnight. The top pie chart shows the share of each component in supplying the electrical demand and EVs of the residential unit: $33 \%$ by the PV system, $22 \%$ by the EVs, $9 \%$ by the battery and $36 \%$ by the generator. The PV system ate $91 \%$ of the cost as shown in the bottom pie chart. $2.49 \mathrm{kWh}$ was used to charge the battery $(0.81$ kWh and $1.68 \mathrm{kWh}$ by the PV system and generator, respectively). Total energy produced by the PV system was $29.83 \mathrm{kWh}$ (11.18 kWh to supply the load, $0.81 \mathrm{kWh}$ to charge the battery and $17.84 \mathrm{kWh}$ dumped).

Fig 6-2 shows that during winter, solar energy is available only from 9:45am to 6pm and less renewable energy is dumped during winter (42\% of total solar energy produced). Figs. 6-3 and 6-4 show the demandrenewable supply graph during summer and winter, respectively, for residential Unit 1 . The figures clearly show that the power outputs of renewable energy resources do not always coincide with the time durations of load demands resulting in $60 \%$ of the solar energy dumped in summer and $42 \%$ in winter. Without the EVs as an additional source of power, the same residential unit would be reliant on the generator and the battery for power when there is no sun as shown in Figs. 6-5 and 6-6. 


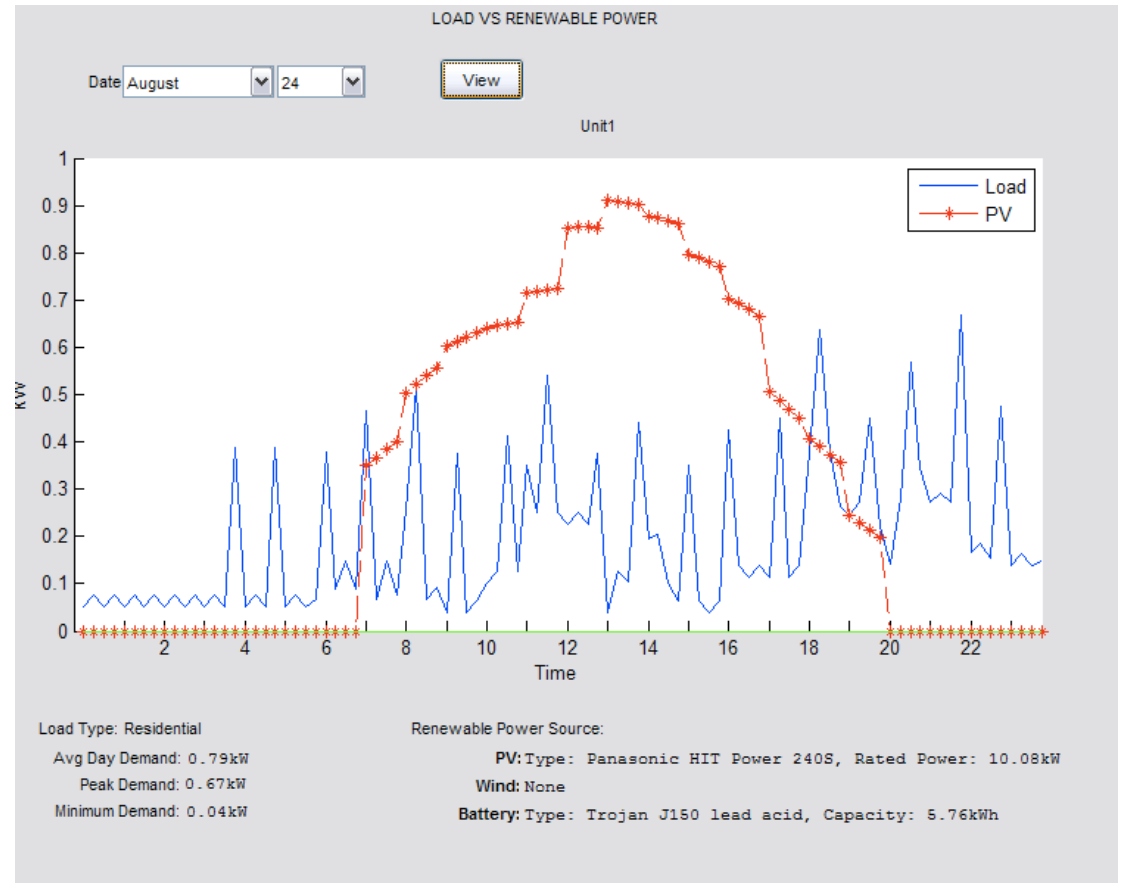

Figure 6-3 Electricity demand vs renewable energy supply for residential Unit 1 on a typical summer day

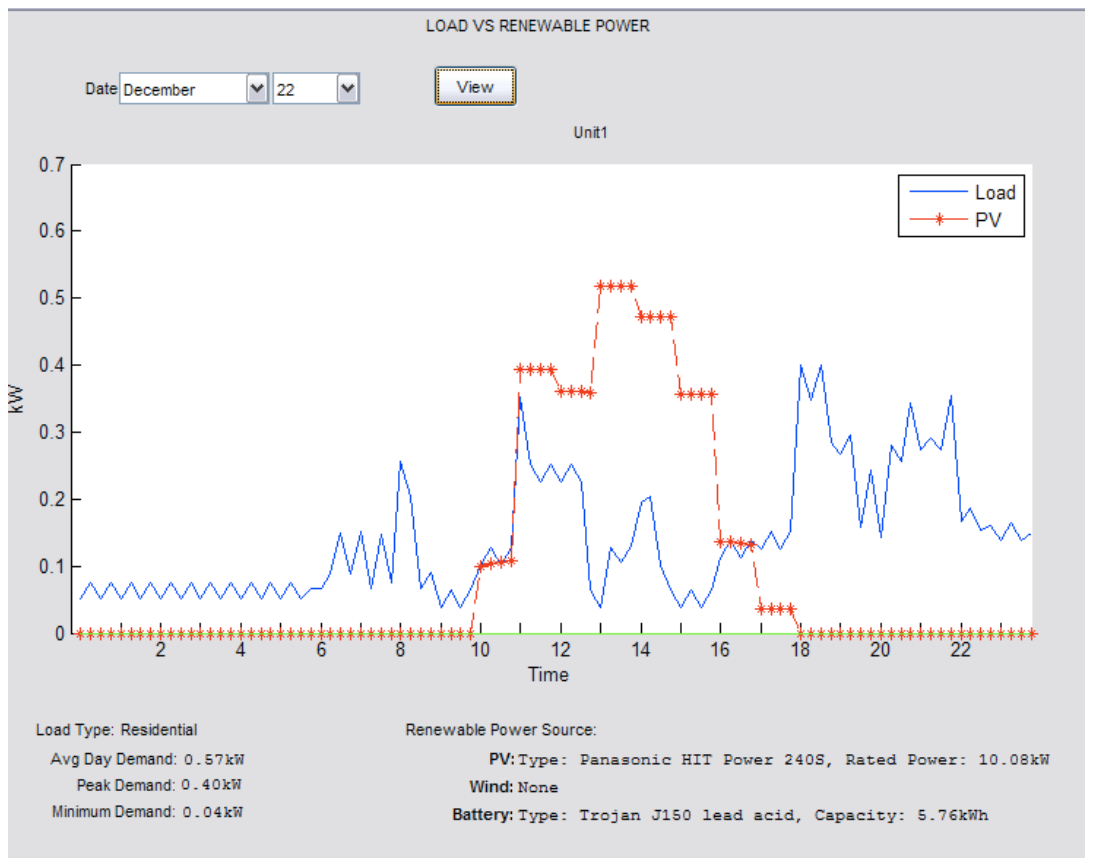

Figure 6-4 Electricity demand vs renewable energy supply for residential Unit 1 on a typical winter day 


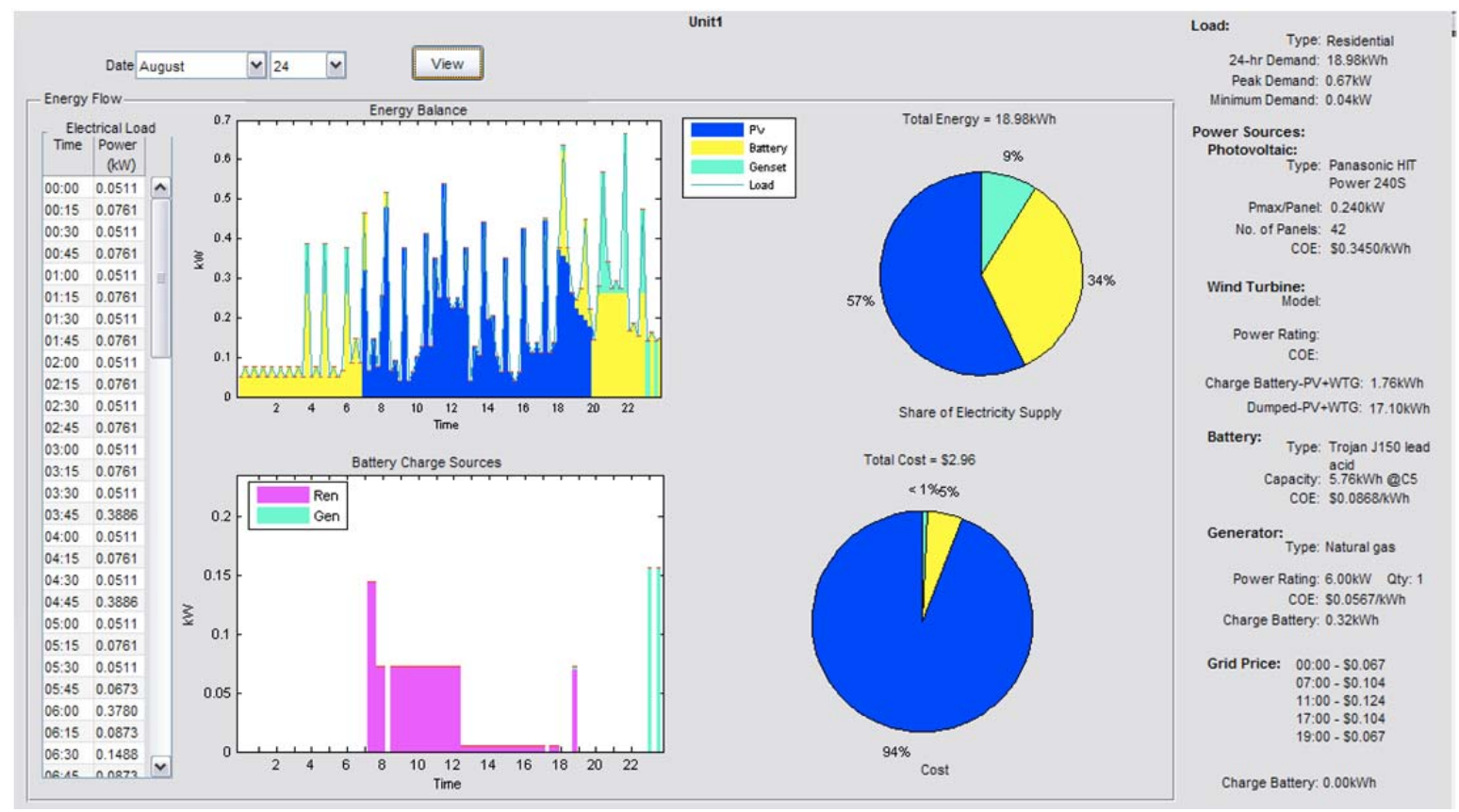

Figure 6-5 Electricity demand vs energy supply for residential Unit 1 without the EVs on a typical summer day

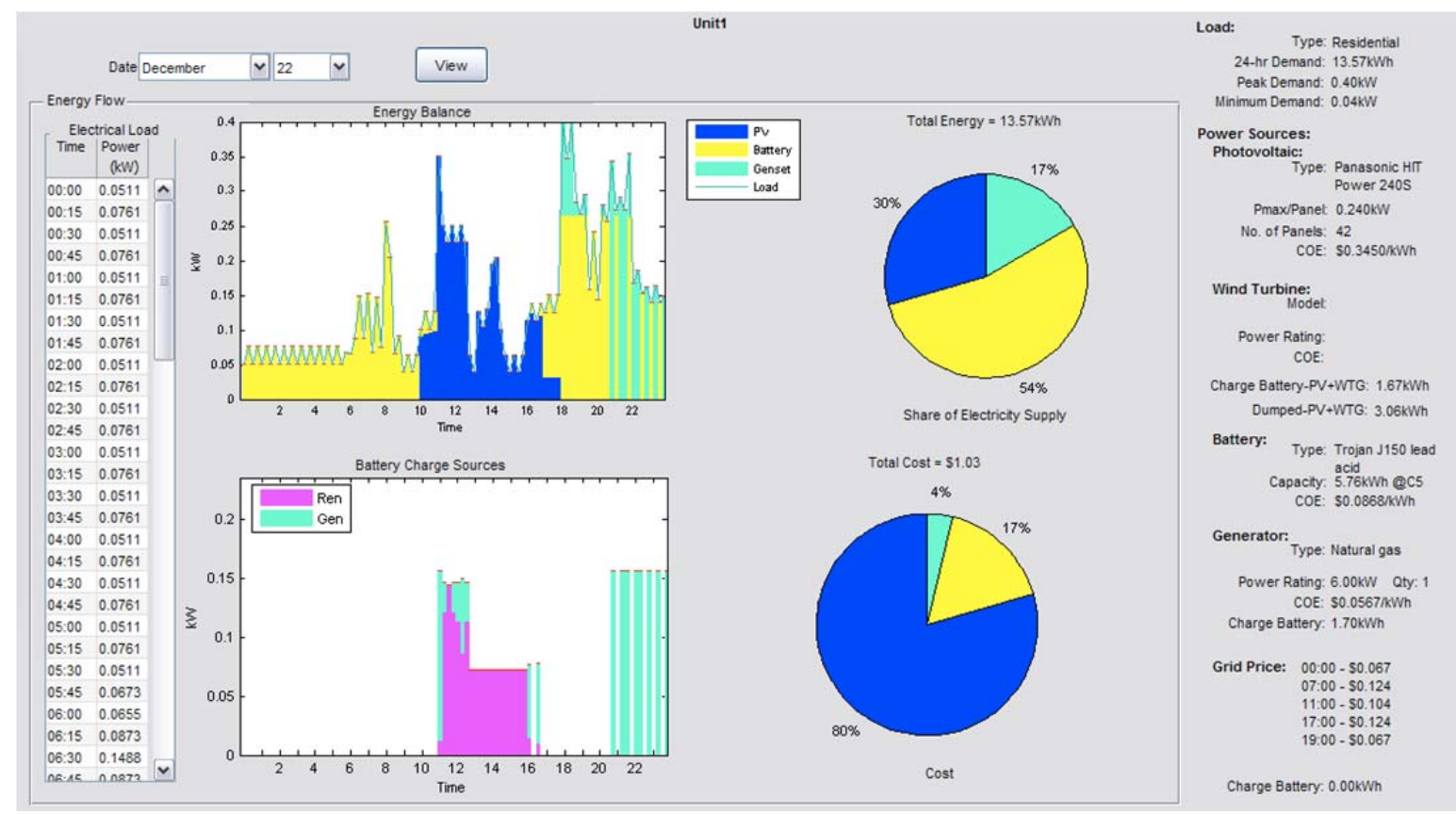

Figure 6-6 Electricity demand vs energy supply for residential Unit 1 without the EVs on a typical winter day 
Figs. 6-7 and 6-8 show how the hybrid wind turbine and PV panels installed in residential Unit 2 are operated during summer and winter, respectively. The system calculated that given the weather pattern and the type of wind turbine and PV panel used and the efficiency of the inverter, the output over 24 hours of the wind turbine on August 24 would be $22.721 \mathrm{kWh}$ (Fig. 6-9) compared to $24.784 \mathrm{kWh}$ for the PV system (Fig. 6-11). On December 22 the wind turbine can produce $20.632 \mathrm{kWh}$ (Fig. 6-10) while the solar panels produced only 7.533 kWh (Fig. 6-12) over 24 hours. Although the PV system produced more power in summer, the power optimization algorithm used by the proposed computer model will maximize the potential of the renewable technology with the cheapest cost (in this case wind energy) first. Any extra energy from the wind turbine and PV panels will be given to the EV and battery, in that order, if they need charging during the time interval. Any excess energy after that will be dumped. It can be seen from Figs. 6-7 and 6-8 that a significant amount of energy is wasted, $43 \%(20.31 \mathrm{kWh})$ of total renewable energy produced in summer and $50 \%(31.27 \mathrm{kWh})$ in winter. Note that during summer, none of the total energy used to charge the battery came from the renewable resources. Starting at 12:15am, only a trickle charge was applied to the battery because it was not discharged deep enough at 12 midnight to require a constant current charge and/or topping charge. The battery provided much of the energy during the time when there was no wind and solar energy and the generator provided all of the energy to charge the battery. Figs 6-13 and 6-14 show the demand-renewable energy balance for summer and winter, respectively. During summer, $66 \%$ of the energy needs of the residential unit were met by the hybrid system. During winter, the hybrid system provided $64 \%$ of the energy used.

As shown by the energy balance in Figs. 6-5, 6-6, 6-15 and 6-16, without the EVs, the dominant supplier of power to the load in the absence of the renewable energy sources was the battery. 


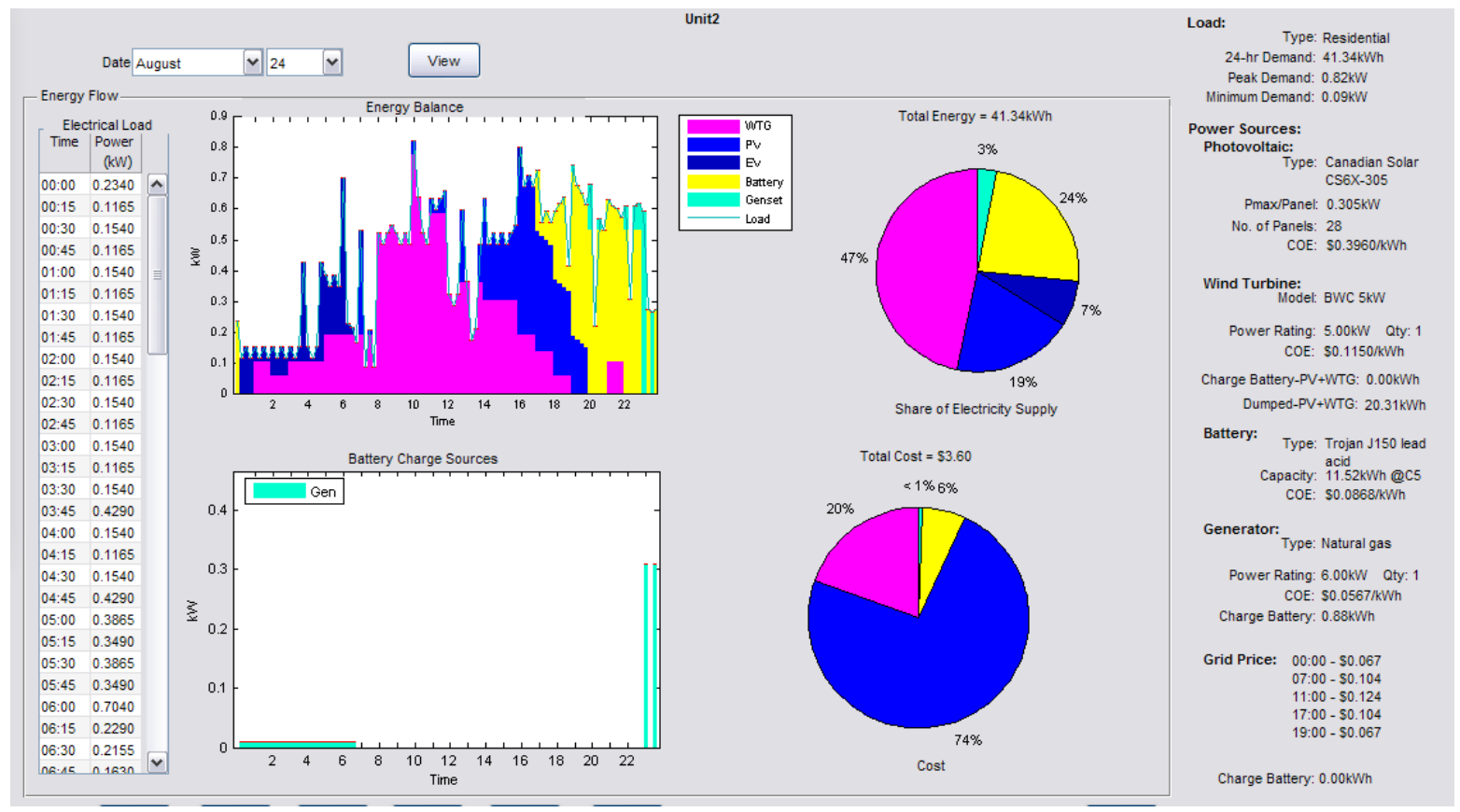

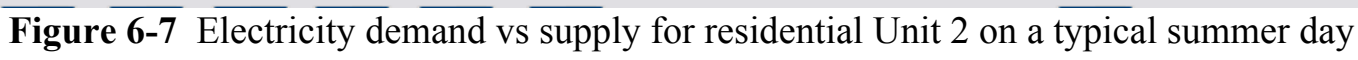

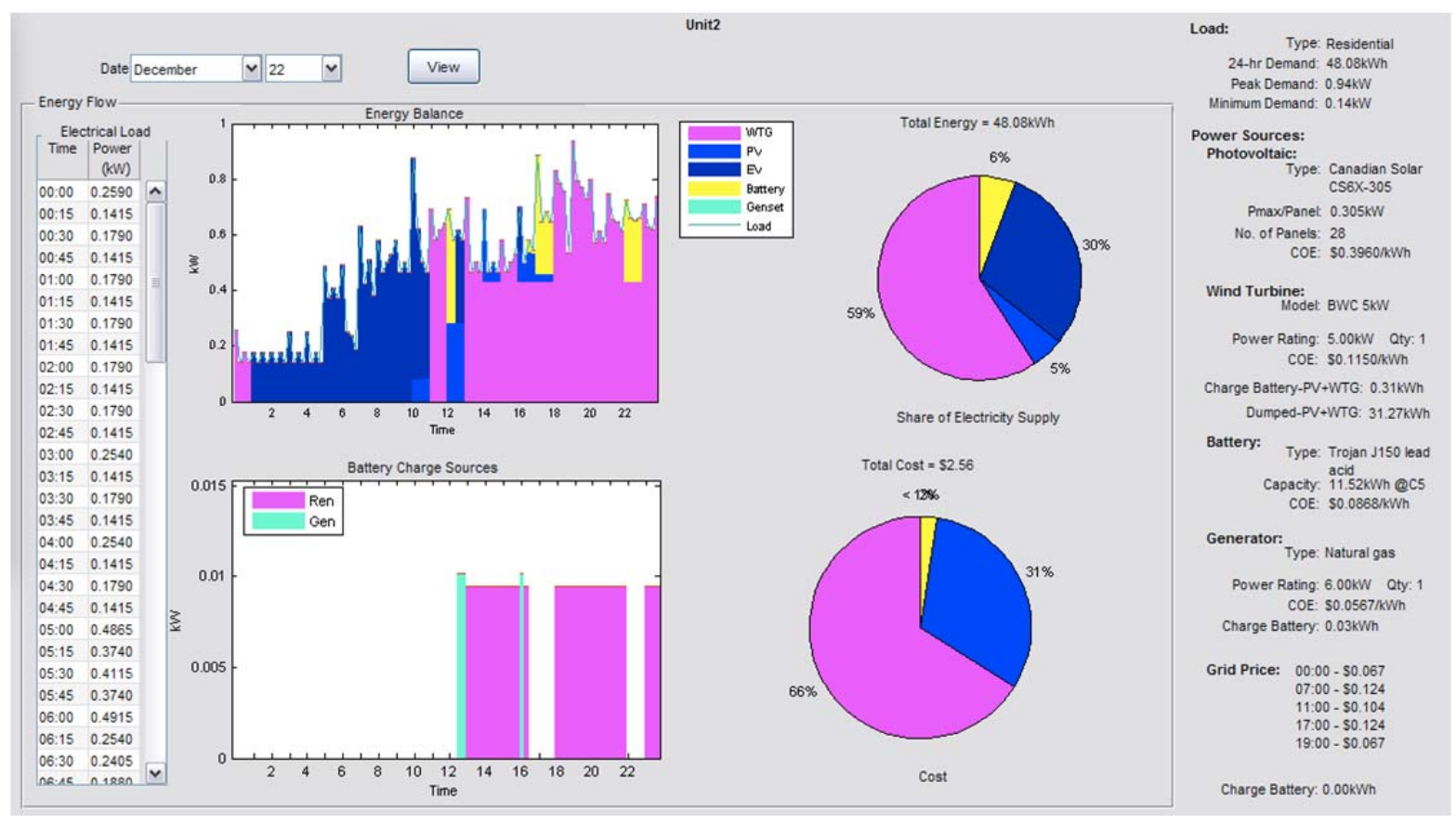

Figure 6-8 Electricity demand vs supply for residential Unit 2 on a typical winter day 


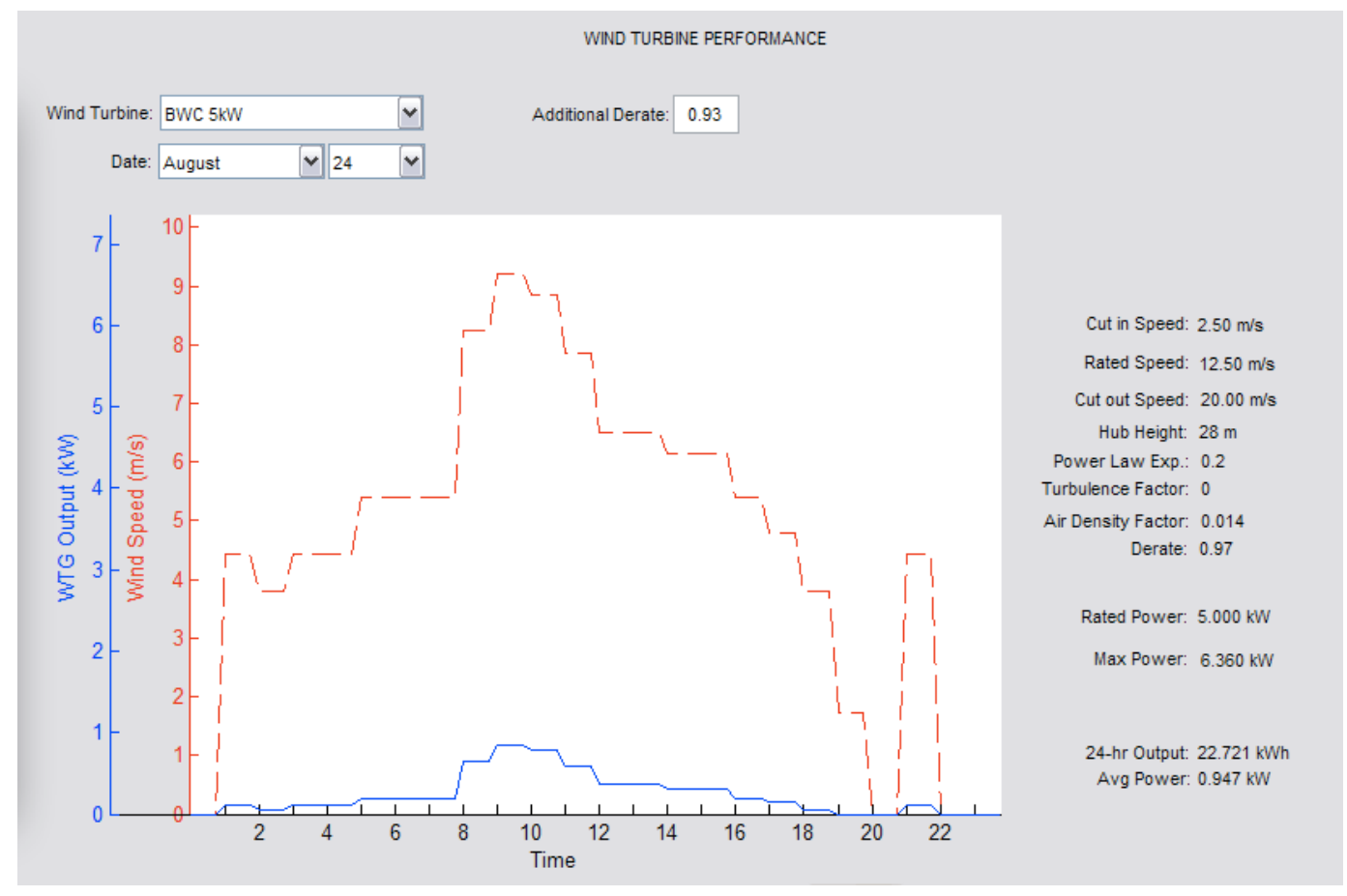

Figure 6-9 Performance of wind turbine installed at residential Unit 2 on a typical summer day

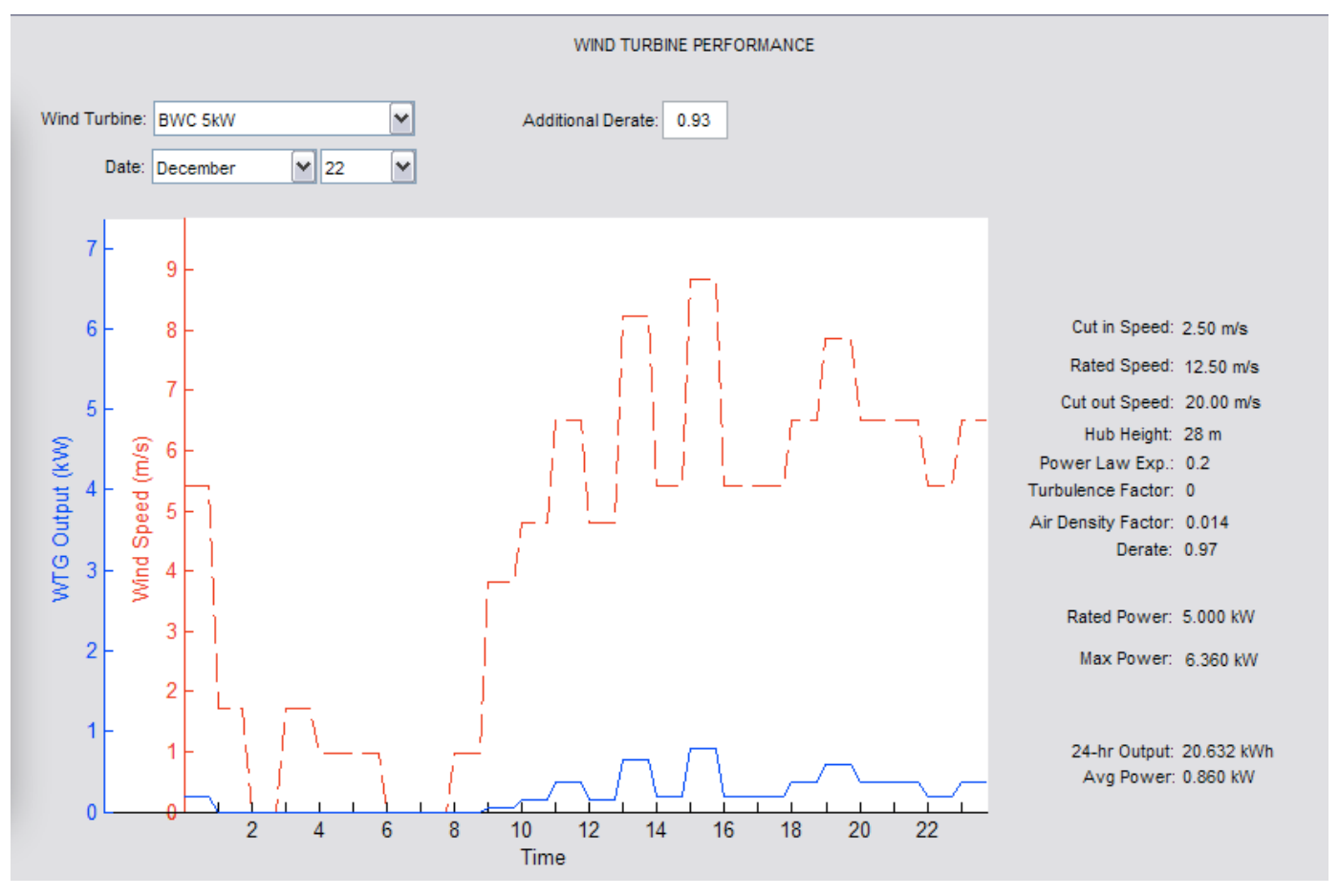

Figure 6-10 Performance of wind turbine installed at residential Unit 2 on a typical winter day 


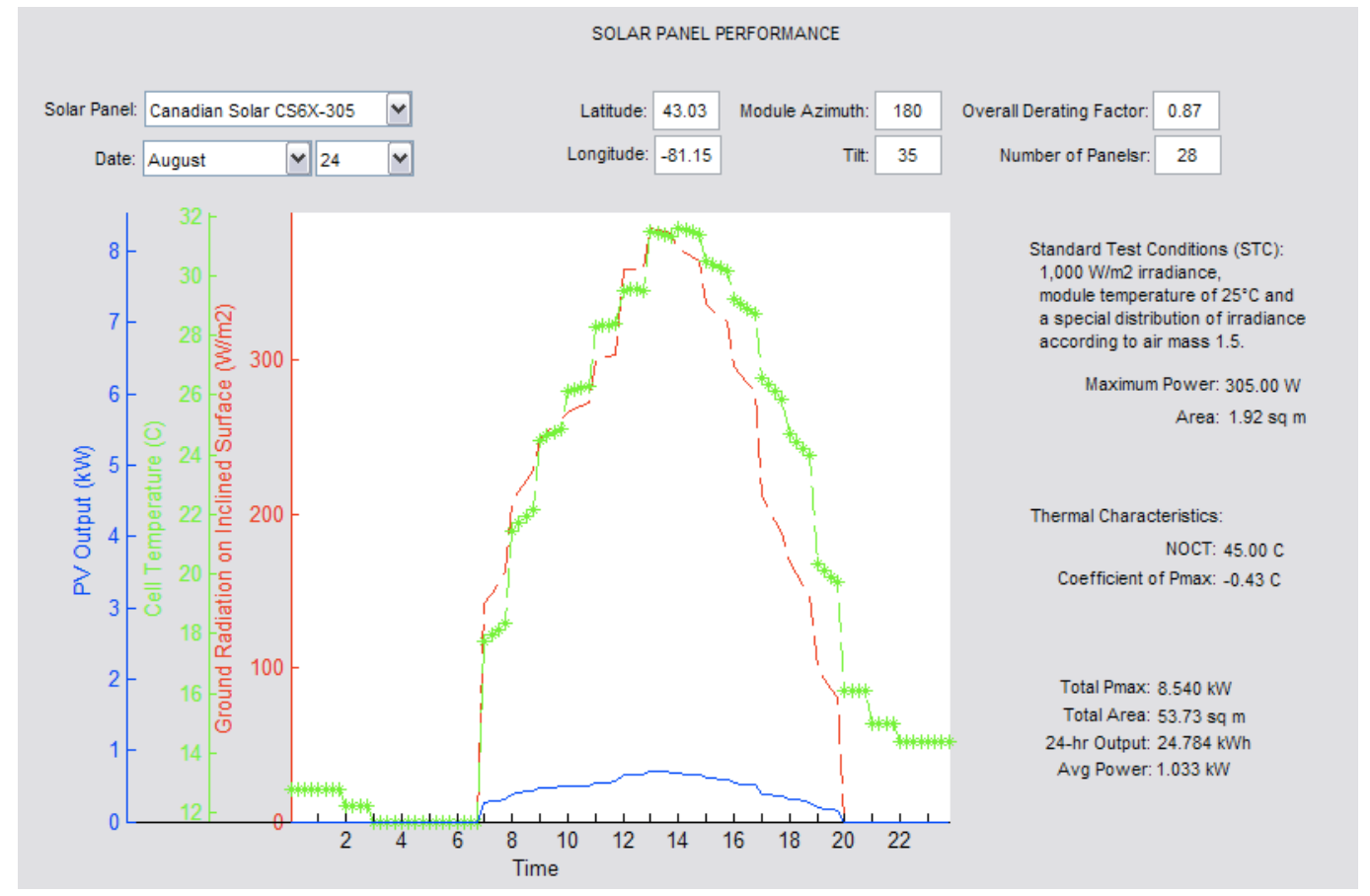

Figure 6-11 Performance of solar panels installed at residential Unit 2 on a typical summer day

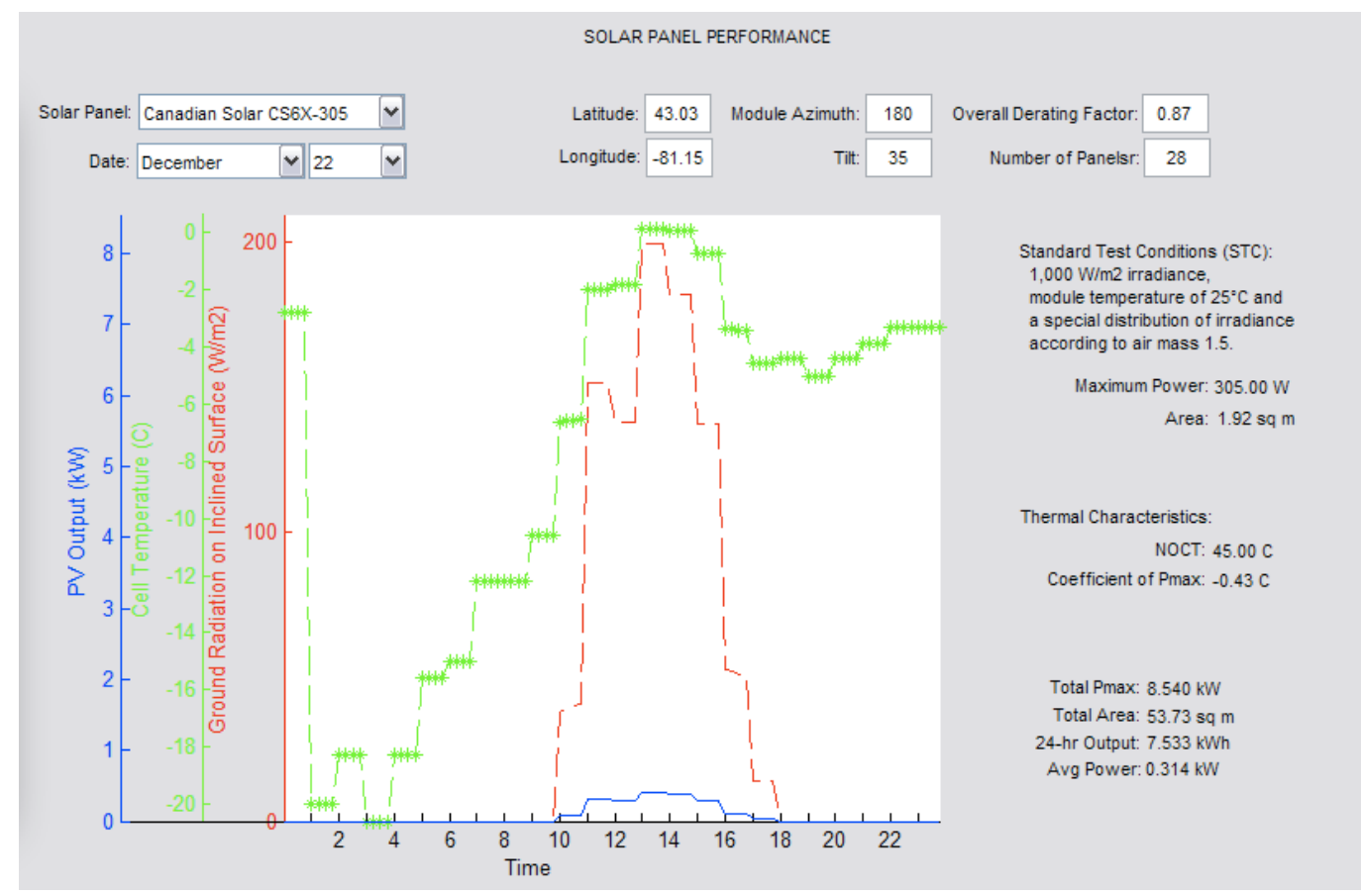

Figure 6-12 Performance of solar panels installed at residential Unit 2 on a typical winter day 


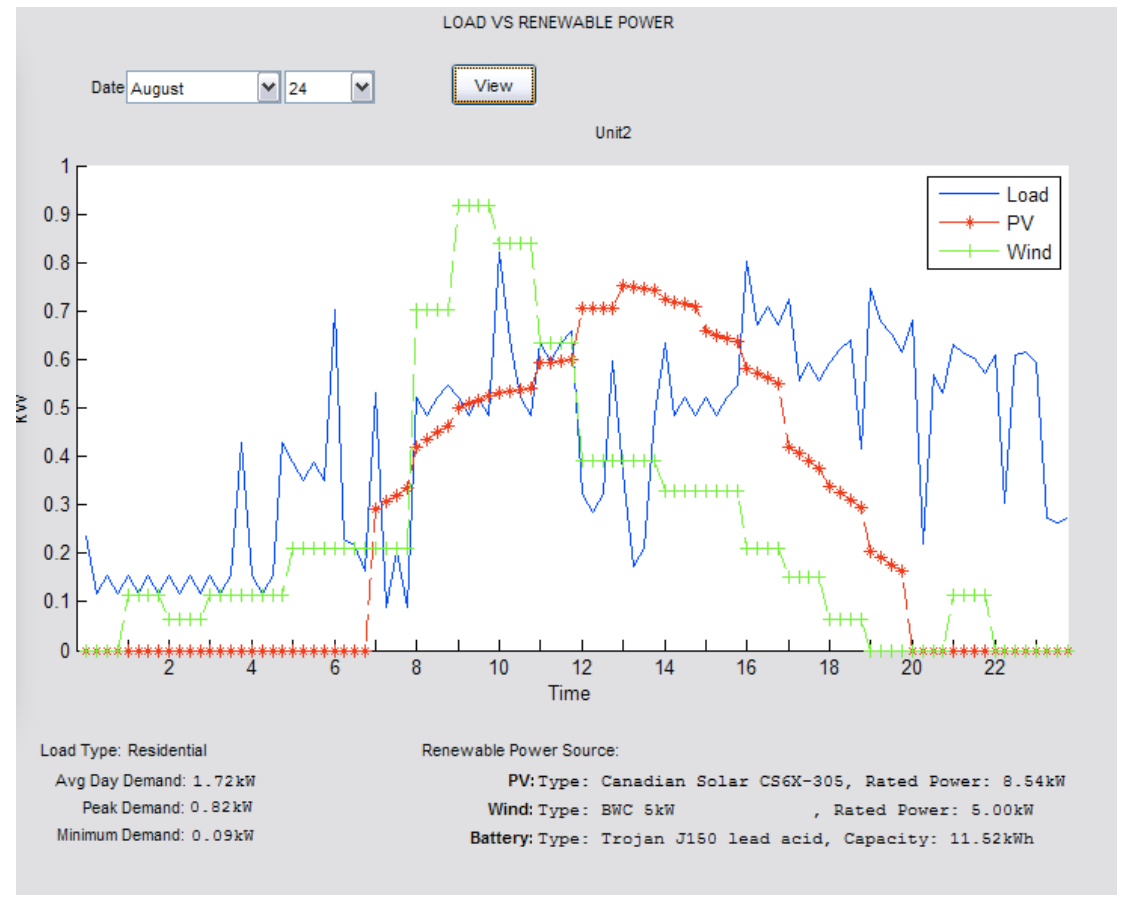

Figure 6-13 Electricity demand vs renewable energy supply for residential Unit 2 on a typical summer day

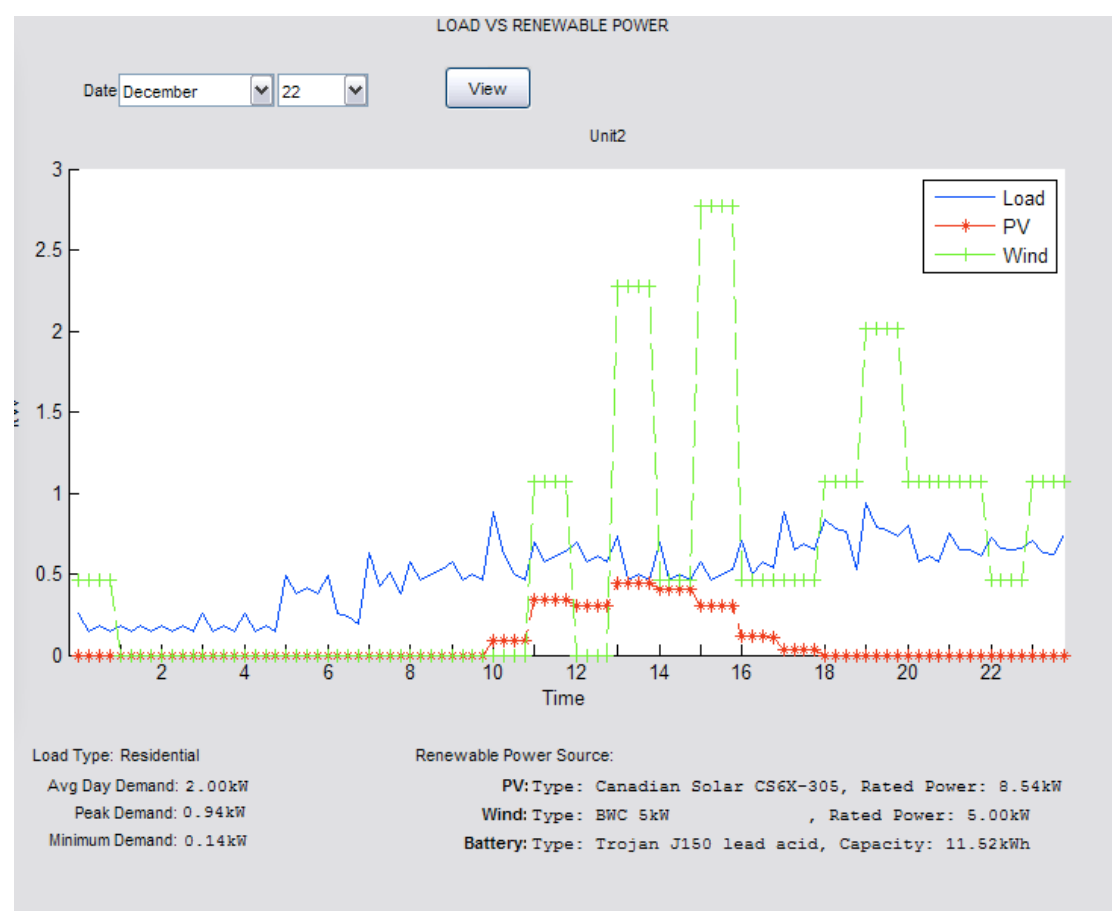

Figure 6-14 Electricity demand vs renewable energy supply for residential Unit 2 on a typical winter day 


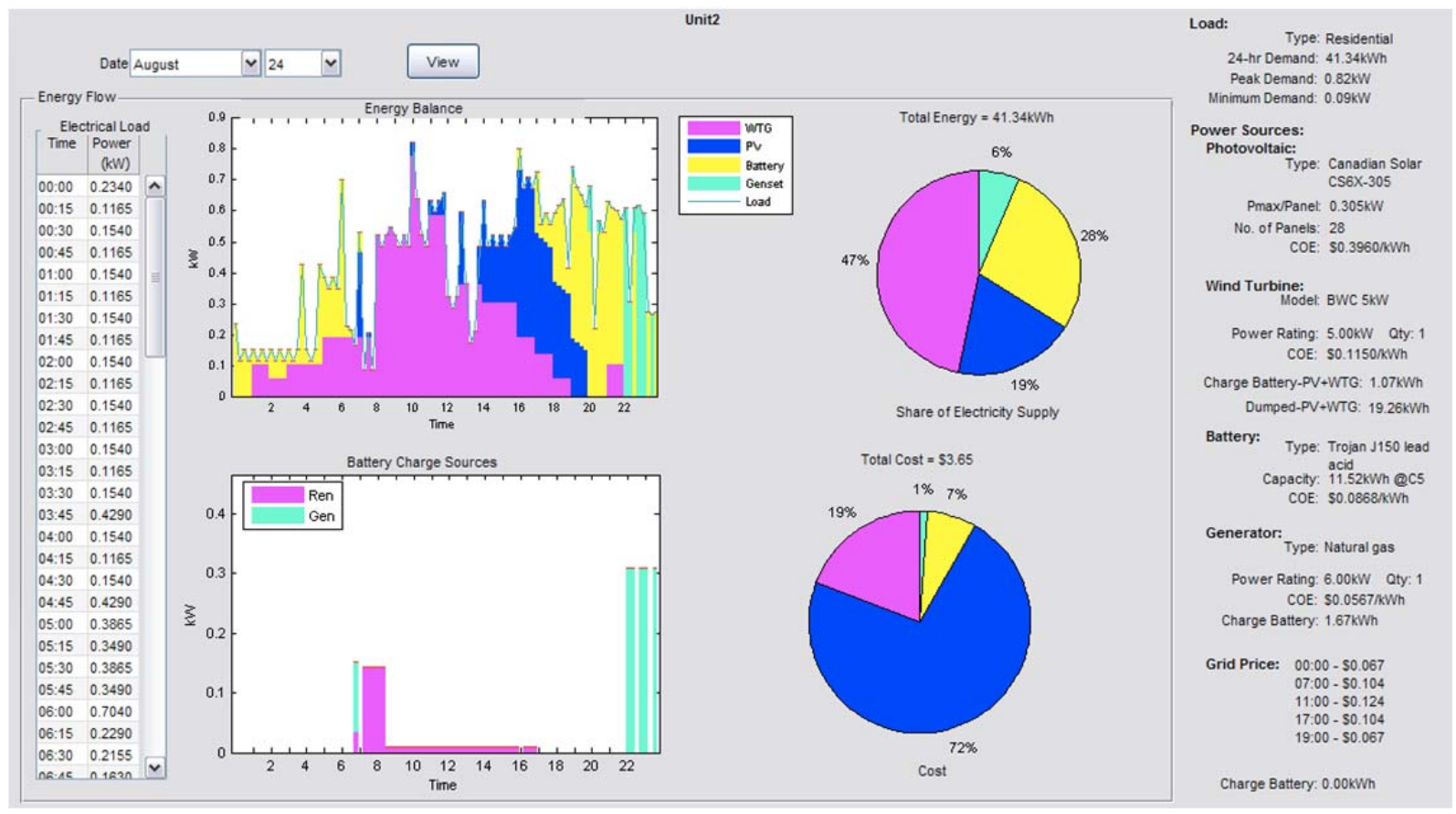

Figure 6-15 Electricity demand vs supply for residential Unit 2 without the EVs on a typical summer day

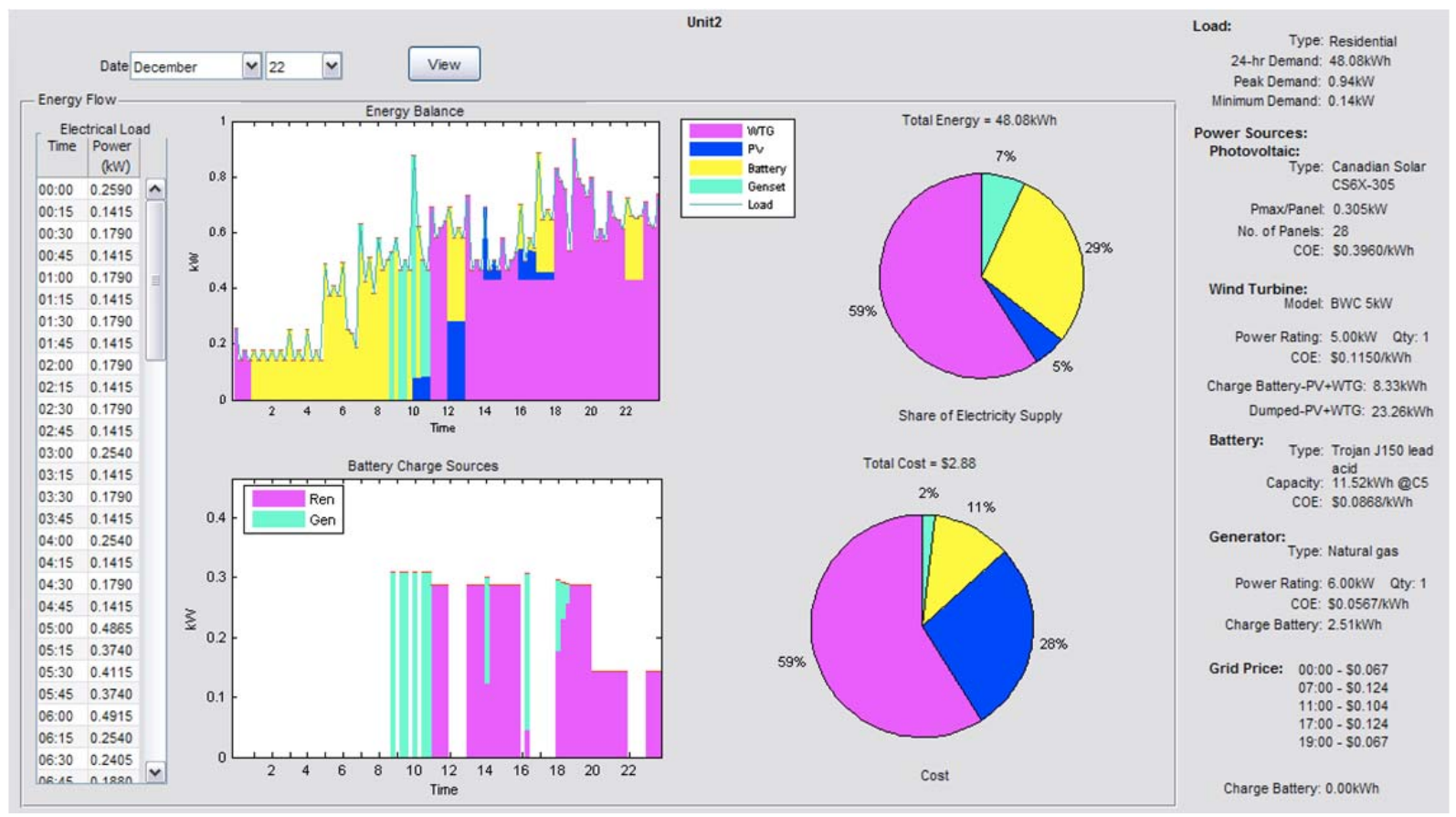

Figure 6-16 Electricity demand vs supply for residential Unit 2 without the EVs on a typical winter day 
Figs. 6-17 and 6-18 show the energy balance for a small office unit during summer and winter, respectively. Figs. 6-19 and 6-20 show the energy balance of the full-service restaurant during summer and winter respectively. Table 6-1 is a summary of the power flows for all load units during the two days used in the case study. It lists the share of each technology in supplying the electricity and EV demand, the share of the cost of each technology, the share of each technology in charging the battery and the amount of energy dumped. Looking at residential Unit 2 that used both wind and solar energy, wind energy was chosen by the simulation program to be the dominant supplier of power during summer and winter with $47 \%$ and $59 \%$ share, respectively, although the PV system was capable of producing more energy in summer. Small office Unit 3 has the following components installed: PV array, 2 wind turbines, battery bank and generator. The generator's cost of energy during summer as illustrated using the cost pie chart of Fig. 6-17 was from supplying the load and charging the battery bank. The bottom bar chart that shows the times when the battery was charged and which technology provided the energy indicated that the generator provided the main source of energy with the PV system and wind turbine helping intermittently. A significant amount of power was dumped, $10.08 \mathrm{kWh}$. There are two reasons for this: (1) the excess energy from the renewable resources may be more than the maximum allowable rate of charge imposed on the battery and (2) the battery may not need charging during times when there was excess energy. The generator and renewable technologies used $27.53 \mathrm{kWh}$ and $11.12 \mathrm{kWh}$ of energy, respectively, to charge the battery. Fig. 617 also shows that a small amount of energy (less than $1 \mathrm{kWh}$ ) was purchased from the grid. Fig. 6-18 shows that excluding EVs, small office Unit 3 has a demand of $379 \mathrm{kWh}$ over 24 hours with a peak of $4.8 \mathrm{~kW}$ during winter. With a total power rating of $71.37 \mathrm{~kW}$, the share of the PV technology in supplying the load was $15 \%$. The PV panels were able to produce power only for 8 hours starting at $10 \mathrm{am}$. Wind technology provided $36 \%$, the battery $16 \%$ and the generator $27 \%$ of the power requirement. The rest was drawn from the EV battery packs.

Because of its huge power demand, the full-service restaurant purchased from the grid $37 \%$ of its power requirement during summer and 24\% during winter despite the 2 wind turbines given to it as seen in Figs. 6-19 and 6-20, respectively. 


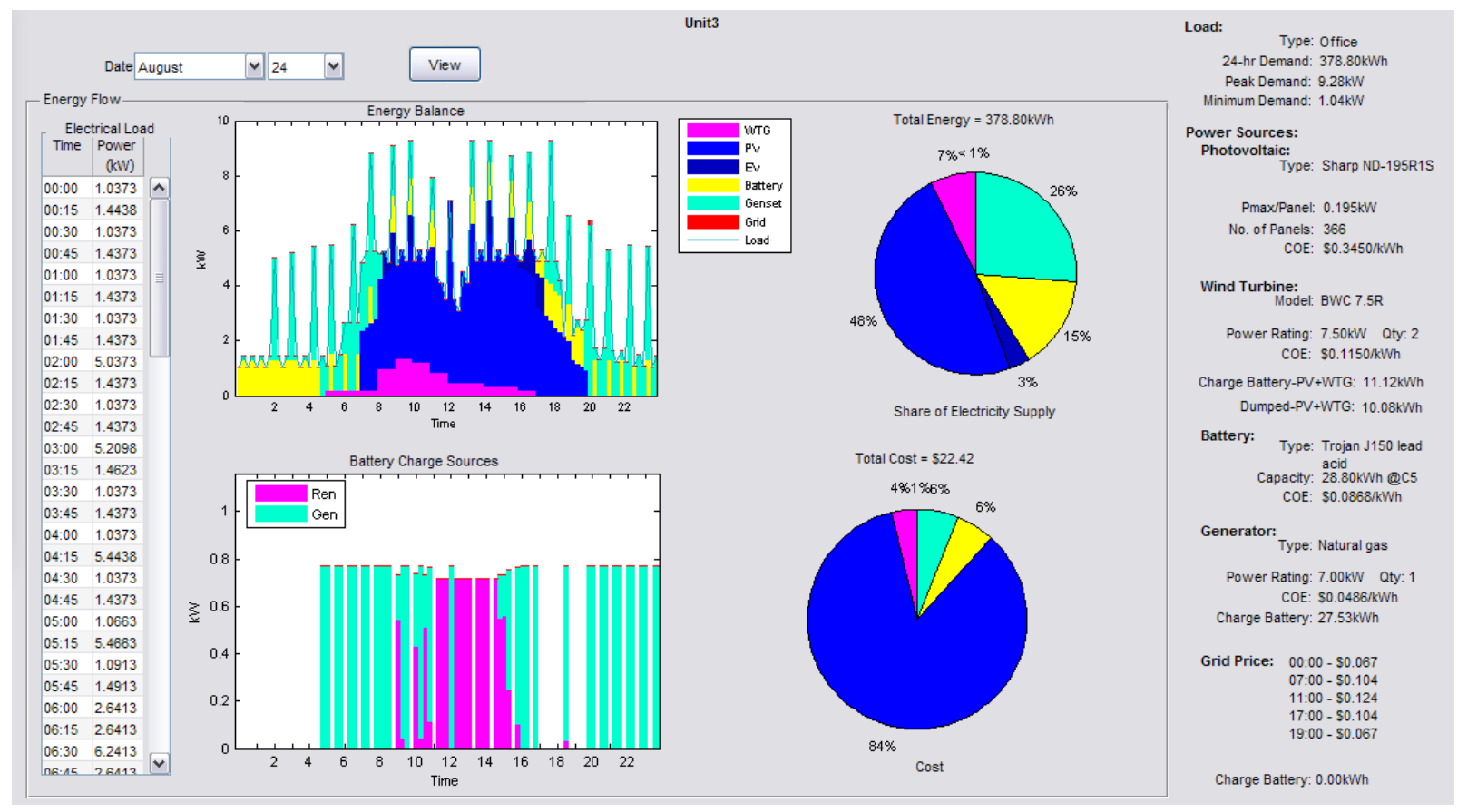

Figure 6-17 Electricity demand vs supply for small office Unit 3 on a typical summer day

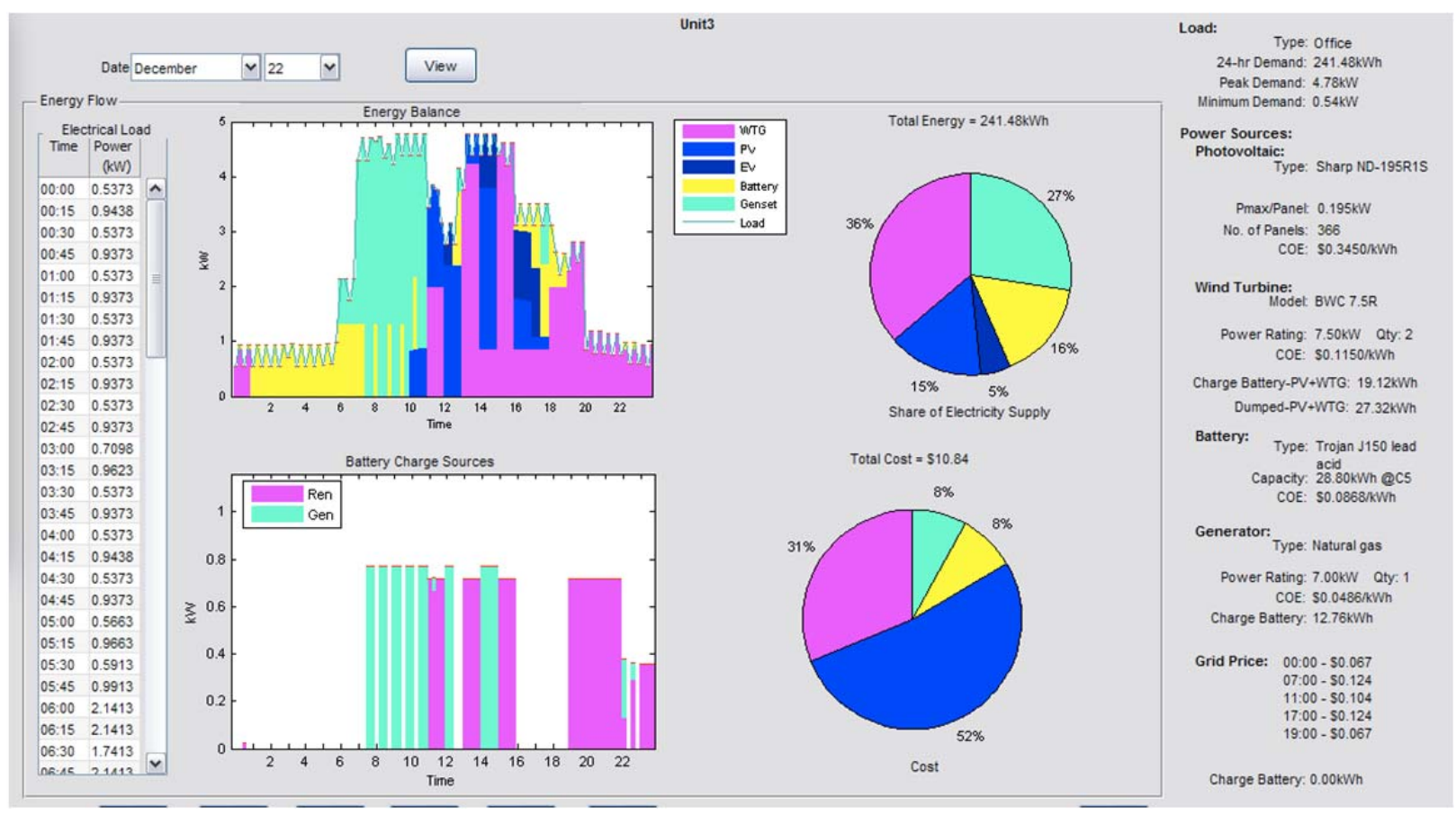

Figure 6-18 Electricity demand vs supply for small office Unit 3 on a typical winter day 


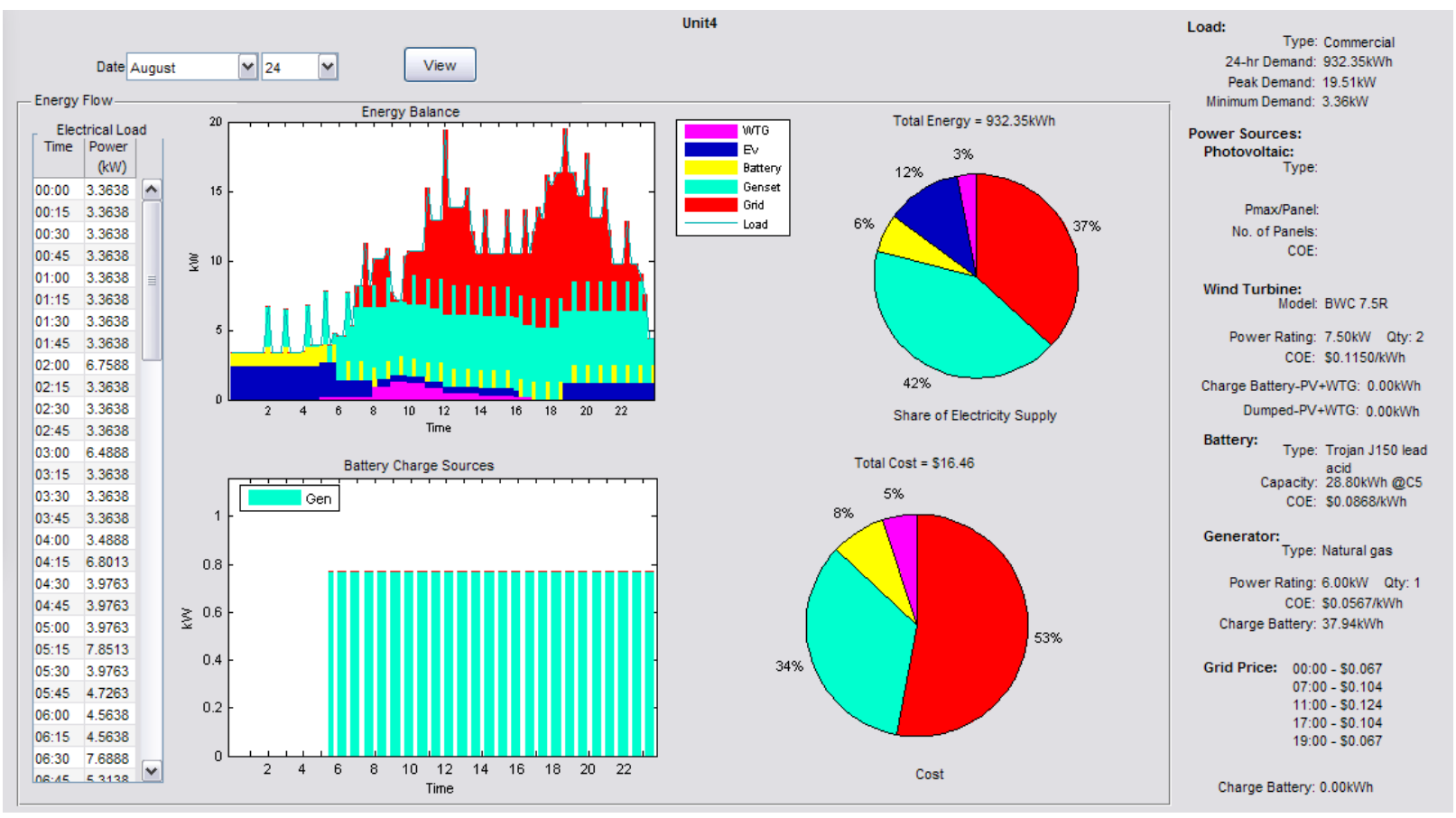

Figure 6-19 Electricity demand vs supply for a full-service restaurant (Unit 4) on a typical summer day

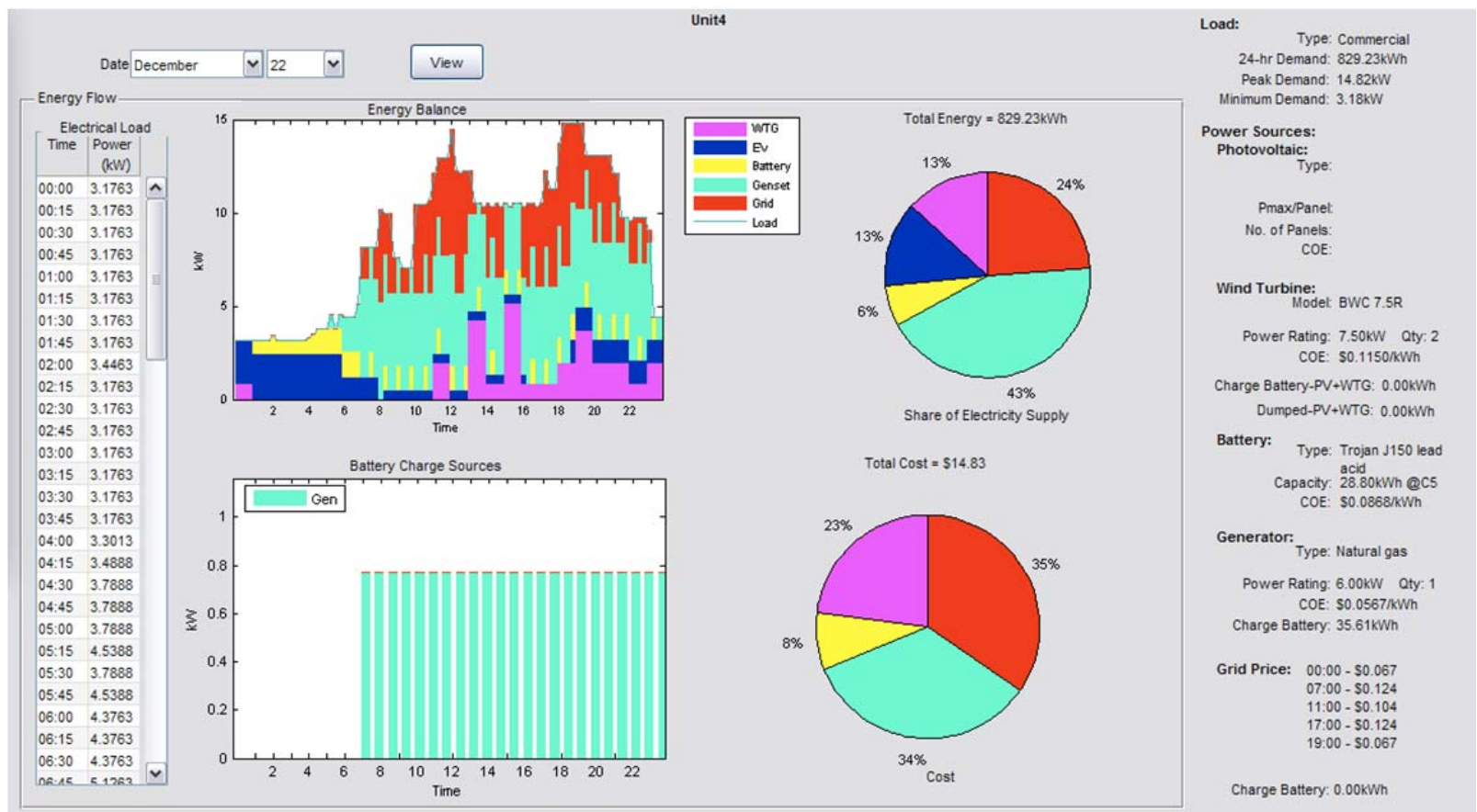

Figure 6-20 Electricity demand vs supply for a full-service restaurant (Unit 4) on a typical winter day 
Table 6-1 Summary of the Simulation Results

\begin{tabular}{|c|c|c|c|c|c|c|c|c|c|c|c|c|}
\hline \multirow[t]{2}{*}{$\begin{array}{c}\text { Load } \\
\text { ID }\end{array}$} & \multirow[t]{2}{*}{ Type } & \multirow[t]{2}{*}{ Season } & \multicolumn{6}{|c|}{$\begin{array}{c}\text { Share of electricity supply / } \\
\text { Share of the cost }\end{array}$} & \multicolumn{3}{|c|}{$\begin{array}{c}\text { Share of energy used to charge } \\
\text { the battery }(\%)\end{array}$} & \multirow{2}{*}{$\begin{array}{c}\text { Energy } \\
\text { dumped } \\
(\mathrm{kWh})\end{array}$} \\
\hline & & & PV & Wind & EV & Battery & Generator & Grid & $\begin{array}{c}\text { PV } \\
+ \text { Wind }\end{array}$ & Generator & Grid & \\
\hline \multirow[t]{3}{*}{ Unit 1} & \multirow[t]{3}{*}{ Residential } & Size & $10.08 \mathrm{~kW}$ & NA & & $7.2 \mathrm{kWh}$ & $6 \mathrm{~kW}$ & & & & & \\
\hline & & Summer & $\begin{array}{l}33 \% \\
91 \%\end{array}$ & NA & $22 \%$ & $\begin{array}{l}9 \% \\
2 \%\end{array}$ & $\begin{array}{r}36 \% \\
6 \%\end{array}$ & 0 & $33 \%$ & $67 \%$ & 0 & 17.84 \\
\hline & & Winter & $\begin{array}{l}14 \% \\
74 \%\end{array}$ & NA & $28 \%$ & $\begin{array}{r}13 \% \\
8 \%\end{array}$ & $\begin{array}{l}45 \% \\
19 \%\end{array}$ & 0 & $35 \%$ & $65 \%$ & 0 & 3.68 \\
\hline \multirow[t]{3}{*}{ Unit 2} & \multirow[t]{3}{*}{ Residential } & Size & $8.54 \mathrm{~kW}$ & $5 \mathrm{~kW}$ & & $14.4 \mathrm{kWh}$ & $6 \mathrm{~kW}$ & & & & & \\
\hline & & Summer & $\begin{array}{l}19 \% \\
74 \%\end{array}$ & $\begin{array}{l}47 \% \\
20 \%\end{array}$ & $7 \%$ & $\begin{array}{r}24 \% \\
6 \%\end{array}$ & $\begin{array}{r}3 \% \\
<1 \%\end{array}$ & 0 & $0 \%$ & $100 \%$ & 0 & 20.31 \\
\hline & & Winter & $\begin{array}{r}5 \% \\
31 \%\end{array}$ & $\begin{array}{l}59 \% \\
66 \%\end{array}$ & $30 \%$ & $\begin{array}{l}6 \% \\
2 \%\end{array}$ & $\begin{array}{r}0 \\
<1 \%\end{array}$ & 0 & $91 \%$ & $9 \%$ & 0 & 31.27 \\
\hline \multirow[t]{3}{*}{ Unit 3} & \multirow[t]{3}{*}{ Office } & Size & $71.37 \mathrm{~kW}$ & $15 \mathrm{~kW}$ & & $36 \mathrm{kWh}$ & $7 \mathrm{~kW}$ & & & & & \\
\hline & & Summer & $\begin{array}{l}48 \% \\
84 \%\end{array}$ & $\begin{array}{l}7 \% \\
4 \%\end{array}$ & $3 \%$ & $\begin{array}{r}15 \% \\
6 \%\end{array}$ & $\begin{array}{r}26 \% \\
6 \%\end{array}$ & $\begin{array}{l}<1 \% \\
<1 \%\end{array}$ & $29 \%$ & $71 \%$ & 0 & 10.08 \\
\hline & & Winter & $\begin{array}{l}15 \% \\
52 \%\end{array}$ & $\begin{array}{l}36 \% \\
31 \%\end{array}$ & $5 \%$ & $\begin{array}{r}16 \% \\
8 \%\end{array}$ & $\begin{array}{r}27 \% \\
8 \%\end{array}$ & $0 \%$ & $60 \%$ & $40 \%$ & 0 & 27.32 \\
\hline \multirow[t]{3}{*}{ Unit 4} & \multirow[t]{3}{*}{ Commercial } & Size & NA & $15 \mathrm{~kW}$ & & $36 \mathrm{kWh}$ & $6 \mathrm{~kW}$ & & & & & \\
\hline & & Summer & NA & $\begin{array}{l}3 \% \\
5 \%\end{array}$ & $12 \%$ & $\begin{array}{l}6 \% \\
8 \%\end{array}$ & $\begin{array}{l}42 \% \\
34 \%\end{array}$ & $\begin{array}{l}37 \% \\
53 \%\end{array}$ & $0 \%$ & $100 \%$ & 0 & 0 \\
\hline & & Winter & NA & $\begin{array}{l}13 \% \\
23 \%\end{array}$ & $13 \%$ & $\begin{array}{l}6 \% \\
8 \%\end{array}$ & $\begin{array}{l}43 \% \\
34 \%\end{array}$ & $\begin{array}{l}24 \% \\
35 \%\end{array}$ & $0 \%$ & $100 \%$ & 0 & 0 \\
\hline
\end{tabular}

As shown by the energy balance of the load units, without the EVs the dominant supplier for the load in the absence of the renewable energy sources was the generator and the dominant source of energy for charging the battery was the generator. 


\section{CONCLUSION}

\subsection{Concluding Remarks}

In this study, a computer model that integrates the models of different energy sources and implements a power flow strategy that prioritizes the use of renewable energy resources and electric vehicles is presented. The system is always connected to the grid to assure a reliable supply of electricity. The computer model was developed using MATLAB with a GUI interface for easy setup and operation.

Load profiles of different types of loads based on the model developed in [23] were used as input to the system. The proposed computer model calculated the power outputs of the wind turbine and PV system using the manufacturer's data sheets and the weather pattern specific to the site under study. Reference [24] developed a model that calculates the demands of electric vehicles and the extra power that it can give. Reference [25] developed the computer models for the dispatch of power provided by the natural gas generators and the grid. These computer models were integrated seamlessly into the proposed system.

Using the GUI interface of the MATLAB model, different component configurations can be built or edited on the fly. Fifteen-minute time series simulations can be run for any day to verify the performance of each component and validate how the various technologies are operated to satisfy the electrical requirements of different load units and the charging requirement of electric vehicles. The proposed computer model can be used to choose, analyze and size the energy resources, test the performance of each resource and validate how the various technologies operate to assure a reliable supply of electricity.

Based on the results of the case study, the following conclusions can be made:

(1) If the renewable resources are sized large enough, taking into consideration physical and technical considerations and not considering economics, hybrid renewable resources can supply at least 50\% of the power requirements of the load.

(2) The individual use of wind and solar energy could result in over-sizing making the technologies expensive to install. 
(3) For systems involving renewable power sources with irregular outputs, the hourly weather data or smaller resolution is required to accurately predict the balance of power between load and demand. The monthly or daily average power output does not give a picture of the timing and variability of the energy source.

(4) Battery size is critical when using renewable energy. It was shown that if the battery bank is not large enough or battery is not used at all, the generator and grid would supply most of the load.

(5) The discharging of the battery depends on how closely the energy from renewable sources matches the load demand.

(6) Energy production of renewable resources does not always coincide with the load duration resulting in a large amount of energy wasted. Energy buy-back should be considered for a better return on investment.

\subsection{FUTURE WORK}

1. Forecasting of wind and solar power can be improved by subscribing to a real-time weather RSS feed and integrating same day and next day weather forecast into the computer model.

2. Forecasting of load demand in [23] can be improved by integrating real-time temperature forecasts in the computer model.

3. Optimizing the size of distributed energy resources by taking into consideration economics and environmental factors to ensure a good return on investment and reduce carbon footprint.

4. Charging and discharging schedule of electric vehicles can be optimized to reduce its impact on the power grid by using forecasted load for the day and the price of electricity.

5. Charging and discharging of storage battery can be optimized by using a similar day forecast of the load, weather RSS feed to forecast the power outputs of the wind and solar energy and taking into consideration the price of electricity.

6. Implementing grid pricing for commercial and industrial establishments instead of TOU pricing. 


\section{REFERENCES}

[1] D. Boroyevich, I. Cvetković , D. Dong, R. Burgos, F. Wang and F. Lee, "Future Electronic Power Distribution Systems A contemplative view", 2010, 12th International Conference on Optimization of Electrical and Electronic Equipment, OPTIM 2010

[2] C. Wang and M.H. Nehrir, "Power Management of a Stand-Alone Wind/Photovoltaic/Fuel Cell Energy System", IEEE Transactions on Energy Conversion, Vol. 23, No. 3, September 2008, pp. 957-967

[3] M. Annamalai and M.V. Kumar, "Modeling \& Simulation of Variable Speed Wind Turbine with Resonant DC-DC Converters", International Conference on Power Electronics, Systems and Applications, Aug 25-27, 2012 Kuala Lumpur (Malaysia)

[4] A.B. Cultura II and Z.M. Salameh, "Modeling and Simulation of Wind Turbine-Generator System"

[5] P. Jansuya and Y. Kumsuwan, "Design of MATLAB/ Simulink Modeling of Fixed-Pitch Angle Wind Turbine Simulator”, Energy Procedia 34 ( 2013 ) $362-370$

[6] M.M. Hussein, T. Senjyu, M. Orabi, M A.A. Wahab and M.M. Hamada, "Control of a Stand-Alone Variable Speed Wind Energy Supply System”, Applied. Sciences 2013, 3, 437-456; doi:10.3390/app3020437

[7] E.W. Peterson and J.P. Hennessey, Jr., "On the use of power laws for estimates of wind power potential”, 1978, J. Appl. Meteorology, Vol. 17, pp. 390-394

[8] N.Z. Al-Rawahi, Y.H. Zurigat and N.A. Al-Azri, "Prediction of Hourly Solar Radiation on Horizontal and Inclined Surfaces for Muscat/Oman", The Journal of Engineering Research, Vol. 8 No. 2, 2011, pp.19-31

[9] R.G. Ross, Jr, "Flat-Plate Photovoltaic Array Design Optimization", 14th IEEE Photovoltaic Specialists Conference, 1980, pp. 1126-1132

[10] A. Luque and S. Hegedus, "Handbook of Photovoltaic Science and Engineering” [Internet], 2003:1117

[11] K. Zaplatilek and J. Leuchter, "Photovoltaic Panel Modeling in MATLAB Environment", Radioengineering, ISSN 1210-2512, 06/2011, Volume 20, Issue 2, pp. $445-450$

[12] R. Perez, P. Ineichen, R. Seals, J. Michalsky and R. Stewart, "Modeling daylight availability and irradiance components from direct and global irradiance", Solar Energy [Internet], 1990, 44:271-289.

[13] A. Dolara, R. Faranda and S. Leva, "Energy Comparison of Seven MPPT Techniques for PV Systems", J. Electromagnetic Analysis \& Applications, 2009, 3: 152-162 
[14] L. Xu and X. Ruan, "An Improved Optimal Sizing Method for Wind-Solar-Battery Hybrid Power System", IEEE Transactions on Sustainable Energy, Vol. 4, No. 3 Jul 2013, pp 774-785

[15] A-K. Daud and M.S. Ismail, "Design of isolated hybrid systems minimizing costs and pollutant emissions", Renewable Energy 44 (2012), pp.215-224

[16] C.S. Supriya and M. Siddarthan, "Optimization and Sizing of a Grid-Connected Hybrid PV-Wind Energy System", IJEST, Vol. 3 No. 5 May 2011, pp 4296-4323

[17] H. Ren, W. Zhou, K. Nakagami, W. Gao and Q. Wu, "Multi-objective optimization for the operation of distributed energy systems considering economic and environmental aspects”, Applied Energy 87 (2010), pp. 3642-3651

[18] T. Senjyu, D.Hayashi, N. Urasaki and T. Funabashi, “Optimum Configuration for Renewable Generating Systems in Residence Using Genetic Algorithm”, IEEE Transactions on Energy Conversion, Vol. 21, No. 2, June 2006, pp. 459-466.

[19] W.D. Kellogg, M.H. Nehrir, G. Venkataramanan and V. Gerez, "Generation Unit Sizing and Cost Analysis for Standalone Wind, Photovoltaic and Hybrid Wind/PV Systems", IEEE Transactions on Energy Conversion, Vol. 13, No. 1, March 1998, pp. $70-75$

[20] R. Chedid and S.Rahman, "Unit Sizing and Control of Hybrid Wind-Solar Power Systems", IEEE Transactions on Energy Conversion, Vol. 12, No. 1, March 1997, pp. 79-85

[21] Y. Liu, C. Jiang and J. Shen, 'Energy Management for Grid-connected Micro Grid with Renewable Energies and Dispatched Loads”, Dept of Electrical Engineering, Shanghai, Jiaotong University

[22] W. Zhou, C. Lou, Z. Li, L. Lu and H. Yang, “Current status of research on optimum sizing of stand-alone hybrid solarwind power generation systems", Applied Energy 87 (2010) 380-389

[23] K.T. Wong and T. Miciu, "Load Profile", EE8120 Project, Ryerson University

[24] M. Cunningham, “A Proposed Implementation of EV-to-Grid Power Delivery and Storage”, EE8120 Project, Ryerson University

[25] S. Craig, "Net Zero Smart Community - Non-renewable Energy Component”, EE8120 Project, Ryerson University [26] National Renewable Energy Laboratory, [Online] www.nrel.gov

[27] Canada Open Data, [Online] http://www.data.gc.ca

[28] Photovoltaic Education Network, [Online] www.pveducation.org

[29] Ontario Power Authority, [Online] http://fit.powerauthority.on.ca 
[30] Y. He, B. Venkatesh and L. Guan, "Optimal Scheduling for Charging and Discharging of Electric Vehicles", Ryerson University

[31] Q. Wu, A.H. Nielsen, J. Ostergarrd, S.T. Cha, F. Marra and P. Andersen, "Modeling of Electric Vehicles (EV) for EV Grid Integration Study", Center for Electric Technology, Technical University of Denmark

[32] Nissan Unveils New Power Supply SystemThrough Nissan LEAF, [Online] http://www.nissanglobal.com/EN/NEWS/2011/_STORY/110802-01-e.html

[33] B.S. Rashford, N. Macsalka and M. Geiger, "The Effect of Altitude on Small Wind Turbine Power Production", University of Wyoming, August 2010.

[34] J.D. Glover, M.S. Sarma, T.J. Overbye, Power System Analysis and Design, Stamford, CT: Cengage Learning, $5^{\text {th }}$ Edition, 2012 


\section{Appendices}

Appendix A: Sharp Solar Panel Data Sheet

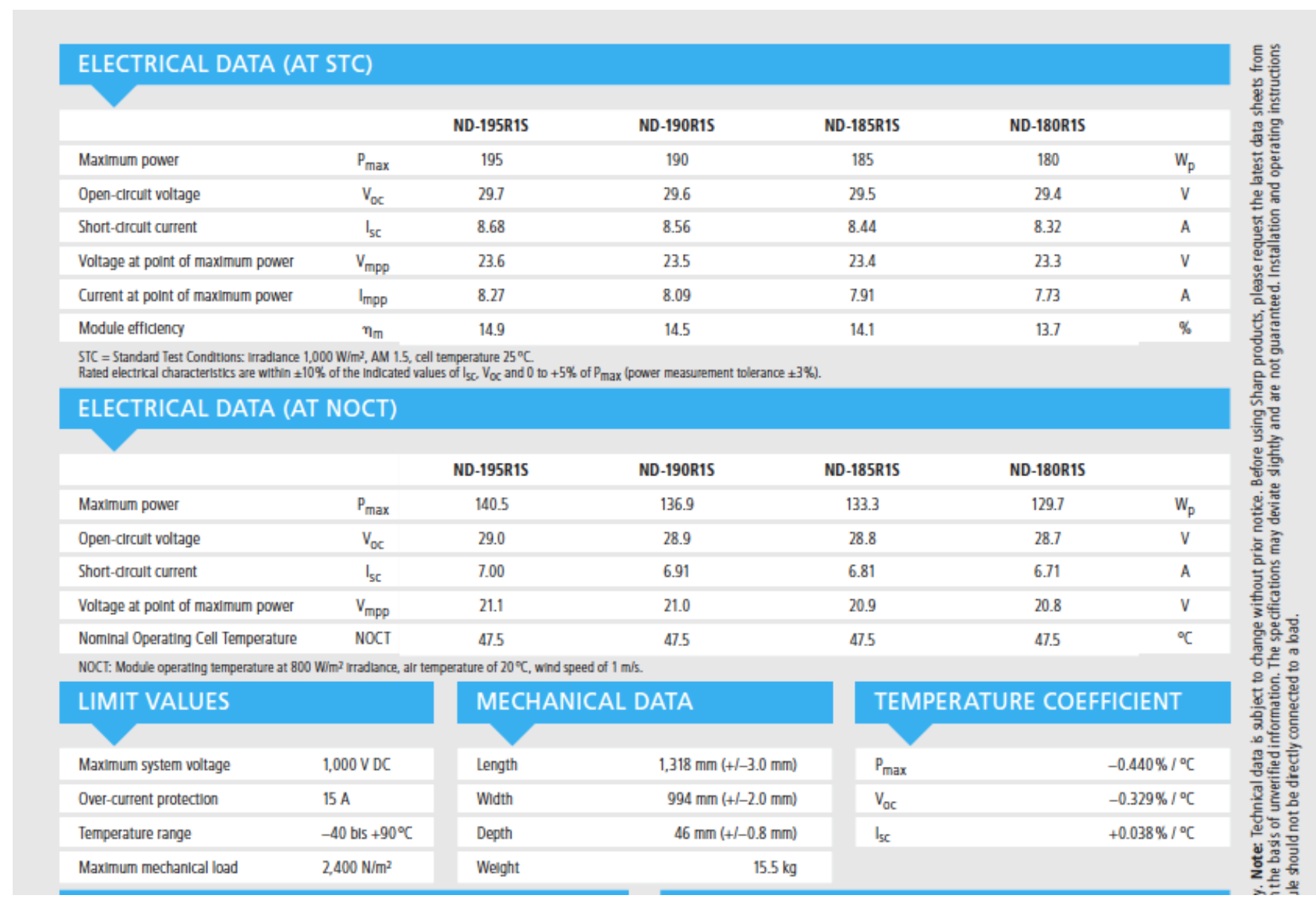


Appendix B: Bergey BWC Excel Wind Turbine Power Curve

WindCad Turbine Performance Model

BWC EXCEL Battery Charging Version

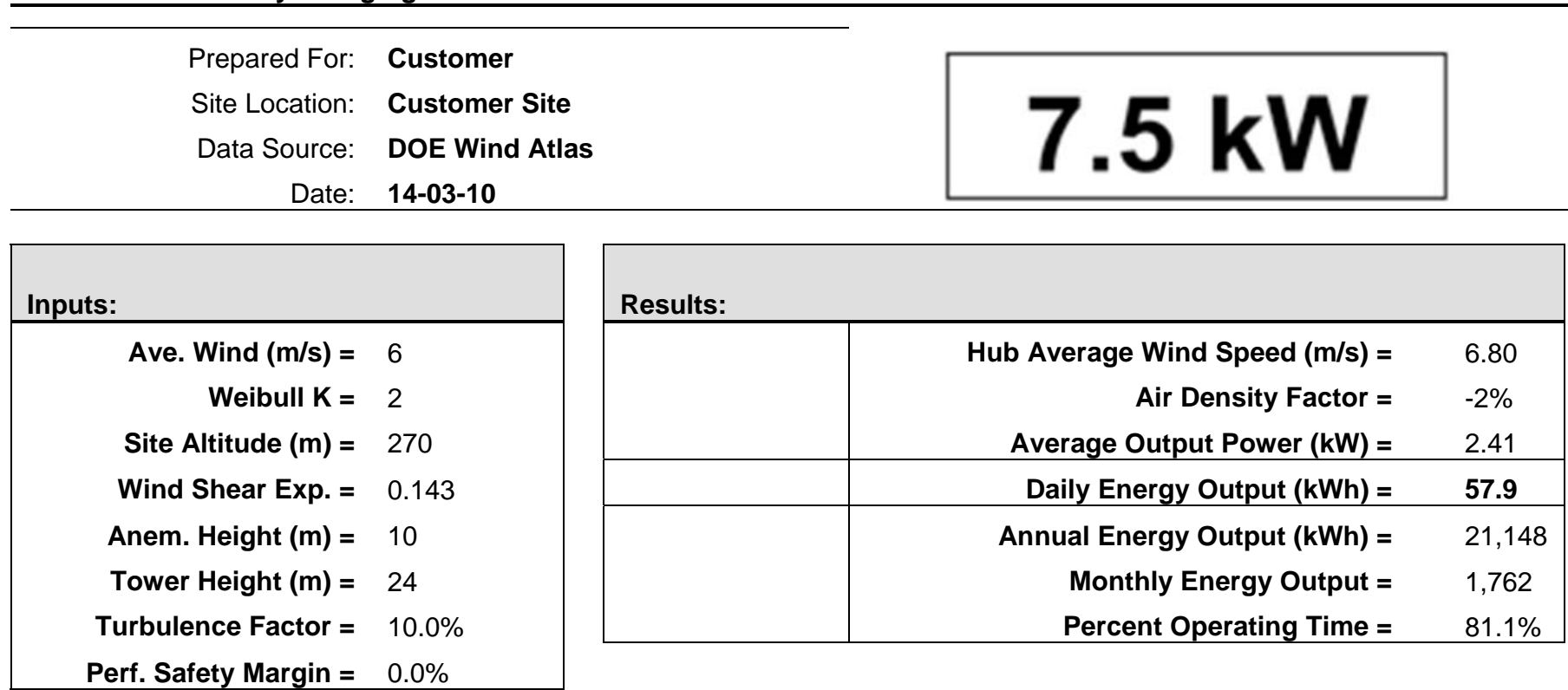

\section{Weibull Performance Calculations}

\begin{tabular}{|cccc|}
\hline Wind Speed Bin (m/s) & Power $(\mathrm{kW})$ & $\begin{array}{c}\text { Wind Probability } \\
(\mathrm{f})\end{array}$ & Net kW @ V \\
\hline 1 & 0.00 & $3.37 \%$ & 0.000 \\
2 & 0.00 & $6.40 \%$ & 0.000 \\
3 & 0.00 & $8.81 \%$ & 0.000 \\
4 & 0.22 & $10.42 \%$ & 0.023 \\
5 & 0.70 & $11.16 \%$ & 0.078 \\
6 & 1.45 & $11.09 \%$ & 0.161 \\
7 & 2.24 & $10.36 \%$ & 0.232 \\
8 & 3.20 & $9.16 \%$ & 0.293 \\
9 & 4.26 & $7.70 \%$ & 0.328 \\
10 & 5.40 & $6.18 \%$ & 0.333 \\
11 & 6.58 & $4.74 \%$ & 0.312 \\
12 & 7.02 & $3.49 \%$ & 0.245 \\
13 & 7.02 & $2.46 \%$ & 0.173 \\
14 & 7.02 & $1.67 \%$ & 0.117 \\
15 & 6.14 & $1.09 \%$ & 0.067 \\
16 & 4.39 & $0.68 \%$ & 0.030 \\
17 & 2.37 & $0.41 \%$ & 0.010 \\
19 & 2.63 & $0.24 \%$ & 0.006 \\
Co. & 2.63 & $0.13 \%$ & 0.004 \\
& 2.63 & $0.07 \%$ & 0.002 \\
\hline
\end{tabular}


Appendix C: Trojan J150 Battery Data Sheet

PRODUCT SPECIFICATIONS

\begin{tabular}{|c|c|c|c|c|c|c|c|c|c|c|c|c|c|c|}
\hline \multirow{2}{*}{$\begin{array}{l}\text { BC } \\
\text { GROUP } \\
\text { SIZE }\end{array}$} & \multirow{2}{*}{ TYPE } & \multicolumn{3}{|c|}{ CAPACTTY ${ }^{\wedge}$ Minutes } & \multicolumn{4}{|c|}{ CAPACITY ${ }^{\text {Amp }}$-Hours (AH) } & \multirow{2}{*}{$\begin{array}{c}\text { ENERGY } \\
\text { (kWh) } \\
100 \text {-Hr Rate }\end{array}$} & \multirow{2}{*}{$\begin{array}{l}\text { TERMINAL } \\
\text { Type }^{\mathrm{A}}\end{array}$} & \multicolumn{3}{|c|}{ DIMENSIONS ' Dedimals (mm) } & \multirow{2}{*}{$\begin{array}{l}\text { WEGGHT } \\
\text { lbs. (kgg) }\end{array}$} \\
\hline & & 925 Amps & (9) $56 \mathrm{Amps}$ & 975 Amps & 5-Hr Rate & 10-Hr Rate & 20-Hr Rate & 100-Hr Rate & & & Length & Width & Height $^{0}$ & \\
\hline \multicolumn{15}{|c|}{12 VOLT DEEP CYCLE BATTERY - with T2 TECHNOLOGY ${ }^{\mathrm{Tm}}$} \\
\hline N/A & J150 & 280 & 102 & 70 & 120 & 134 & 150 & 166 & 1.99 & 1,2 & $13.70(348)$ & 7.13 (181) & $11.13(283)$ & $84(38)$ \\
\hline
\end{tabular}

A. The number of minutes a battery can dellver when dlscharged at a constant rate at $80 \%$ ( $27 \mathrm{C}$ ) and maintain a voiltage above $1.75 \mathrm{~V} / \mathrm{cell}$. Capactles are based on peak performance.

B. The amount of amp-hours (AH) a battery can dellver when dlscharged at a constant rate at $80 \% \mathrm{~F}(27 \mathrm{CC})$ for the 20 -Hour and 100 Hour rates and $86^{\circ} \mathrm{F}\left(30^{\circ} \mathrm{C}\right.$ ) for the 5 - Hour rate and maintailn a voltage above $1.75 \mathrm{~V} / \mathrm{cell}$. Capactles are based on peak performance.

C. Dimenstonsare basefon nor

to the highest point on the battery. Helghts may vary dependling on type of terminal.

E. Terminal Images are representative only.

Trojants battery testing procedures adhere to both $\mathrm{BC}$ and IEC test standards

\section{CHARGING INSTRUCTIONS}

\section{CHARGER VOLTAGE SETTINGS (AT $77^{\circ} \mathrm{F} / 25^{\circ} \mathrm{C}$ )}

\begin{tabular}{|l|c|c|c|c|c|}
\hline \multicolumn{1}{|c|}{ System Voltage } & $\mathbf{6 V}$ & $\mathbf{1 2 V}$ & $\mathbf{2 4 V}$ & $\mathbf{3 6 V}$ & $\mathbf{4 8 V}$ \\
\hline Absorption Charge & 7.40 & 14.8 & 29.6 & 44.4 & 59.2 \\
\hline Float Charge & 6.60 & 13.2 & 26.4 & 39.6 & 52.8 \\
\hline Equalize Charge & 7.75 & 15.5 & 31.0 & 46.5 & 62.0 \\
\hline
\end{tabular}

Do not install or charge batteries in a sealed or non-ventilated compartment. Constant under or overcharging will damage the battery and shorten its life as with any battery.

\section{CHARGING TEMPERATURE COMPENSATION}

$.028 \mathrm{VPC}$ for every $10^{\circ} \mathrm{F}\left(5.55^{\circ} \mathrm{C}\right.$ ) above or below $77^{\circ} \mathrm{F}\left(25^{\circ} \mathrm{C}\right)$ (add $.028 \mathrm{VPC}$ for every $10^{\circ} \mathrm{F}\left(5.55^{\circ} \mathrm{C}\right)$ below $77^{\circ} \mathrm{F}$ and subtract $.028 \mathrm{VPC}$ for every $10^{\circ} \mathrm{C}$ above $\left.77^{\circ} \mathrm{F}\right)$.

\section{OPERATIONAL DATA}

\begin{tabular}{|l|l|}
\hline Operating Temperature & Self-discharge \\
\hline $\begin{array}{l}-4^{\circ} \mathrm{F} \text { to } 113^{\circ} \mathrm{F}\left(-20^{\circ} \mathrm{C} \text { to }+45^{\circ} \mathrm{C}\right) \text {. At temperatures } \\
\text { below } 32^{\circ} \mathrm{F}\left(0^{\circ} \mathrm{C}\right) \text { maintain a state of charge } \\
\text { greater than } 60 \% .\end{array}$ & $\begin{array}{l}5-15 \% \text { per month depending on } \\
\text { storage temperature conditions. }\end{array}$ \\
\hline
\end{tabular}

greater than $60 \%$.

\section{TERMINAL CONFIGURATIONS}

\begin{tabular}{|c|c|}
\hline 1 ELPT & Embedded Low Profile Terminal \\
\hline & $\begin{array}{c}\text { Terminal Height Decimals }(\mathrm{mm}) \\
1.22(31) \\
\text { Torque Values in-1b }(\mathrm{Nm}) \\
95-105(10.7-11.9) \\
\text { Bolt Size } \\
5 / 16-18\end{array}$ \\
\hline 2 EHPT & Embedded High Profile Terminal \\
\hline & $\begin{array}{c}\text { Terminal Height Decimals }(\mathrm{mm}) \\
1.50(38) \\
\text { Torque Values in-1b }(\mathrm{Nm}) \\
95-105(10.7-11.9) \\
\text { Bolt Size } \\
5 / 16-18\end{array}$ \\
\hline
\end{tabular}


Appendix D: 6-kW / 7-kW Generator Data Sheet

\section{General Information}

\subsection{SYSTEM READY LED}

The "System Ready LED" is illuminated when all of the following conditions are true:

1. The AUTO/OFF/MANUAL switch is set to the AUTO position.

2. The utility voltage supplied to the unit is sensed by the controller.

3. No alarms are present, for example, low oil pressure, high temperature, etc.

\subsection{FUEL REQUIREMENTS AND RECOMMENDATIONS}

With LP gas, use only the vapor withdrawal system. This type of system uses the vapors formed above the liquid fuel in the storage tank.

The engine has been fitted with a field convertible fuel system. The unit will run on natural gas or LP gas, but it has been factory set to run on natural gas. Should the primary fuel need to be changed to LP gas, the fuel system needs to be reconfigured. See the reconfiguring the Fuel System section for instructions on reconfiguration of the fuel system.

Recommended fuels should have a Btu content of at least 1,000 Btus per cubic foot for natural gas; or at least 2,520 Btus per cubic foot for LP gas. Ask the fuel supplier for the Btu content of the fuel.

Required fuel pressure for natural gas is five (5) inches to seven (7) inches water column ( 0.18 to $0.25 \mathrm{psi})$; and for liquid propane, 10 inches to 12 inches of water column ( 0.36 to 0.43 psi). The primary regulator for the propane supply is NOT INCLUDED with the generator.

\section{NOTE}

All pipe sizing, construction and layout must comply with NFPA 54 for natural gas applications and NFPA 58 for liquid propane applications. Once the generator is installed, verity that the fuel pressure NEVER drops below five (5) inches water column for natural gas or 10 inches water column for liquid propane.

Prior to installation of the generator, the installer should consult local fuel suppliers or the fire marshal to check codes and regulations for proper installation. Local codes will mandate correct routing of gaseous fuel line piping around gardens, shrubs and other landscaping to prevent any damage.

Special considerations should be given when installing the unit where local conditions include flooding, tornados, hurricanes, earthquakes and unstable ground for the flexibility and strength of piping and their connections.
Use an approved pipe sealant or joint compound on all threaded fittings.

All installed gaseous fuel piping must be purged and leak tested prior to initial start-up in accordance with local codes, standards and regulations.

\subsection{FUEL CONSUMPTION}

\begin{tabular}{|c|c|c|c|c|}
\hline \multirow{2}{*}{ Unit } & \multicolumn{2}{|c|}{ Nat. Gas* } & \multicolumn{2}{c|}{ LP Vapor** } \\
\cline { 2 - 5 } & $\mathbf{1} / \mathbf{2}$ Load & Full Load & $\mathbf{1 / 2}$ Load & Full Load \\
\hline $6 / 7 \mathrm{~kW}$ & 66 & 119 & $0.82 / 30$ & $1.47 / 53$ \\
\hline
\end{tabular}

Values given are approcimate.

- Natural pes is in cubic feet per hour.

* IP is in palons per hourcubic feet per hour.

Verify that gas meter is capable of providing enough fuel flow to include household appliances.

\section{9 .1 BTU FLOW REOUIREMENTS - NATURAL GAS}

BTU flow required for each unit based on 1000 BTU per cubic foot.

- $6 \mathrm{~kW}-119,000 \mathrm{BTU} / \mathrm{Hour}$

\section{$\triangle D A N G E R !$}

Gaseous fuels such as natural gas and liquid propane (LP) gas are highly explosive. Even the slightest spark can ignite such fuels and cause an explosion. No leakage of fuel is permitted. Natural gas, which is lighter than air, tends to collect in high areas. LP gas is heavier than air and tends to settle in low areas.

\section{NOTE:}

A minimum of one approved manual shut-off valve must be installed in the gaseous fuel supply line. The valve must be easily accessible. Local codes determine the proper location.

\subsection{RECONFIGURING THE FUEL SYSTEM}

\subsubsection{KW. 432CC ENGINE}

1. Remove the generator enclosure roof by turning the four quarter turn latches on the roof top. Push down slightly on the latch then turn 90 degrees to release. The latch should pop up as shown in Figure 1.2. 